\title{
III „Ein eigenes Museum“: Thorvaldsens Ateliers
}

\section{1 „unter uns gesagt, nicht selbst gemacht“: Thorvaldsens Werkstattpraxis}

Bei der Untersuchung zeitgenössischer Porträts von Thorvaldsen fällt auf, dass dieser zwar oft in seinem berufsspezifischen Kontext, jedoch nie bei der physischen Arbeit dargestellt ist. In erster Linie lässt sich dies sicherlich mit dem damaligen Nobilitierungs- und Stilisierungsbedürfnis des Künstlers als Genie erklären. Eine zusätzliche Bedeutungsebene erhält diese Darstellungsweise aber vor dem Hintergrund der stark arbeitsteiligen Organisation in Thorvaldsens Ateliers, die im Zentrum des vorliegenden Kapitels steht. Die Arbeitsteilung im Allgemeinen hatte seit ihrer Beschreibung durch den Ökonomen und Aufklärungsphilosophen Adam Smith in seinem epochalen Werk The Wealth of Nations von 1776 stark an Bedeutung gewonnen. ${ }^{1}$ Smith postulierte, dass die Produktion durch Aufteilung eines Herstellungsablaufs in verschiedene Arbeitsschritte gesteigert werden könne, wofür drei Faktoren entscheidend seien: der Einsatz spezialisierter Arbeitskräfte, eine daraus resultierende Ersparnis an Zeit sowie die Nutzung von Maschinen. Wie sich zeigen wird, finden sich diese Faktoren auch in Thorvaldsens Werkstattpraxis. Dass der Bildhauer die Arbeitsteilung durchaus auch als Mittel der Selbstvermarktung nutzte, soll im Folgenden auf der Grundlage von zeitgenössischen Darstellungen seiner Ateliers und Beschreibungen derselben veranschaulicht werden.

Das bereits eingeführte und an anderer Stelle noch genauer zu betrachtende, 1828 - 1829 entstandene Gemälde von Martens präsentiert Thorvaldsens sogenanntes studio grande in Rom mit dem wenige Jahre zuvor erfolgten Besuch von Papst Leo XII. (Taf. II). ${ }^{2}$ Bei der hell beleuchteten Merkur-Statue im Bildmittelgrund handelt es sich um das einzige Werk im Atelier, an dem gearbeitet wird. Zudem wird diese Arbeit nicht von Thorvaldsen selbst, sondern von einem Gehilfen vorgenommen. Er steht stellvertretend für den zeitweise bis zu 39 spezialisierte Handwerker umfassenden Werkstattbetrieb des

1 Smith 1776, 5-20.

2 Siehe dazu Kap. I.2 und bes. III.2. 
Dänen. ${ }^{3}$ Dabei prägte die Arbeitsteilung Thorvaldsens Schaffen nicht erst, nachdem er sich als einer der führenden Bildhauer der Zeit etablieren konnte. Ganz im Gegenteil hatte er die Marmorausführung von Porträtbüsten bereits in seinen ersten Jahren in Rom günstigen, als Tagelöhner angestellten Steinmetzen übertragen. ${ }^{4}$ Gründete die Arbeitsteilung in diesem Fall noch auf der Bequemlichkeit des Bildhauers, dem die Ausführung von Büsten laut Quellen ebenso widerstrebte wie die kräfteraubende Arbeit am Marmor, so wurde mit dem mehrere Statuen und Büsten umfassenden Auftrag der russischen Gräfin Irina Vorontsova im Jahr 1804 eine arbeitsteilige Werkstattorganisation geradezu notwendig. ${ }^{5}$

\section{Thorvaldsens Arbeitsweise}

Grundsätzlich lässt sich die Arbeitsweise in Thorvaldsens Werkstätten folgendermaßen rekonstruieren: Den Anfang bildeten grobe Studien, die der Bildhauer gerne auf ein beliebiges Stück Papier zeichnete, weshalb etwa auf Briefen in seinem Nachlass nicht selten eigenhändige Zeichnungen des Künstlers zu finden sind. Daraufhin modellierte er einen Bozzetto, ein kleines Modell aus Ton. Zu seinen Werken fertigte er in der Regel verschiedene grobe Skizzen an und überarbeitete auch die Tonmodelle oft mehrmals. Wie die Zeichnungen blieben auch die üblicherweise rund einen halben Meter hohen Bozzetti äußerst skizzenhaft. Dennoch wurden diese in Gips gegossen und dienten als Basis für die Tonmodelle in der definitiven Größe. Bei Statuen wurden diese originalgroßen Tonmodelle von Thorvaldsens Gehilfen über einem Drahtskelett mit kleinen Holzkreuzen als Stützen ausgeführt, bei Büsten und Reliefs nahm der Bildhauer diese Arbeit selbst vor. Da die Tonmodelle rasch austrockneten, brüchig wurden und deshalb nicht von Dauer waren, wurden sie in Gips gegossen. Dafür stellte man eine Negativform her, die mit flüssigem Gips gefüllt wurde; das Tonmodell ging in diesem Prozess für gewöhnlich verloren. Die aus dem Gussverfahren gewonnene Figur war das sogenannte Originalmodell. Dabei handelte es sich um eine genaue Kopie des großen Tonmodells, jedoch in dauerhafterem Material. Es war auch das Originalmodell und weniger der Marmor, an dem Thorvaldsen Korrekturen und Feinarbeiten vornahm. ${ }^{6}$ Gemäß einem erhaltenen Briefentwurf des

Oppermann 1930, 85; Helsted 1977, 13; Beck 1991, 79; Tesan 1991b, 232; Jørnæs 2011, 118 -119; auch Wittstock 1984, 108; Jørnæs 1989c, 31.

Tesan 1991b, 223; Tesan 1998, 57.

5 Ebd. Zu Vorontsovas Bestellungen siehe auch Jørnæs 2011, 51. Thorvaldsens Unwilligkeit, Büsten auszuführen, zeigte sich noch 1827, als der bayerische König Ludwig I. eine Porträtbüste seiner Geliebten Marianna Florenzi bestellte. Wie dessen Kunstagent Wagner ihn am 25. September 1827 informierte, habe der Bildhauer seit Beginn der 1820er Jahre die Preise für Büsten verdoppelt, „mehr deswegen, um keine Büste mehr machen zu dürfen, da er es ungern tue“; zit. nach von Urlichs 1887, 18. Die Büste der Marianna Florenzi wurde dennoch 1828 modelliert und 1858 unter Bissens Aufsicht in Marmor vollendet; Kopenhagen, Thorvaldsens Museum (Inv.-Nr. A278 und A727).

6 Diese Beschreibung basiert auf Wittstock 1975, 87; Helsted 1977, 10 -12; Helsted 1982a, 49-51; Jørnæs 1989c, 31; Kat. Nürnberg/Schleswig 1991, 584; Tesan 1991b, 232 -233; Miss 2008, 32; Jørnæs 2011, 120. 
Bildhauers an den Architekten Hansen aus dem Jahr 1807 pflegten die „Künstler hier in Rom, wo es nicht an guten Arbeitern fehlt, die Figur in voller Größe und so [weit] ausgeführt als möglich zu modellieren, sodass die Ausführung in Marmor meist ganz mechanisch sein kann"?

Nach dem Originalmodell wurde eine mehrteilige Gussform hergestellt, wodurch das entsprechende Werk beliebig oft in Gips kopiert werden konnte. Das Originalmodell oder dessen Abguss bildete derweil die Grundlage für die Übertragung der Figur in Marmor, die von Thorvaldsens Gehilfen vorgenommen wurde. Dafür wurden zuerst einige Eckpunkte auf dem Modell mit Bleistift gekennzeichnet, die anschließend mithilfe von Senkbleien, die von einem Holzrahmen über dem Marmorblock hingen, auf diesen übertragen wurden. Es folgte die Behauung des Marmors mittels verschiedener Meißel, Hämmer und Bohrer. Den Abschluss dieses Prozesses bildete der Schliff des Marmors mittels Schmirgel, Sand- oder Bimsstein. Wie die Übertragung der Skulptur vom Gipsmodell in den Steinblock wurden auch die hierauf folgenden Arbeitsschritte am Marmor bis auf den letzten Schliff in den meisten Fällen nicht von Thorvaldsen selbst, sondern von seinen Gehilfen vorgenommen. ${ }^{8}$ Insofern vermittelt der an der Merkur-Statue arbeitende Gehilfe in Martens' Gemälde einen realistischen Einblick in Thorvaldsens Werkstattpraxis, wenn auch diese Arbeit kaum im studio grande ausgeführt wurde, worauf noch zurückgekommen wird.

Auch Hess' bereits erwähntes, nicht erhaltenes Porträt des Bildhauers von 1834 zeigte im Hintergrund einen Gehilfen, der die Jason-Statue bearbeitet (Abb. 28). ${ }^{9}$ In jenem fiktiven Atelier sind außerdem die Modelle des Alexanderzuges und des Relieftondos der Nacht von 1815 ausgestellt. Der Maler präsentierte damit keine aktuellen, sondern drei der bedeutendsten Werke für Thorvaldsens Künstlerbiografie und Berühmtheit. Diese Thematik wird im Vordergrund durch den vor dem Bildhauer liegenden Lorbeerzweig als Symbol des unsterblichen Ruhms verdeutlicht. Die Gesamtkomposition von Hess' Gemälde mit dem im Halbprofil wiedergegebenen Thorvaldsen zitiert zweifellos Dürers Selbstbildnis von 1498 im Madrider Prado und bringt dadurch - ähnlich Diofebis im Kapitel II.1 vorgestelltem Gemälde von Raffaels Graböffnung (Taf. VII) - einen doppelten Künstlerkult zum Ausdruck: Im frühen 19. Jahrhundert wurde Dürer neben Raffael als der

7 Bertel Thorvaldsen an Christian Frederik Hansen, nach dem 15. Juni 1807 (Entwurf), TMA, Ref. m28, nr. 104: „Konstner[en] bruger der fore her i Rom / hvor man ikke mangler gode Arbeidere / at modellere Figuren sin fulde Størrelse og saa udført som mulig saaledes at Udførelsen i Marmor kan blive for det meste ganske Mekanissk." Siehe auch Bencard 2009; Kofoed 2014b.

8 Diese Beschreibung basiert auf Helsted 1977, 12 -13; Helsted 1982a, 51-52; Jørnæs 1989c, 31; Springer, P. 1991, 216; Jørnæs 2011, 121. Zu den verschiedenen Werkzeugen in Thorvaldsens Werkstattbetrieb siehe Kat. Nürnberg/Schleswig 1991, 580 - 595.

9 Dieses Gemälde entstand im Auftrag von Graf Franz Erwein von Schönborn-Wiesentheid und basiert auf einem früheren Thorvaldsen-Porträt des Malers aus dem Jahr 1823, das sich heute in der Neuen Pinakothek in München befindet (Inv.-Nr. WAF 348); Kanzenbach 2007, 324, inkl. Anm. 1239 und 1240. 
größte Künstler vergangener Zeiten verehrt, während Thorvaldsen bereits zu Lebzeiten regelrecht vergöttert wurde. ${ }^{10}$

Wie auch der oben zitierte Briefentwurf von Thorvaldsen an Hansen verdeutlicht, war das beschriebene Verfahren der Skulpturherstellung im frühen 19. Jahrhundert außerhalb Italiens noch weitgehend unbekannt. So fragte der Fürst Clemens von Metternich am 11. April 1812 beim österreichischen Gesandten in Rom, Carlo d'Andreoli, beunruhigt nach, ob es stimme, dass der Stipendiat der Wiener Kunstakademie, Leopold Kiesling, die Ausführung seiner Skulpturen in Marmor an Gehilfen delegiere. ${ }^{11}$ Daraufhin informierte d'Andreoli den Fürsten, dass es sich bei solcher Arbeitsteilung um eine gängige Praxis „in allen Bildhauerateliers und bei Canova und bei Thorwaldsen und bei allen anderen“ handle sowie dass die „Hauptwerke der berühmtesten Bildhauer“ bis auf den letzten Schliff zu einem großen Teil von Gehilfen ausgeführt und „den Meistern nur die Erfindung und das Modell zugeschrieben “ würden. ${ }^{12}$ Bemerkenswert ist diesbezüglich ferner, dass Thorvaldsen für einen anderen Wiener Stipendiaten, Johann Nepomuk Schaller, im Jahr 1817 eine Kostenberechnung für eine Skulpturengruppe erstellte, in der als ein substanzieller Posten die Arbeit von Steinmetzen ausgewiesen ist. ${ }^{13}$

D’Andreolis Erwähnung von Canova ist in diesem Zusammenhang zentral: Es war der aus dem Veneto stammende, seit 1779 in Rom wirkende Bildhauer, der die Herstellung von Skulpturen revolutioniert hatte und ohne dessen Innovationen Thorvaldsens arbeitsteiliger Werkstattbetrieb kaum denkbar gewesen wäre. ${ }^{14}$ Bezeichnenderweise nahm mit Peter Kauffmann 1804 ein Gehilfe seine Arbeit in Thorvaldsens Atelier auf, der zugleich für Canova tätig war. ${ }^{15}$ Thorvaldsen folgte zwar im Wesentlichen der Arbeitsweise des Italieners, wich in Einzelheiten jedoch davon ab. Der augenfälligste Unterschied war die bei Canova deutlich ausgeprägtere Bedeutung der Vorstudien und der abschließenden Behandlung des Marmors durch den Meister. ${ }^{16}$ Im Gegensatz zu Canova polierte Thor-

10 Zum Vergleich von Hess' Gemälde mit Dürers Selbstbildnis von 1498 siehe auch Skjøthaug 2015b. Zum Kult um Dürer und Raffael im frühen 19. Jahrhundert siehe v. a. Kat. Göttingen/Rom 2015; auch Kat. Nürnberg/Schleswig 1991, 549; Ruppert 1998, 180 - 181 und 282; Hellwig 2005, 64- 71 und 76 -79; Reichardt 2009, 30; Hess/Agazzi/Décultot 2012; Kepetzis 2012, 10; Schmälzle 2012, 99.

11 Burg 1915, 123-124; auch Wittstock 1975, 113; Wittstock 1984, 105.

12 Carlo d'Andreoli an Clemens von Metternich, 9. Mai 1812, zit. nach Burg 1915, 124: „Dans tous les Ateliers des sculpteurs et chez Canova et chez Thorwaldsen et chez tous les autres on voit travailler des ouvriers à la journée aux chefs d'œuvres des plus célèbres artistes, au maître n'est attribuée que l'invention et le modèle qu'il achève et perfectionne, le gros de l'ouvrage est l'ouvrier qui le fait et ordinairement il n'y met que la dernière main [...]. “Ein Hinweis auf diese Korrespondenz findet sich auch bei Wittstock 1975, 113, und Wittstock 1984, 105, inkl. Anm. 1.

13 Burg 1915, 123.

14 Kat. Nürnberg/Schleswig 1991, 585; Miss 2008, 32. Zu Canovas Arbeitsweise siehe ausführlich Honour 1972a und 1972b; Myssok 2010; Myssok 2011, 16 - 17.

15 Tesan 1991a, 259; Tesan 1991b, 224; Tesan 1998, 58.

16 Zur Bedeutung der Zeichnung bei den beiden Bildhauern siehe auch Licht 1991, 49. 
valdsen seine Marmorwerke nicht mit Wachs, sondern beließ die opake, etwas raue Oberfläche des Steins. ${ }^{17}$ Ein weiteres, die Arbeitsweise der beiden Bildhauer unterscheidendes Detail besteht in den Messpunkten auf den großen Gipsmodellen, die bei Canova mit Metallstiften, bei Thorvaldsen hingegen mit Bleistift- oder gravierten Zeichen markiert wurden. ${ }^{18}$ Schließlich ging Thorvaldsen auch mit der Neugierde der Öffentlichkeit anders um, indem er dieser Zutritt zu seinen privaten Räumen und damit einen Blick auf eben begonnene Werke ermöglichte, wohingegen Canova seine Zeichnungen und Bozzetti weitestgehend vom breiteren Publikum fernhielt. ${ }^{19}$

Die wichtigste durch Canova eingeführte Neuerung war der Gebrauch von Gipsmodellen in voller Größe, den sogenannten Originalmodellen. ${ }^{20}$ Zwar ist bereits in Denis Diderots ab 1751 publizierter Encyclopédie unter dem Begriff „Sculpture en marbre“ das Verfahren beschrieben, mittels der in jener Zeit an der Académie de France in Rom entwickelten Punktiermaschine antike Skulpturen von originalgroßen Gipsabgüssen in Marmor zu übertragen. ${ }^{21}$ Es ist gemäß Johannes Myssok jedoch fraglich, ob dieses Verfahren von Bildhauern vor Canova zusätzlich zur Antikenreproduktion auch zur Herstellung eigener Werke angewandt wurde. ${ }^{22}$ Bevor Canova für die Schaffung eigener Werke auf das genannte Verfahren zurückgriff, hatten die einzelnen Schritte der bildhauerischen Praxis im Wesentlichen im gezeichneten Entwurf, dem Bozzetto, dem Gipsmodell in halber Größe und schließlich der Marmorversion auf der Basis dieses Modells bestanden. Bereits der Barockbildhauer Gian Lorenzo Bernini hatte jedoch mit Tonmodellen in voller Größe gearbeitet. Um das Modell vor Austrocknung und daraus resultierender Brüchigkeit zu schützen, wurde es in ausgehöhlter Form gebrannt. Die erstmals für Canova belegte Übertragung des großen Tonmodells in das weniger fragile Material Gips verlieh der Komposition eine deutlich längere Lebensdauer, sodass viele Originalmodelle bis heute erhalten sind. Dazu trugen zudem die neuen Funktionen des Künstlerateliers als Ausstellungs- und Verkaufsraum bei, die im nächsten Kapitel besprochen werden. Canovas Einführung des Gipsmodells in voller statt in halber Größe und der Rückgriff auf das Punktiergerät erleichterten die Übertragung der Figur in den Marmorblock erheblich, da in diesem Schritt kein Umrechnen der Maße mehr erforderlich war. ${ }^{23}$ Dies verringerte Fehler bei der Ausführung in Marmor, was wiederum ein arbeitsteiliges Verfahren begünstigte.

17 Hartmannn 1956, 81; Hartmann 1972, 41; Salling 1972, 41; Wittstock 1975, 113; Helsted 1982a, 52; Jørnæs 1989c, 31; Kat. Nürnberg/Schleswig 1991, 593; Jørnæs 2011, 121; Grandesso 2015, 159. Zu Canova siehe Honour 1972a, 146 - 148; Honour 1972b, 218 -219; Myssok 2010, 281.

18 Miss 2008, 32; Jørnæs 2011, 121.

19 Zu Canova siehe Myssok 2011, 17.

20 Siehe dazu ausführlich Myssok 2010; auch Myssok 2017, 144.

21 Encyclopédie 1751-1772, Bd. 14, 841; auch Helsted 1977, 12; Wittstock 1984, 106; Myssok 2010, 272 - 273; Gallo 2017, 118.

22 Myssok 2010, 273 - 277, auch für die folgenden Ausführungen.

23 Ebd., 275; Kofoed 2014b. 
Bereits im November 1805 schrieb der Baron Schubart über Thorvaldsen, dass „die öffentliche Meinung ihn bald über Canova setzen würde, wenn ihm seine Verhältnisse erlaubten, ein so großes Atelier und so viele mechanische Gehilfen wie dieser zu haben".24 Während Atelierbetriebe mit mehreren Gehilfen keineswegs eine neue Erscheinung des frühen 19. Jahrhunderts waren - man denke nur an Tizian oder Peter Paul Rubens -, sollte die gleichsam fabrikhafte Organisation von Thorvaldsens Werkstätten bald alles bis dahin Gekannte übertreffen. ${ }^{25}$ Sie wurde von den Zeitgenossen denn auch mit entsprechender Neugierde und Überraschung aufgenommen. So schrieb Thiele rückblickend auf das Jahr 1805, dass Thorvaldsens Werke in erster Linie dessen „Gehilfen beschäftigten“.26 Dementsprechend notierte von der Hagen am 14. Dezember 1816 in sein Tagebuch:

Merkwürdig ist dabei die Sicherheit, mit welcher gegenwärtig vermittelst des Senkbleis und des Zirkels mit gekrümmten Schenkeln, überall das Maaß [sic] des Modells auf den Marmor übertragen, und durch unzählige Punkte überall die Tiefe bestimmt wird, bis auf welche die Steinhauer vorarbeiten, so daß der Meister nur die vollendende Hand anlegt. ${ }^{27}$

In ähnlicher Weise erklärte auch der Historiker Christian Molbech die Herstellung der Marmorskulpturen in Thorvaldsens Werkstätten, die er im Sommer 1820 besucht hatte:

Diese eigentliche Arbeit des Bildhauers ist inzwischen zu einem großen Teil ganz mechanisch. Über dem Marmorblock wird ein Holzrahmen aufgerichtet, von dem herabhängende Lote, nach einer genauen Ausmessung des Gipsmodells, die Weite und Lage zuerst von dessen äußersten Punkten bezeichnen, die sich mit schwarzen Punkten auf dem Stein absetzen; und danach, wenn der Meißel sich tiefer in den Block hineinarbeitet, werden mehr und mehr Dimensionen des Gipsmodells bezeichnet, und diese werden mit mathematischer Genauigkeit auf die Marmorstatue überführt, der man aber doch immer eine solche, stark erhöhte und großzügigere, Oberfläche belässt, dass der Künstler selbst, indem er diese wegnimmt, letzte Hand an seine Arbeit legen kann..$^{28}$

24 Hermann Schubart an Nicolai Abildgaard, 10. November 1805, TMA, Thieles afskrifter af Thorvaldsens breve, vol. I, 1805: „Lykkes de, saa vil Rygtet snart svinge ham over Canova, hvis Ligemand han alt vilde være, om hans Stilling tillod ham, at have et saa stort Atelier og saa mange mekaniske Medhiælpere, som denne." Deutsche Übersetzung nach Helsted 1977, 9 - 10. Siehe auch Thiele 1852, 47; Springer, P. 1991, 214.

25 Tesan 1998, 9; Grandesso 2015, 166.

26 Thiele 1852-1856, Bd. 1, 139. Eine ähnliche Beschreibung von Thorvaldsens Arbeitsweise findet sich auch bei Peale 1855,162 .

27 Von der Hagen 1818 - 1821, Bd. 2, 336.

28 Molbech 1822, 209: „Dette Billedhuggerens egentlige Arbeide er imidlertid for en stor Deel ganske mechanisk. Over Marmorblokken opreises en Træstilling, hvorfra nedhængende Lodder, efter en nøiagtig Udmaaling af Gibsmodellen, betegne Vidden og Beliggenheden først af dennes yderste Punkter, som med sorte Prikker afsættes paa Stenen; og efterhaanden, som Meiselen arbeider sig dybere ind i Blokken, betegnes flere og flere af Gibsmodellens Dimensioner, og disse overføres med mathematisk Nøiagtighed paa Marmorstatuen, som man dog altid lader beholde en saa, meget forhøiet og rummeligere Overflade, at Konstneren selv, i at borttage denne, kan lægge sidste Haand paa sit Arbeide." (Hervorhebung im Original.) Siehe auch Wittstock 1975, 114; Wittstock 1984, 105-106. 
Von der Hagen und Molbech geben in ihren Beschreibungen die Technik der Übertragung des Originalmodells auf den Marmorblock insgesamt korrekt wieder. Eine nicht endgültig geklärte Frage ist indessen, ob Thorvaldsen den letzten Schliff seiner Werke grundsätzlich selbst vornahm. Man geht in der Forschung zwar davon aus, doch wurde sein handwerklicher Anteil an der Vollendung seiner Skulpturen von Zeitgenossen bisweilen infrage gestellt. ${ }^{29}$ So notierte Grillparzer am 14. April 1819 nach einem Besuch in Thorvaldsens Werkstatt in sein Tagebuch:

Ich habe keine seiner ganz fertigen Statuen gesehen, und ich weiß daher nicht, ob er in der Vollendung des mechanischen Teils der Arbeit seinem Nebenbuhler [d.h. Canova] gleichkommt - und eine Statue in seinem Studio, von der mir die Gehilfen sagten, es fehle nichts als die Politur, schien diesen Zweifel eher zu bekräftigen als zu heben -, aber was die edle Form, die Belebung des Toten und die Komposition betrifft, hierin steht meiner Meinung nach Thorwaldsen weit über Canova. ${ }^{30}$

In ihren Memoiren berichtete auch die Malerin Seidler, die sich in den Jahren um 1820 in Rom aufhielt, über Thorvaldsens Werkstattpraxis:

Er fertigte die Skizzen zu seinen Werken gewöhnlich nur einen Fuß hoch an und ließ sie darauf von einem geschickten Schüler oft über Lebensgröße modellieren. Dies Tonmodell wurde sodann abgegossen und in Marmor kopiert. [...] Die gröberen Arbeiten, wie das Aushauen der Figuren aus dem rohen Marmorblock, waren untergeordneten Bildhauern anvertraut; die feinere Arbeit ging dann in geschicktere Hände über. ${ }^{31}$

Neben diesen Zeugnissen über Thorvaldsens Werkstattpraxis gab es zahlreiche Zeitgenossen, die sich spezifisch zu dessen geringem Anteil an der Bearbeitung des Marmors äußerten, wie im Folgenden ausgeführt wird.

\section{Thorvaldsen und der Marmor}

Die für Ludwig von Bayern geschaffene Marmorversion der 1808 modellierten AdonisStatue ist eines der wenigen eigenhändigen Werke von Thorvaldsen. ${ }^{32}$ Wie diverse Quellen bestätigen, war dessen handwerklicher Anteil an anderen Marmorausführungen insgesamt gering bis inexistent. Letzteres galt etwa für die um 1800/1801 geschaffene Büste des Arztes Mathias Saxtorph, „die ich, unter uns gesagt, nicht selbst gemacht habe ${ }^{\text {“ }{ }^{33} \text { Dieses }}$

31 Erinnerungen der Malerin Louise Seidler 1922, 122.

32 Ebd.; Schultz 1944, 96; Wittstock 1975, 115; Helsted 1982a, 53; Wittstock 1984, 108; Kofoed 2014 b.

33 Bertel Thorvaldsen an Nicolai Abildgaard, 23. September 1806 (erster Entwurf), TMA, Ref. m28, nr. 34v: „[...] Saxtorff Byste til Her dr Schel som jeg imellem os sagt ikke selv har giord [...]“; Bertel Thorvaldsen an Nicolai Abildgaard, 23. September 1806 (zweiter Entwurf), TMA, Ref. m28, nr. 33: „[...] Saxorfs Byste til Doctor Schel som ieg i mellem os sagt ikke har giort [...].“ Siehe auch Thiele 1852-1856, Bd. 1, 72; Springer, P. 1991, 214. 
Eingeständnis von Thorvaldsen findet sich in zwei vom 23. September 1806 datierenden Entwürfen eines Briefes an Abildgaard, während es in der definitiven Abschrift signifikanterweise fehlt. ${ }^{34}$ Auch gemäß dem zweiten Earl of Minto, der zwischen 1821 und 1822 in Rom weilte, tat Thorvaldsen „wenig am Marmor, und seine Statuen sind weniger als jene von beinahe jedem anderen Künstler das tatsächliche Werk des Meisters“, was man ihnen durchaus ansehe..$^{35}$ In entsprechender Weise hielt Raczynski in seiner Geschichte der neueren deutschen Kunst fest:

Thorwaldsen bearbeitet fast niemals selber den Marmor. Es giebt eine große Anzahl seiner Bildwerke, an welche er nicht die Hand gelegt hat. Er macht das Modell für sie, und beaufsichtigt die Ausführung. Ich habe ihn im Jahre 1821 mehrmals in seiner Werkstätte besucht. Er ging von einem Arbeiter zum andern, und bezeichnete mit Bleistift die Stellen, welche verbeßert oder vollendet werden sollten. ${ }^{36}$

Aus dieser Beschreibung geht hervor, dass Thorvaldsen trotz seines geringen handwerklichen Anteils die Ausführung seiner Schöpfungen in Marmor genau überwachte - vergleichbar einem Arzt auf Visite, wie er es selbst gegenüber Brøndsted formuliert haben soll. ${ }^{37}$ Dies ist der Grund für die durchgehend hohe Qualität der Marmorwerke, die zu seinen Lebzeiten entstanden. Demgegenüber mangelt es den posthum unter der Aufsicht von Thorvaldsens Schülern für dessen Museum ausgeführten Marmorskulpturen oft an Virtuosität in den Details, wie sich beispielsweise in der Darstellung des von Adern gezeichneten Körpers von Pferden zeigt, was die Werke zuweilen etwas oberflächlich und kühl erscheinen lässt. ${ }^{38}$

Rembrandt Peale reduzierte in seinen 1855 publizierten „Reminiscences“ Thorvaldsens ohnehin geringes eigenhändiges Zutun zum Marmorwerk noch, wenn er schrieb, dass der Däne wie auch Gibson - im Gegensatz zu anderen Bildhauern der Zeit - den „Marmor nie berührt“ habe. ${ }^{39}$ Zudem hat der amerikanische Maler die vermutlich nicht ganz wahre Anekdote überliefert, wonach Thorvaldsen ihm seine Skulptur von Ganymed

34 Bertel Thorvaldsen an Nicolai Abildgaard, 23. September 1806, KB, Ref. Abr. nr. 2163, 4º (Transkript im TMA): „Professor Badens Byste er færdig og skal efter Forlangende blive afsendt tillige med et andet Byste til Doctor Schel.“ (Hervorhebung durch T. S.) Siehe auch Thiele 1852-1856, Bd. 1, 149.

35 Gilbert Elliot-Murray Kynynmound, 2. Earl of Minto, 7. Januar 1822, Edinburgh, National Library of Scotland, Ref. MSS 11986-7 (Transkript im TMA): „But Thorwaldson himself does little to the marble, and his statues are less than those of almost any other artist the actual work of the master; indeed they betray this too strongly."

36 Von Raczynski 1836 - 1841, Bd. 3, 277, Anm. Siehe auch Wittstock 1975, 113 - 114; Wittstock 1984, 105; Kat. Nürnberg/Schleswig 1991, 593. Eine ähnliche Beschreibung ist auch von Thomas Crawford überliefert, zit. bei Dimmick 1991, 179.

37 Peter Oluf Brøndsted an Jens Møller, 15. Juni 1822, zit. bei Hartmann 1972, 41; Wittstock 1975, 113; Helsted 1977, 10 und 13; Helsted 1982a, 53; Jørnæs 1989c, 31; Tesan 1991b, 232; Kofoed 2014b.

38 Siehe auch Schultz 1944, 98; Helsted 1977, 14; Tesan 1991b, 235.

39 Peale 1855, 162: „The British artist, Gibson, told me that he never touched his marble, nor did Thorwaldsen, [...]. “ Ähnliche Aussagen über Thorvaldsens geringen Anteil am Marmorwerk finden sich ferner in: 
mit Jupiters Adler von 1815-1817 gezeigt und angemerkt habe, dass der Adler nicht sein eigenes Werk sei. ${ }^{40}$ Bei ihrem späteren Besitzer, dem Marquis of Stafford in London, sei dieselbe Skulptur hingegen mit den Worten angepriesen worden, dass „kein Meißel außer jenem von Thorwaldsen [dieses Werk] ausführen konnte, und speziell [nicht] den Adler". ${ }^{41}$ Über die Statuen von Christus und den Aposteln ab 1821 für die Kopenhagener Frauenkirche behauptete Peale indessen, dass die Gipsmodelle nach Carrara gebracht und dort in Marmor gehauen worden seien, sodass Thorvaldsen diese Werke nie gesehen habe, „bis sie fünf Jahre später ihren Platz in der Kathedrale von Stockholm einnahmen“.42 Die Tatsache, dass Peale die beiden skandinavischen Städte verwechselte und offensichtlich nicht wusste, dass die genannten, über rund zwei Jahrzehnte ausgeführten Skulpturen Thorvaldsens bedeutendster Auftrag für seine Heimatstadt Kopenhagen war, zeigt erneut, dass er den Bildhauer wohl in erster Linie als zeitgenössische Berühmtheit wahrnahm und mit Thorvaldsens Biografie und Euvre nur bedingt vertraut war, wie im Kapitel II.2 ausgeführt wurde.

Angesichts der Kommentare zu Thorvaldsens geringem Anteil an seinen Marmorwerken überrascht es nicht, dass unter Zeitgenossen gelegentlich die Kritik laut wurde, Thorvaldsen könne nicht in Marmor arbeiten. So konstatierte sogar Caroline von Humboldt, eine der eifrigsten Verehrerinnen von Thorvaldsens Kunst, in einem Brief vom 24. Dezember 1817 an die Dichterin Brun: „Als Künstler steht er auf lichter Höhe, das gilt aber nur von der Erfindung, denn in der Ausführung und Vollendung des Marmors gehen die anderen ihm voran. " ${ }^{43}$ Thorvaldsen konnte indessen recht brüsk reagieren, wenn ihm die Fähigkeiten als Marmorbildhauer abgesprochen wurden. Auf den Vorwurf seines schwedischen Kollegen Johan Niklas Byström, dass er zwar ein „großer Künstler“ sei, aber nicht in Marmor arbeiten könne, soll Thorvaldsen entgegnet haben: „Hör zu, Byström,

„Albrecht Dürers Standbild“, Allgemeine Zeitung, 504/505, 26. Oktober 1836, 2013-2015 (hier 2014); Francesco Gasparoni, Peregrinazioni a Genzano, Rom 1845, 31, zit. bei Tesan 1998, 69.

40 Peale 1855, 162: „[...] Thorwaldsen, who, in showing me his Ganymede, remarked that the eagle was entirely the work of the young man who was chiselling it, as he himself knew nothing about the bird: $[\ldots] . “$

41 Ebd.: „[...] yet this same Ganymede, which I afterwards saw at the Marquis of Stafford's, in London, was commended as a work that ,no chisel but that of Thorwaldsen could execute, and especially the eagle." Beim genannten Marquis of Stafford handelt es sich um George Granville Sutherland-Leveson-Gower, den 2. Duke of Sutherland, der 1817 eine Marmorausführung von Ganymed mit Jupiters Adler bestellt hatte; http://arkivet.thorvaldsensmuseum.dk/people/gower-george-granville-leveson (zuletzt aufgerufen am 15. April 2020).

42 Ebd.: "Christ and his Apostles were copied in marble at Carrara from his models, and the author never saw them till five years after, when they occupied their places on the Cathedral at Stockholm. "Auf Peales Aussagen verweist auch Dimmick 1991, 175.

43 Caroline von Humboldt an Friederike Brun, 24. Dezember 1817, zit. nach Wittstock 1975, 304. Siehe auch Foerst-Crato 1975, 161 (hier datiert der Brief jedoch vom 29. Dezember 1817); Tesan 1991b, 233. Eine ähnliche Kritik findet sich auch in „ART. IX“ 1832, 213. 
binde mir die Hände auf den Rücken, und ich werde den Marmor besser beißen, als du ihn haust!“44 Dass die negativen Urteile über Thorvaldsens Fähigkeiten als Marmorbildhauer in der Tat nicht berechtigt waren, davon zeugen die wenigen eigenhändigen Werke des Dänen, wie der genannte Adonis. ${ }^{45}$

\section{Die räumliche Trennung der Arbeitsschritte}

Während seiner ersten Jahre in Rom hielt Thorvaldsen Werkstätten im Vicolo delli Aliberti nahe der Via del Babuino und im Vicolo delle Colonnette (auch Vicolo della Catena genannt, heute Vicolo Barberini) in der Nähe des Palazzo Barberini. ${ }^{46}$ Im November 1815 unterzeichnete er einen Mietvertrag für drei kleine, zu diesem Palazzo gehörende Gebäude ebenfalls im Vicolo delle Colonnette, die zu den piccoli studi wurden. ${ }^{47}$ Am 3. Juni 1817 berichtete Caroline von Humboldt an ihren Ehemann Wilhelm über insgesamt „[v]ier Studien“ und am 3. März des darauffolgenden Jahres bereits über „fünf grosse Ateliers“.48 Eine genaue Beschreibung des Rundgangs durch diese Räume und der darin aufgestellten beziehungsweise in Entstehung begriffenen Werke findet sich beispielsweise in Molbechs Erinnerungen an seinen Romaufenthalt im Sommer $1820 .{ }^{49}$ Der Mietvertrag für das in Martens' Gemälde dargestellte studio grande, das ehemalige Stallgebäude des Palazzo

44 Zit. nach Sass 1963 -1965, Bd. 2, 398: „Hør, Bystrøm, bind mine Hænder paa Ryggen, og jeg skal bide i Marmoret bedre end du hugger." Diese in Charlotte Bournonvilles Memoiren Erindringer fra Hjemmet og fra Scenen (1903) überlieferte Anekdote beschreibt eine durch Thorvaldsen gegenüber Bournonvilles Mutter bestätigte Begebenheit aus den 1820er Jahren. Es handelt sich dabei um eine vielfach, jedoch meist ohne verlässliche Quellenangabe und teils auch verändert wiedergegebene Anekdote; siehe bspw. Thiele 1831-1850, Bd. 2, 135; Oehlenschläger 1850, Bd. 4, 149; Plon 1867, 215; Helsted 1977, 14; Helsted 1982a, 53. In Christine Stampes Memoiren wurde Byström zu Rauch; Baronesse Stampes Erindringer 1912, 103. Bei Andersen dreht sich der in dieser Anekdote dargestellte Streit indessen nicht um die Arbeit in Marmor, sondern um Thorvaldsens Fähigkeiten im Basrelief vs. der Skulpturengruppe; Andersen 1961, 159.

45 Erinnerungen der Malerin Louise Seidler 1922, 122; Schultz 1944, 96; Wittstock 1975, 115; Helsted 1982a, 53; Wittstock 1984, 108; Kofoed 2014b.

46 Thiele 1852-1856, Bd. 1, 50; Plon 1867, 28; Hartmann 1963, 1; Sutton 1972, 5; Jørnæs 1989c, 29; Jørnæs 2011, 116; Mrgan 2015b. Die Werkstatt im Vicolo delli Aliberti hatte zuvor dem Bildhauer John Flaxman gehört.

47 Thiele 1852-1856, Bd. 1, 263; Trier 1903, 104 (Triers weitere Ausführungen sind jedoch fehlerhaft); Oppermann 1927, 122; Hartmann 1963, 6; Hartmann 1971, 34; Wittstock 1975, 116; Jørnæs 1989c, 29; Jørnæs 1991c, 89; Tesan 1991b, 225; Randolfi 2010, 80; Mrgan 2015b.

48 Caroline von Humboldt an Wilhelm von Humboldt, 3. Juni 1817, zit. nach Wittstock 1975, 300; Caroline von Humboldt an Wilhelm von Humboldt, 3. März 1818, zit. nach Wittstock 1975, 305. Auch Peder Hjort berichtete am 23. April 1818 von fünf, an einem kleinen Garten gelegenen Gebäuden; Hjort 1818, 5.

49 Molbech 1822, 224-229. Detaillierte Zeugnisse über Thorvaldsens Werkstätten, einschließlich des studio grande, finden sich zusätzlich zu den hier zitierten Quellen bspw. bei Thiele 1831-1850, Bd. 2, 128-132; Carus 1835, I, 350; Ponciano Ponzano y Gascón, „Studio o arsenale dello scultore Thorwaldsen“, zwischen 1832 und 1838, zit. bei. Hartmann 1971, 38 - 39. 
Barberini, wurde schließlich am 18. Juli 1822 abgeschlossen (Taf. II). ${ }^{50}$ Neben den designierten Werkstätten hatte der Bildhauer ferner in seiner Privatwohnung in der Casa Buti mindestens ein als Atelier eingerichtetes Zimmer, worauf im Kapitel III.3 zurückgekommen wird.

In enger Verbindung mit der stark arbeitsteiligen Organisation von Thorvaldsens Kunstunternehmen - man kann seine Werkstätten tatsächlich so nennen - steht die räumliche Trennung der verschiedenen Arbeitsschritte. Auch diesbezüglich gehörte Canova zu den Vorreitern, indem er in einem Atelier mit seinen Gehilfen die handwerkliche Arbeit ausführte und in einem zweiten Atelier seine Kunden empfing und so den Eindruck erweckte, als ob er alle Skulpturen eigenhändig geschaffen hätte. ${ }^{51}$ Eine räumliche Trennung künstlerischer Arbeitsschritte war seit dem späten 18. Jahrhundert im Übrigen nicht nur bei Bildhauern verbreitet, sondern auch bei Malern, wie Séverine Sofio am Beispiel von Jacques-Louis David gezeigt hat..$^{52}$

Thorvaldsens Ateliers waren spätestens ab den 1820er Jahren in drei Kategorien unterteilt: Während der Bildhauer die ersten Entwürfe üblicherweise in seiner privaten Wohnung zeichnete und modellierte, stellten seine zahlreichen Gehilfen die großen Tonund Gipsmodelle sowie die Marmorstatuen in den kleinen Ateliers an der Piazza Barberini her. Wie auch Martens' Gemälde veranschaulicht, diente das studio grande derweil hauptsächlich der Werkpräsentation und der Selbstrepräsentation des Meisters. Die nach Arbeitsschritten und Funktionen erfolgte Trennung von Thorvaldsens Ateliers hatte zur Folge, dass die Besucherinnen und Besucher dem Bildhauer immer seltener in einer der offiziellen Werkstätten begegneten. Stattdessen wurden sie von einem eigens dafür bezahlten Gehilfen herumgeführt, während sich weitere Bedienstete um Preisanfragen und Bestellungen kümmerten. ${ }^{53}$ In Carl Gustaf Estlanders 1867 erschienenem Überblickswerk über die Kunstgeschichte seit dem ausgehenden 18. Jahrhundert werden die Aufgaben der erwähnten Gehilfen Thorvaldsens ausgeschmückt, indem einer davon den Besuchenden

Thiele 1852-1856, Bd. 2, 90; Hartmann 1971, 34; Helsted 1982a, 52; Jørnæs 1991c, 89; Kat. Nürnberg/ Schleswig 1991, 529; Tesan 1991b, 226; Tesan 1998, 58; Randolfi 2010, 80 (mit anderem Datum); Jørnæs 2011, 148; Grandesso 2015, 165. Die Gebäude an der Piazza Barberini, die Thorvaldsens Werkstätten beherbergten, existieren nicht mehr. Insgesamt dürften sie sich ungefähr an der Stelle des 1875 eröffneten heutigen Hotels Bernini Bristol befunden haben; Hartmann 1963, 10; Hartmann 1971, 36 und 39-40; Jørnæs 1991c, 90 - 92. Entsprechende Lagepläne finden sich bei Jørnæs 1991c, 86, und Kat. Nürnberg/ Schleswig 1991, 569. Siehe zur Lage von Thorvaldsens Werkstätten außerdem Giovanni Corboli Bussi, Memorie di Roma, Manuskript, 1827, zit. bei Randolfi 2010, 79 - 80; Hartmann 1971, 34 - 35; Jørnæs 1991c, $88-92$.

51 Griener 2014, 21.

52 Séverine Sofio, in: Guillouët u. a. 2014, 36. Es gab im 19. Jahrhundert diesbezüglich jedoch deutliche Unterschiede zwischen Bildhauer- und Malerateliers, da erstere in der Regel sowohl auf mehr Arbeitskräfte als auch auf größere finanzielle Mittel angewiesen waren; siehe dazu Pierre-Michel Menger, in: Guillouët u. a. 2014, 27. 
verheimlichen sollte, welcher der zahlreichen Arbeitskräfte der Meister der Werkstatt war. ${ }^{54}$ Estlanders vielzitierte Behauptung ist allein schon deshalb unglaubwürdig, weil Thorvaldsens auffallendes Äußeres nicht nur allgemein bekannt war, sondern sich zweifellos von jenem seiner Gehilfen und Schüler abhob. Zugleich ist der Bericht vielsagend mit Blick auf den auch über Thorvaldsens Tod hinaus gepflegten und genährten Kult um den Bildhauer. Dabei waren die starke Arbeitsteilung in Thorvaldsens Werkstätten und die räumliche Trennung der verschiedenen Arbeitsschritte durchaus auch Mittel künstlerischer Selbstdarstellung: Durch sie wurde vor allem das studio grande noch mehr zu jenem Ort, an dem sich der Mythos um das Künstlergenie materialisierte und zelebriert wurde. ${ }^{55}$ Darüber hinaus trug diese inhaltliche und räumliche Organisation der Arbeitsstätten wesentlich zu Thorvaldsens öffentlichem Bild und seiner Sichtbarkeit bei, was sie wiederum zu einem wichtigen Teil des celebrity-Kults um ihn machte.

\section{Thorvaldsens Ateliers als Bildhauerschule}

Gerade für die Ausbildung der häufig aus dem Ausland stammenden, jüngeren Bildhauer war Thorvaldsens Betrieb oft die erste Anlaufstelle, was diesem gleichsam den Charakter einer eigenen Schule verlieh. ${ }^{56}$ Umgekehrt wurden auch die Werkstätten der Schüler für die Ausführung von Thorvaldsens Arbeiten genutzt. ${ }^{57}$ Beides steigerte ebenfalls die Sichtbarkeit des dänischen Bildhauers im kulturellen Leben Roms maßgeblich. Schließlich trugen die nach ihrer Ausbildung in Italien in ihre Heimatländer zurückkehrenden Künstler entscheidend zur Verbreitung von Thorvaldsens Namen und Ruhm bei, weshalb die Mentorentätigkeit für den Bildhauer mit einem direkten Nutzen verbunden war. ${ }^{58}$ So war es mit Rauch einer von Thorvaldsens frühesten und erfolgreichsten Schützlingen, der nicht nur 1812 und 1816 die wohl ersten Porträtbüsten des Dänen schuf (darunter Abb. 79), sondern in den späten 1810er Jahren auch die bei Thorvaldsen erlebte Werkstattpraxis nach Deutschland brachte. ${ }^{59}$

54 Estlander 1867, 271. Siehe auch Helsted 1977, 13; Helsted 1982a, 52; Springer, P. 1991, 213; Jørnæs $2011,122$.

55 Siehe bspw. Ruppert 1998, 316 - 320; Séverine Sofio, in: Guillouët u. a. 2014, 39; in ähnlichem Zusammenhang auch Beck 1991, $78-79$.

56 Tesan 1991a, 259; Tesan 1998, 9, 63 und 69-70; Salling 2012, 166. Zu Thorvaldsens Schülern siehe ausführlich Tesan 1998.

57 Tesan 1998, 72.

58 Siehe auch Tesan 1991a, 259.

59 Zu Rauch siehe ebd., 260 - 261; auch Helsted 1977, 12; Wittstock 1984, 108. Die Gipsmodelle der beiden Büsten befinden sich in Thorvaldsens Museum in Kopenhagen (Inv.-Nr. Dep.31, früher Pietro Tenerani zugeschrieben; G260). Die Marmorversion der Büste von 1812 wurde 1854 posthum durch Georg Christian Freund und Stephan Ussing unter Bissens Aufsicht ausgeführt und befindet sich als Dauerleihgabe von Thorvaldsens Museum (Inv.-Nr. G1) auf Schloss Gottorf in Schleswig. Die Marmorfassung der Büste von 1816 ist Teil der Sammlung der Alten Nationalgalerie in Berlin. 
79_Christian Daniel Rauch (früher Pietro Tenerani zugeschrieben), Porträtbüste von Bertel Thorvaldsen, 1812, Gipsmodell, Höhe: $60 \mathrm{~cm}$, Kopenhagen, Thorvaldsens Museum (Inv.-Nr. Dep.31)

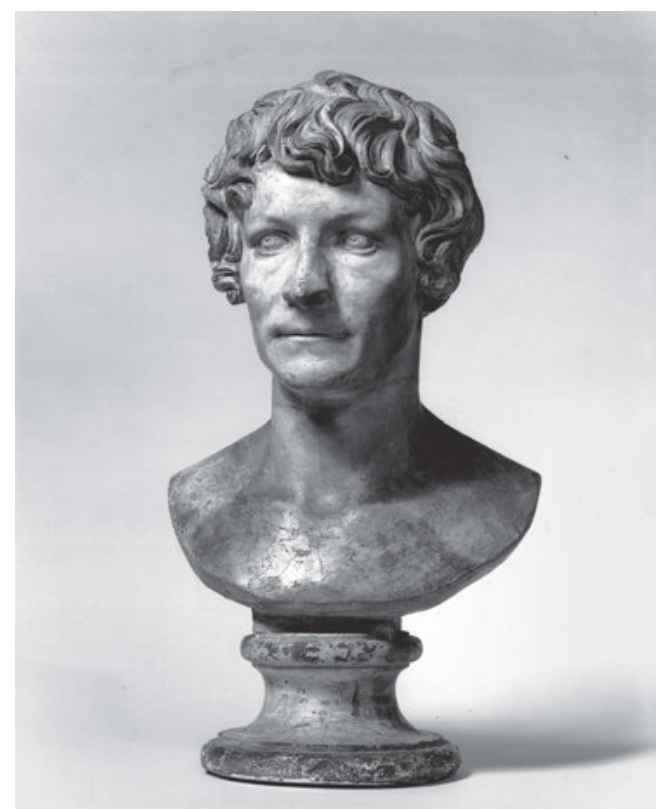

Ein weiterer Bildhauer und Protegé Thorvaldsens, der aus seiner tiefen Bewunderung für den Dänen zweifellos zu dessen Sichtbarkeit speziell in Großbritannien beitrug, war Gibson, den Atkinson bezeichnenderweise „England's Thorwaldsen“ nannte. ${ }^{60}$ Gibson selbst berichtete dem Autor Edward Bulwer Lytton am 2. Januar 1836:

Ich modelliere nie ein Werk, ohne Thorvaldsen und andere zu konsultieren, und habe immer sehr profitiert von dieser Praxis - sie vereint, um die Kunst zu erhöhen - wo Kunst lediglich ein Gewerbe ist, ist dies nicht das übliche Vorgehen. ${ }^{61}$

Bereits aus dieser Textpassage wird ersichtlich, was Gibson auch später betonte: Seiner Meinung nach war die Kunst in Rom kein geldorientiertes Gewerbe, sondern werde einzig durch das Streben unzähliger internationaler Künstler nach Ruhm begünstigt. ${ }^{62}$ Diese Behauptung ist eine deutliche Verklärung des anonymen, höchst kompetitiven Kunstmarkts in Rom, auf dem sich nur ein kleiner Bruchteil der dort wirkenden Künstler aus ganz

60 Atkinson 1873, 54.

61 John Gibson an Edward Bulwer Lytton, 2. Januar 1836, Hertford, Hertfordshire Archives and Local Studies, The Lytton Archive, Ref. DE/K/C3/114 (Transkript im TMA): „I never model a work without consulting Thorvaldsen and others and have always found great benefit from this practice - it is combining together to advance art - where art is a mere trade this is not the practice."

62 John Gibson an John Crouchley, 6. Mai 1837, Aberystwyth, The National Library of Wales, MS 4914D-39 (Transkript im TMA). 
Europa sowie Nordamerika behaupten konnte. Gleichzeitig spiegelt sie Gibsons eigenen Wunsch mehr nach Ruhm als nach Geld wider. Auf Thorvaldsens Vorschlag hin, Gibson sollte nach England zurückkehren, der Nachfolger des kürzlich verstorbenen, gefeierten Bildhauers Francis Legatt Chantrey werden und ein Vermögen verdienen, meinte Gibson: „Ruhm ist meine Ambition, nicht ein Vermögen. Ich denke, Cavaliere, dass niemand außerhalb Roms Werke von anhaltendem Ruhm schaffen kann." ${ }^{63}$

Die Kehrseite von Thorvaldsens Hilfsbereitschaft gegenüber jüngeren Kollegen war seine Besitzergreifung derselben. So günstig die Vorteile für die jungen Künstler waren, so unbestritten war die Hierarchie in Thorvaldsens Werkstätten: Die Schüler profitierten zwar vom berühmten Namen und stetig wachsenden Ruhm ihres Meisters, doch dieser besaß die alleinige und unangetastete Autorität in seinen Ateliers. Dies führte nicht selten zu einer starken künstlerischen wie finanziellen Abhängigkeit der jungen Bildhauer von Thorvaldsen. ${ }^{64}$ Harald Tesan spricht von dem - jedoch im Endeffekt gescheiterten - Streben der Schüler nach „Replikation des Genies“ durch deren Arbeit in Thorvaldsens Ateliers. ${ }^{65}$ Die Abhängigkeit der Schüler vom Meister ging indessen so weit, dass sie seinen zuweilen rücksichtslosen Umgang erfuhren. Folglich gab es neben den unzähligen Lobpreisungen und Idealisierungen von Thorvaldsen und seinem Werk auch immer kritische Stimmen. Für den vorliegenden Kontext sind dabei weniger die Kritiken an Thorvaldsens Schöpfungen als vielmehr jene an seiner Arbeitsweise und seinem Umgang mit Künstlerkollegen und Aufträgen vielsagend. Denn sie zeichnen ein Gegenbild zur damals wie heute bevorzugten Persona des Bildhauers.

Ein Beispiel dafür ist Bruns Äußerung in einem am 27. Juni 1820 verfassten Brief an Caroline von Humboldt. Brun, die eine fast grenzenlose Bewunderung für Thorvaldsens Werk hegte, klagte in ihrem Schreiben über den Bildhauer: „Als Mensch hat er bei mir verlohren! Er hat bitter u. hart und unedel an Lund gehandelt [...]! Basta cosi! Es hat mich bitter geschmerzt dieses Urtheil aussprechen zu müßen. “" ${ }^{66}$ Diese Aussage dürfte sich auf Thorvaldsens Vorschlag einer Christus-Statue für die Apsis der Kopenhagener Frauenkirche beziehen, für die der Maler Johan Ludwig Gebhard Lund bereits ein Altargemälde geschaffen hatte. Die Kirchenbaukommission entschied sich am 20. Mai 1820 jedoch für Thorvaldsen und zog die genannte Bestellung bei Lund zurück. ${ }^{67}$ Ohnehin schien der 20566E-25 (Transkript im TMA): „[... ] fame is my ambition not a fortune. I think, Cavaliere, that no one can produce works for lasting fame out of Rome."

64 Helsted 1977, 10; Tesan 1991a, 266 und 275; Tesan 1998, 63.

65 Tesan 1998, bes. 76.

66 Friederike Brun an Caroline von Humboldt, 27. Juni 1820, zit. nach Foerst-Crato 1975, 210.

67 Kirchenbaukommission (Kommissionen ang. genopførelse af Vor Frue Kirke i København) an Bertel Thorvaldsen, 20. Mai 1820, TMA, Ref. m6 1820, nr. 17. Siehe auch Thiele 1852 - 1856, Bd. 2, 28; Henschen 1997, 16-18. Lunds bereits 1818 gemaltes Altarbild von Christi Himmelfahrt wurde dennoch bezahlt und schließlich in der Kopenhagener St. Johannes-Kirche angebracht. 
Bildhauer im Hinblick auf die Neugestaltung der Frauenkirche keine Skrupel gegenüber seinen Weggefährten zu haben, handelte es sich doch um einen an Prestige kaum zu überbietenden Auftrag aus der Heimat. ${ }^{68}$ So verdrängte er von jenem Auftrag nicht nur Lund, sondern auch seinen Zögling Freund, der ursprünglich mit der Ausführung der Kolossalstatuen der zwölf Apostel betraut worden war. ${ }^{69}$ Quasi zur Wiedergutmachung wurden Lund und Freund schließlich mit anderen, wenngleich unbedeutenderen Arbeiten für die Frauenkirche sowie für Schloss Christiansborg beauftragt. ${ }^{70}$

Bemerkenswert ist im Zusammenhang mit der Kritik an Thorvaldsen außerdem das sich im Laufe von Arnims erstmals 1848 publiziertem, später jedoch ergänztem Briefroman Ilius Pamphilius und die Ambrosia verändernde Urteil über den Bildhauer. So schreibt Pamphilius am 20. Juni an Ambrosia:

Nun hat mein Bruder eine kleine Statue von ihm [Lord Byron] bekommen, nach Thorwaldsen in der Kopenhagener Porzellanfabrik gemacht. Die frappierte mich - dürftig wie sie ist - auf den ersten Blick, den ich in das Kistchen tat, und versetzte mich in eine so lebhafte Freude, als ob mir Großes widerfahren wäre, und ich jedem, den ich sah, viel mitzuteilen hätte. [...] Dies Bild belehrt mich mehr über den Mann als alles, was ich gelesen habe, da ist mehr Urteil und Auffassung des Charakters darin als in allen den Bänden voll Schreiberei; da sieht man, was geistiges Verständnis ist, wie der Genius dem Genius brüderlich die Hand reicht. Thorwaldsen muß ein liebenswürdiger Mann sein, so milde in seinem Urteil, wie kräftig in der Empfindung, und sein Aug' muß tief in die Menschen gesehen haben. ${ }^{71}$

In diesem Zitat werden verschiedene Komponenten der celebrity-Kultur und des Geniekults der ersten Hälfte des 19. Jahrhunderts angesprochen: Pamphilius' gleichsam erleuchtende Betrachtung der Porzellanfigur nach Thorvaldsens Denkmal für Lord Byron steht hier nicht nur für die Verehrung zweier als Berühmtheiten und Genies betrachteter Zeitgenossen, sondern zeigt auch deren Eingang in die Populärkultur. In einem späteren Brief vom 19. April gibt Pamphilius ein gegenteiliges Urteil über den Bildhauer ab, das die auch von anderen Zeitgenossen geäußerten Kritikpunkte nochmals aufnimmt:

In Thorwaldsen würdest Du Dich sehr verrechnet haben nach allem, was ich von ihm mehr gehört als selbst gesehen habe. Geiz nach Geld und eigner Ehre sollen ihn mit zunehmendem Alter, wo dem ju-

Der Auftrag zur skulpturalen Ausstattung der Kopenhagener Frauenkirche umfasste neben den kolossalen Christus- und Apostelstatuen den Knienden Taufengel, die Relieffriese Christus auf dem Weg nach Golgatha und Einzug in Jerusalem, diverse kleinere Reliefs mit biblischen Themen sowie eine Giebelgruppe um Johannes den Täufer über dem Haupteingang zur Kirche. Die originalgroßen Gipsmodelle dieser Werke befinden sich in Thorvaldsens Museum in Kopenhagen.

69 Henschen 1997, 18 - 20; Tesan 1998, 64; Jørnæs 2011, 134-135; Grandesso 2015, 173.

$70 \mathrm{Zu}$ Lund siehe die Briefe von Christian Frederik von Dänemark (später Christian VIII.) an Christian Frederik Hansen vom 12. März, 15. September und 23. Dezember 1820, alle TMA, Ref. m30A, nr. 63, Ref. m30A, nr. 64 und Ref. m30A, nr. 66. Zu Freund siehe Johan Gunder Adler an Bertel Thorvaldsen, 2. März 1821, TMA, Ref. m7 1821, nr. 14.

71 Von Arnim 1920, 146. 
gendlichen Genius, der ihnen vielleicht das Gegengewicht hielt, die Flügel sinken, mehr und mehr beherrschen, bis zur Gemeinheit. - Diese moralischen Fehler kehren, wie nicht anders sein kann, in seinen Werken als ästhetische Fehler wieder. In der Nähe ist mir der Nimbus von ihnen im Ganzen geschwunden und ich habe, nachdem ich sie gerechter betrachtete, gesehen, daß er nur einen beschränkten Kreis hat, innerhalb dessen er das Unübertreffliche leistet. - In Marmor zu arbeiten soll er nie verstanden haben. Die letzten Jahre ist der einzige, der gute Sachen für ihn ausgeführt hat, ein junger Deutscher namens Scholl gewesen. [...] ein außerordentliches Talent hat er, sich in Thorwaldsens unvollständige Modelle hineinzudenken und sie mit ihrem völligen Ausdruck in Marmor wiederzugeben, während die Italiener ihm alles verhunzen. Thorwaldsen hat ihn daher immer hochgehalten und gehegt, bis jetzt, wo er ihn bald nicht mehr gebrauchen wird $[\ldots]_{.72}^{72}$

In drastischeren Worten als diesen, die Thorvaldsen selbst die Erstellung einwandfreier Originalmodelle absprechen, wurden dessen Werkstattpraxis und Selbstvermarktung sowie der Künstlerkult um ihn wohl selten hinterfragt.

\section{Die Frage des Originals}

Wie die oben beschriebene Arbeitsweise in Thorvaldsens Werkstätten nahelegt, repräsentieren weniger die vollendeten Marmorwerke als vielmehr die Bozzetti und die Originalmodelle den schöpferischen Akt des Bildhauers. ${ }^{73}$ Dieser selbst soll das Modellieren des Tons als das "Allerwichtigste“ im bildhauerischen Arbeitsprozess bezeichnet haben. ${ }^{74}$ Dementsprechend erklärt Oehlenschläger in seinen 1850 erschienenen Lebens-Erinnerungen:

Um dies zu verstehen, muß man wissen, daß Thorwaldsen mit dem reichen Genie und der großen Erfindungsgabe lieber seine Gestalten in Thon modellirte, was dann doch das eigentliche Kunstwerk war, als eine Copie davon in Marmor zu hauen, was eine beschwerliche und fast ängstliche Arbeit ist $[\ldots] .{ }^{75}$

Die Bedeutung des Modellierens veranschaulicht auch Thorvaldsens aus dem Jahr 1819 bekannte Absicht, seine Tonmodelle brennen zu lassen und dadurch dauerhaft zu machen. So berichtete Brun in einem Brief vom 3. Dezember 1819 an Caroline von Humboldt über Thorvaldsens „Idée[,] unsterbliche Modelle von Thon zu brennen[,] welche dann Form zu [O]riginalen für alle Zeiten wären" ${ }^{76}$ Dieses Vorhaben scheiterte jedoch aus technischen Gründen; erst im letzten Lebensjahr des Bildhauers sollte das Brennen einiger Tonmodelle erfolgreich verlaufen. ${ }^{77}$ Der zentrale Stellenwert des Modellierens in Thor-

Von Arnim 1920, 216 - 217.

Siehe auch Kanzenbach 2007, 184; Miss 2008, 35; Friborg 2014.

Thiele 1852 - 1856, Bd. 2, 22; auch Andersen 1845, 42; Trier 1903, 121; Kanzenbach 2007, 185. Die Bedeutung des Modellierens in Ton führt zudem Plon 1867, 214, an.

Oehlenschläger 1850, Bd. 4, 149. Siehe auch Tesan 1991b, 233.

Friederike Brun an Caroline von Humboldt, 3. Dezember 1819, zit. nach Foerst-Crato 1975, 187.

Helsted 1977, 15. 
valdsens künstlerischer Praxis kommt schließlich auch in zahlreichen Porträts des Bildhauers zum Ausdruck. Diejenigen Bildnisse, die ihn mit einer oder mehreren seiner Schöpfungen zeigen, geben diese nicht als Marmorwerke, sondern als Bozzetti oder Originalmodelle wieder. Darüber hinaus verraten auch die oft mit dargestellten Werkzeuge wie Modellierholz oder Schabeisen eher eine Arbeit am Ton- oder Gipsmodell als am Marmor. ${ }^{78}$

Die Einführung des großen, in der Regel unverkäuflichen Gipsmodells, nach dem beliebig viele Marmorversionen ausgeführt werden konnten, kehrte die gängigen materiellen Konnotationen um, wonach Gips in erster Linie ein reproduktives Medium war, während dem Marmor der Wert der Einzigartigkeit zukam. Dass die mit dieser Umkehrung verbundene und bis heute aktuelle Frage nach dem Wert von Original und Kopie bereits Canovas und Thorvaldsens Zeitgenossen beschäftigte, veranschaulicht etwa die im Kapitel I.2 thematisierte Korrespondenz um die Bestellung einer Marmorversion von Thorvaldsens Alexanderzug für Schloss Christiansborg im Jahr 1818. ${ }^{79}$ Zur selben Zeit schrieb der Kritiker Peder Hjort über die damalige Werkstattpraxis der Bildhauer:

Er [der Bildhauer] behält selbst immer das Original, nämlich seine Form in Gips, die in seinem Atelier bewahrt wird, und fertigt danach so viele Kopien, wie man bestellt. Diese werden ganz mechanisch von seinen Handlangern verarbeitet, [...] und der Künstler vollendet sie, indem er bei der Arbeit selbst letzte Hand anlegt. Alle Kopien sind derart von gleichem Wert $[\ldots]{ }^{80}$

Gerade mit dem letzten Satz wies Hjort auf den Unterschied zwischen der Bildhauerei und der Malerei hin, da der Wert einer Replik dem des jeweiligen Originalgemäldes deutlich nachstehe. ${ }^{81}$ Bemerkenswert ist außerdem, dass verschiedene Zeitgenossen - darunter Hjort in aller Deutlichkeit - die Gipsmodelle von Thorvaldsens Werken als Originale und die Marmorversionen als Kopien bezeichneten..$^{82}$ Noch 1837 sollte sich Høyen im Hinblick auf das zu errichtende Museum für Thorvaldsen bemühen, seine Landsleute von der Gleichwertigkeit der Gipsmodelle und der Marmorausführungen zu überzeugen. ${ }^{83}$

Wurde ein Werk mehrmals in Marmor bestellt, so nahm Thorvaldsen wie Canova gelegentlich am großen Gipsmodell noch Veränderungen vor. ${ }^{84}$ Ein markantes Beispiel

Siehe auch Kat. Nürnberg/Schleswig 1991, 584; Kanzenbach 2007, 184.

Siehe dazu Kap. I.2.

Hjort 1818, 13: „Han beholder selv altid Originalen, nemlig hans Form i Gyps, som bevares i hans Attelier, og giver derefter saamange Copier, som man bestiller. Disse forarbeides ganske mechanisk af hans Haandlangere, [...] og Kunstneren fuldender dem ved at lægge sidste Haand selv paa Arbeidet. Alle Copier ere saaledes af lige Værdie [...]. “ Siehe auch Jørnæs 2011, 123.

Hjort 1818, $12-13$.

Oehlenschläger 1850, Bd. 4, 149; Erinnerungen der Malerin Louise Seidler 1922, 122.

Høyen 1837, 11-12; auch Miss 2008, 34.

Thiele 1852 - 1856, Bd. 1, 265; Wittstock 1975, 65 und 87; Helsted 1977, 12; Kat. Nürnberg/Schleswig 1991, 584; Springer, P. 1991, 216; Tesan 1991b, 235; Tesan 1998, 71. Spezifisch zu Canova siehe Myssok 2010, 
für zahlreiche Bestellungen von jeweils leicht individualisierten Ausführungen in unterschiedlichen Materialien ist der im Kapitel I.2 besprochene Alexanderzug. Doch nicht alle Auftraggeber gaben sich mit kleinen Veränderungen zufrieden. Fürst Metternich etwa, der sich - wie erwähnt - 1812 noch über die neue Werkstattpraxis der zeitgenössischen Bildhauer empört hatte, scheint diese später zwar akzeptiert zu haben, begnügte sich aber dennoch nicht mit einer leicht veränderten Kopie: Im Sommer 1817 bestellte er eine Marmorversion der beiden zwei Jahre zuvor modellierten Relieftondi Tag und Nacht - oder in den Worten von Metternichs Mittelsmann Jakob Ludwig Salomon Bartholdy: „Copien derselben, in der Grösse des Originals“ ${ }^{85}$ Auch hier wird das Gipsmodell als originales Werk und die Marmorversion als Kopie benannt. Um jedoch die bestellten Fassungen der äußerst beliebten und weitverbreiteten Reliefs nicht als reine Kopien bezeichnen zu müssen, wünschte der Fürst nebst einer kleinen Änderung am Motiv auch die Signatur des Bildhauers. ${ }^{86}$ Im Übrigen illustriert diese Bestellung den mehrfach erwähnten, zweifellos als Teil seiner Selbstvermarktung zu betrachtenden politischen Opportunismus Thorvaldsens: Während er noch 1812 für Napoleon den Alexanderzug modelliert hatte, war er nun für dessen Kontrahenten und die Leitfigur der Restauration, Fürst Metternich, tätig.

Obwohl das Gipsmodell in Canovas und Thorvaldsens Arbeitsweise einen entscheidenden Stellenwert einnahm, wurde es grundsätzlich nicht als definitives Werk betrachtet. Dazu trug sicherlich die Assoziation der Materialien Ton, Gips und Marmor mit Leben, Tod und Auferstehung bei. ${ }^{87}$ Gips sollte grundsätzlich erst um 1900 mit Bildhauern wie Auguste Rodin oder Medardo Rosso als definitives Material für Skulpturen anerkannt werden. ${ }^{88}$ Eine bekannte Ausnahme bildeten Canovas Reliefs aus dem späten 18. Jahrhundert mit Szenen aus antiken Epen wie jenen von Homer oder Vergil, die offenbar von Beginn an nicht als Marmorversionen bestimmt waren, sondern ausschließlich in Gips vollendet werden sollten. ${ }^{89}$ Thorvaldsens Werke hingegen existieren gelegentlich einzig in Gips, weil eine Marmorausführung aus verschiedenen - in der Regel finanziellen - Gründen nicht zustande kam. Ein weiterer Grund war während Thorvaldsens frühen Jahren in Kopenhagen zudem die Tatsache, dass es in Dänemark keinen Marmor gab und der Bild-

281-283. Das genannte Vorgehen ist etwa für die Jason-Statue (Kap. I.1), den Alexanderzug (Kap. I.2) oder die Skulpturengruppe Amor und die Grazien belegt; siehe dazu auch Kat. Nürnberg/Schleswig 1991, 584. Ebd.; auch Thiele 1852 - 1856, Bd. 1, 255: „[...] den Wunsch hegte, der Künstler möchte an diesen Exemplaren irgend eine kleine Veränderung vornehmen und denselben seinen Namen beifügen, um ihnen dadurch einigen Originalwerth zu verleihen.“; Bott, K. 1991, 155; Springer, P. 1991, 216.

87 Siehe bspw. Helsted 1977, 14; Jørnæs 2011, 120; Schindler 2013, 145-146. Gemäß der zeitgenössischen Autorin und Historikerin Elizabeth Fries Ellet assoziierte auch Thorvaldsen selbst die Materialien Ton, Gips und Marmor mit Schöpfung, Tod und Auferstehung; Ellet 1859, 352.

89 Siehe dazu ausführlich ebd., 284-286. 


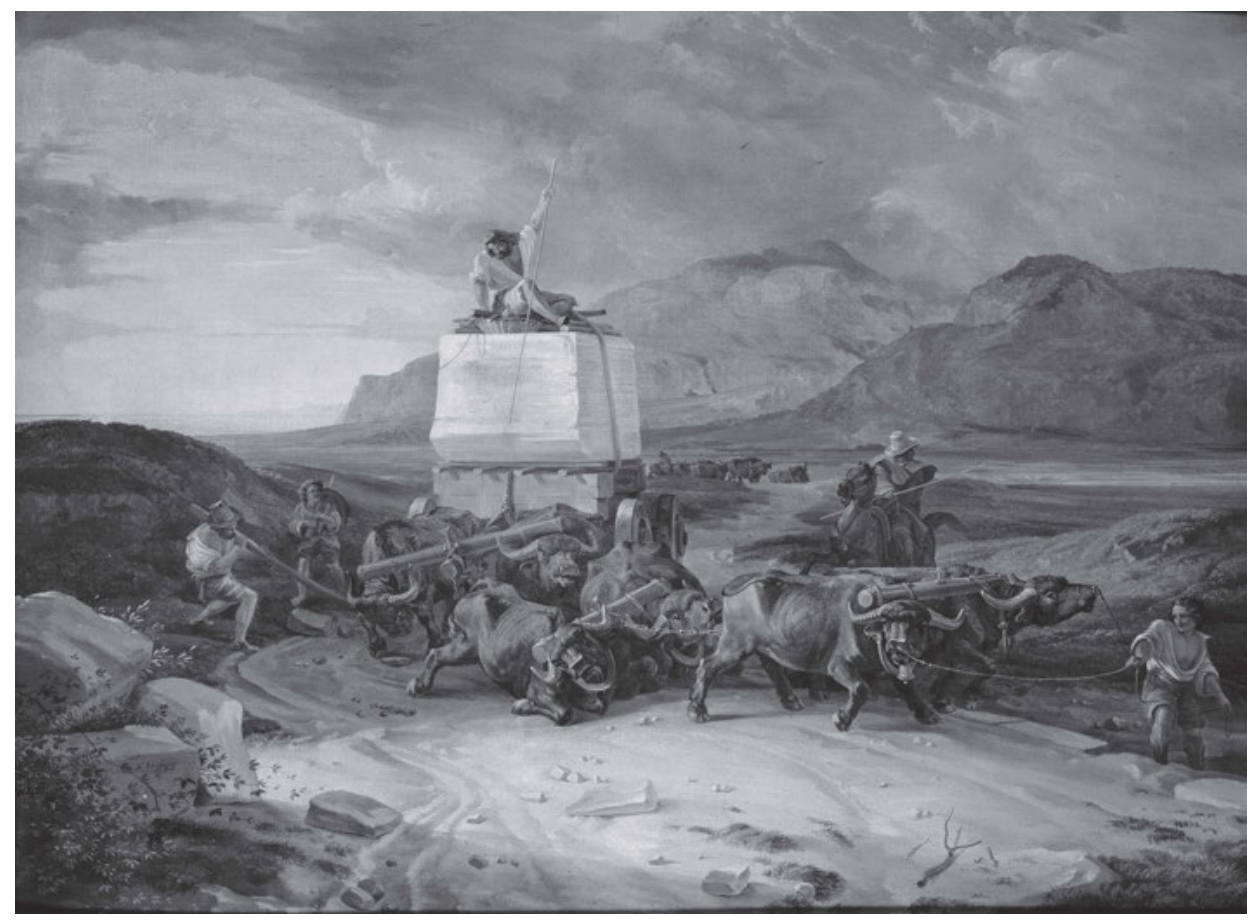

80__Friedrich Nerly, Ochsen ziehen einen Marmorblock, zwischen 1831 und 1844, Öl auf Leinwand, $74,5 \times 99,4$ cm, Kopenhagen, Thorvaldsens Museum (Inv.-Nr. B133)

hauer die Kosten für solchen aus Italien nicht hätte tragen können; erst 1811 wurde in Norwegen weißer Marmor entdeckt. ${ }^{90}$ Während seiner rund vier Jahrzehnte dauernden Tätigkeit in Rom bezog Thorvaldsen den Marmor aus den berühmten Steinbrüchen im toskanischen Carrara. ${ }^{91}$

Den Transport eines Marmorblocks für Thorvaldsens Werkstatt stellte Friedrich Nerly 1831 in einem Gemälde dar, das sich heute im Staatlichen Museum in Schwerin befindet und von dem eine Replik in Thorvaldsens Museum aufbewahrt wird (Abb. 80). Es zeigt ein sechsteiliges Ochsengespann, das unter Hieben einen großen Marmorblock durch eine karge, von Hügeln gesäumte Landschaft zieht, während in der Ferne das Meer zu sehen ist. Aufgrund der wiedergegebenen Topografie darf angenommen werden, dass der Steinblock aus Carrara stammt, das am Fuß der Apuanischen Alpen gegen das Tyrrhenische Meer hin gelegen ist. Die gemeißelte Inschrift auf dem Marmorblock verrät, für $2008,30$.

91 Helsted 1977, 13. 
wen dieser bestimmt ist: „XXIII Thorwaldsen Roma“.92 Die römische Ziffer könnte auf das Jahr 1823 verweisen, in dem Thorvaldsen den prestigeträchtigen Auftrag zum Grabmal für Papst Pius VII. im Petersdom in Rom erhalten hatte. ${ }^{93}$ Die Annahme, dass der von Nerly dargestellte Marmorblock das Rohmaterial für ebendieses Grabmonument war, kann indessen nicht bestätigt werden, da genanntes Werk in seinen Umrissen noch vor Ort in Carrara aus dem Stein gehauen wurde. ${ }^{94}$

\section{Johann Martin von Wagner über Thorvaldsens Arbeitsweise}

Die wohl kritischste Stimme zu Thorvaldsens Werkstattpraxis und seinem Umgang mit Bestellungen war Wagner. Der Würzburger Künstler war im Jahr 1804 für einen mehrjährigen Aufenthalt nach Rom gekommen, wo er Thorvaldsen kennen lernte. Nach einer kurzen Zeit zu Hause in Deutschland kehrte er 1810 in die Ewige Stadt zurück, wo er als Kunstagent in den Dienst des bayerischen Kronprinzen Ludwig trat. ${ }^{95}$ Damit löste er Thorvaldsen als dessen wichtigsten Berater beim Ankauf von Antiken ab, griff jedoch anfänglich noch auf Thorvaldsens kennerschaftliches Urteil und später auf jenes der Brüder Vincenzo und Pietro Camuccini zurück. ${ }^{96}$

Wagners Briefe an Ludwig von Bayern geben ab 1811 Aufschluss über das Schaffen und die Wesenszüge des dänischen Bildhauers, mit dem Wagner bis zu dessen Rückkehr nach Kopenhagen 1838 in engem Austausch stand. ${ }^{97}$ Wagners Berichte offenbaren - gerade im Vergleich mit den jeweiligen Antwortschreiben Ludwigs - ein die gängigen Ideale kontrastierendes Bild des Dänen: Während die fast grenzenlose Bewunderung für Thorvaldsen den Kronprinzen stets über Kritik hinwegsehen und Enttäuschungen geduldig ertragen ließ, bilden Wagners Briefe eine der seltenen nüchtern-realistischen Quellen zu Thorvaldsen. ${ }^{98}$ Wurde dieser von den Zeitgenossen in der Regel als freundliche, bescheidene Person charakterisiert und für seine Schnelligkeit im Modellieren gelobt, sind dessen Unzuverlässigkeit und Saumseligkeit ein dominierendes Thema in Wagners Briefen. Der Personenkult um Thorvaldsen wurde durch Wagners Berichte infrage gestellt, ähnlich wie in den obigen Kritiken zu seiner Werkstattpraxis.

Thorvaldsens Unzuverlässigkeit hatte Wagner seit seiner Tätigkeit als Ludwigs Kunstagent zu spüren bekommen, da er es war, der im Zusammenhang mit Aufträgen aus München in unmittelbarem Kontakt zum Bildhauer stand. Eine der ersten Angelegenheiten Gemälde erinnert an Eugène Delacroix’ Meisterwerk Die Freiheit führt das Volk von 1830 im Musée du Louvre in Paris.

93 Siehe bspw. Kat. Nürnberg/Schleswig 1991, 534; Myssok 2012b, 11.

94 Thiele 1852-1856, Bd. 2, 175; auch Kat. Nürnberg/Schleswig 1991, 536.

95 Lorenz 1991, 249; Wünsche 1991, 311; Kraus 2006, 88.

96 Wünsche 1991, 311-312.

97 Siehe auch von Urlichs 1887, 3.

98 Siehe auch ebd.; Wünsche 1991, 311-312. 
war die 1808 von Thorvaldsen modellierte Adonis-Statue, die bereits 1809 für die in Planung befindliche Glyptothek in München bestellt wurde. ${ }^{99}$ In einem Brief vom Juli 1811 bemerkte Wagner über Thorvaldsen: „Er widerspricht sich, von einem Tage zum andern, und ist sich selbst nicht mehr geständig dessen, was er kurz zuvor geäussert hat. "100 Die Adonis-Statue sollte im Frühjahr 1812 fertiggestellt sein, tatsächlich geschah dies aber erst im Oktober 1831. ${ }^{101}$ Noch 1827 hatte Wagner an den inzwischen gekrönten Ludwig I. geschrieben, dass Thorvaldsen versprochen habe, die Adonis-Statue nach München zu senden, doch dann „wich er wieder durch eine nichtssagende Phrase aus“ ${ }^{102}$ Solche Verzögerungen waren nicht ungewöhnlich für Thorvaldsen und erklären sich zum einen mit weiteren eingegangenen Bestellungen, zum anderen womöglich damit, dass sich Thorvaldsen gemäß Wagner „sehr ungern an die Vollendung eines Werkes begibt, da die Ausführung in Marmor nicht seine Stärke ist“.103

Aus demselben Grund sowie wegen Thorvaldsens inzwischen bekannter Unzuverlässigkeit äußerte Wagner um 1815/1816 Bedenken, ihn mit der Restaurierung der Ägineten zu betrauen, die im Kapitel I.3 thematisiert wurde: „Th. kann die Aegineten ergänzen, ist aber ein wenig zu saumselig und überlässt die Bearbeitung des Marmors gänzlich seinen Leuten. Finelli ist in Behandlung des Marmors Th. bei weitem überlegen. "104 Eine fast identische Formulierung findet sich auch in Wagners Brief vom 7. Oktober 1815, wonach der Däne

unstreitig der tauglichste Künstler [ist]; nur hat er den Fehler, daß er zu saumselig und zu schläfrig ist, und die Bearbeitung des Marmors gänzlich seinen Arbeitern überläßt. Bei dieser natürlichen Schläfrigkeit seines Charakters, würde man wohl 6 Jahre warten müssen, ehe das ganze zustande käme. ${ }^{105}$

Ab den frühen 1830er Jahren versuchte Ludwig I. den Dänen zudem von einem Umzug nach München zu überzeugen und bot ihm eine Professur an der dortigen Kunstakade-

99 Zur Bestellung und Ausführung der Adonis-Statue siehe von Urlichs 1887, 5 und 19-25. Zu Thorvaldsens launenhaftem Umgang mit Bestellungen siehe auch Bott, K. 1991, 150 - 151.

100 Johann Martin von Wagner an Ludwig von Bayern (später Ludwig sI.), im Juli 1811, zit. nach von Urlichs 1887, 3. Siehe auch Oppermann 1927, 167; Wittstock 1975, 363.

101 Bertel Thorvaldsen an Ludwig I. von Bayern, 14. Oktober 1831, TMA, Ref. m28, nr. 145; Von Urlichs $1887,5$.

102 Johann Martin von Wagner an Ludwig I. von Bayern, 12. April 1827, zit. nach von Urlichs 1887, 18.

103 Zitat: Johann Martin von Wagner an Ludwig von Bayern (später Ludwig I.), 19. März 1815, zit. nach von Urlichs 1887, 5. Siehe auch Wittstock 1975, 363.

104 Johann Martin von Wagner an Ludwig I. von Bayern, nicht datiert, zit. nach von Urlichs 1887, 7 (Hervorhebungen im Original). Siehe auch Wittstock 1984, 108. Thorvaldsens Saumseligkeit kommt auch in einem Brief von Heinrich Keller an Karl Pfyffer von Altishofen mit Bezug auf das Luzerner Löwendenkmal zum Ausdruck, 19. Juni 1819, Luzern, Staatsarchiv, Ref. PA 18/4 nr. p. $43-44$ (Transkript im TMA).

105 Johann Martin von Wagner an Ludwig von Bayern (später Ludwig I.), 7. Oktober 1815, zit. nach Wünsche 2011, 88. Siehe auch von Urlichs 1887, 7; Wittstock 1975, 115. 
mie an. ${ }^{106}$ Der bayerische König hegte die Hoffnung, sein München mithilfe des allgemein bewunderten Bildhauers zu einem Zentrum der Künste, einem ,Isar-Athen', zu machen. ${ }^{107}$ Auch in Wagners Augen wäre Thorvaldsens Präsenz in München der „grösste Gewinn, umsomehr da wir im Fache der Bildhauerei nicht sonderlich gut beraten sind und Th. gerade der rechte Mann wäre, eine Schule der Plastik zu bilden“. ${ }^{108}$ Doch wie in seinen Briefen ebenso zum Ausdruck kommt, scheint Wagner seit jeher an Thorvaldsens Willen, nach München zu ziehen, gezweifelt zu haben. ${ }^{109}$ In der Tat zögerte Thorvaldsen seine Entscheidung hinaus, sodass Wagner am 3. Januar 1832 an den König schrieb:

Dass er Rom gänzlich verlassen und seinen Wohnsitz in M. [München] aufschlagen werde, ist mir jedoch nicht ganz wahrscheinlich, so sehr ich solches für M. wünschen möchte. Th. ist gewohnt viel zu versprechen, aber wenig zu halten. ${ }^{110}$

Am Ende entschied sich Thorvaldsen gegen einen Umzug nach München, empfahl den Bildhauer Ludwig von Schwanthaler für die freie Professur und bereitete sich seinerseits auf eine Rückkehr nach Kopenhagen vor. ${ }^{111}$ Thorvaldsens Wankelmut zeigte sich schließlich auch bei der Planung einer gemeinsamen Reise mit Wagner. Ohne Überraschung berichtete Letzterer am 18. April 1837 an den bayerischen König:

Was ich gleich von Anfang an geachtet, ist nun endlich eingetroffen. Th., der so sehr auf eine baldige Abreise drang, der mich nötigte, das letzte Stück des Walhallafrieses einem andern zur Vollendung zu übertragen [...] und [...] sich erst vor wenigen Tagen von Seiner Päbstlichen Heiligkeit feierlich beurlaubt hat, dieser Th. will nun mit einemmal, ohne dass ein Beweggrund einzusehen, nichts mehr von der Abreise wissen und hat bereits ein neues Bassovirievo [sic] zu modellieren angefangen. Alle Welt findet die Sache sehr lustig, um so mehr, da niemand an seine Abreise ernstlich glauben wollte, indem man von ihm solchen unbeständigen Wechsel schon längst gewöhnt ist. ${ }^{112}$

Im Jahr darauf thematisierte Wagner erneut Thorvaldsens Unverbindlichkeit im Hinblick auf Versprechungen, diesmal im Zusammenhang mit Gipsabgüssen nach Werken des Bildhauers, die dieser anscheinend dem bayerischen König in Aussicht gestellt hatte. In einem Brief vom 2. April 1838 an Ludwig I. erklärte Wagner:

106 Miss 1991, 347; auch von Urlichs 1887, 22.

107 Wünsche 1991, 316. Siehe zu diesem Gedanken auch Kap. II.1.

108 Johann Martin von Wagner an Ludwig I. von Bayern, 25. September 1830, zit. nach von Urlichs 1887, 22 (Hervorhebung im Original).

109 Von Urlichs 1887, $22-24$.

110 Johann Martin von Wagner an Ludwig I. von Bayern, 3. Januar 1832, zit. nach von Urlichs 1887, 25 (Hervorhebung im Original).

111 Ludwig von Schwanthaler an Bertel Thorvaldsen, 15. Februar 1835, TMA, Ref. m20 1835, nr. 14; Wünsche 1991, 321.

112 Johann Martin von Wagner an Ludwig I. von Bayern, 18. April 1837, zit. nach von Urlichs 1887, 30 (Hervorhebungen im Original). Zu Thorvaldsens Unzuverlässigkeit siehe auch Bott, K. 1991, 150 - 151. 
Wenn E. K. M. wünschen, dass Th.'s einst getanes Versprechen gewissermassen in Erfüllung gehe, so wird jetzt der beste Augenblick sein, denselben auf irgend eine Weise daran zu erinnern. - Er scheint nun alles einzupacken, zu verschenken oder abschicken zu wollen. Was noch nicht vergeben ist, wird er gewiss geben. Man muss bei ihm nicht blöde sein, wenn man etwas von ihm zu erhalten wünscht, denn er scheint eine grosse Leichtigkeit im Versprechen, aber eine noch grössere Leichtigkeit im Vergessen seiner Versprechungen zu besitzen. Und da es bei Lebzeiten so schwer ist, etwas von ihm zu erhalten, so ist nach seinem Tode wol noch weniger zu erwarten. ${ }^{113}$

Thorvaldsen sollte diese Kritik kurz darauf selbst durch eine weitere unerfüllt gebliebene Zusicherung bestätigen: Im Juni 1838 versprach er Wagner, ein Reiterstandbild des bayerischen Königs „unentgeldlich zu modellieren und in Gyps zu stellen“"14 Bei Thorvaldsens - mehrere Jahre hinausgeschobenem - Besuch in München im Juli 1841 wurde ihm als dem ersten Künstler überhaupt das Großkreuz des St. Michaelsorden und damit die höchste bayerische Auszeichnung verliehen. ${ }^{115}$ Zugleich entschied man sich zur Finanzierung des Bronzegusses des versprochenen Reiterstandbildes von Ludwig I. Wie sich nach Thorvaldsens Tod jedoch herausstellen sollte, hatte er noch nicht einmal einen Entwurf zu diesem Werk gezeichnet. ${ }^{116}$

Ein großer Teil der Briefe von Wagner an den bayerischen König wurde 1887 von Ludwig von Urlichs herausgegeben, der Thorvaldsen während eines eigenen Romaufenthalts ebenfalls kennen gelernt hatte. Auf den ersten beiden Seiten seiner Publikation wird deutlich, dass Urlichs' Meinung über den Bildhauer weniger jener von Wagner als vielmehr dem gängigen, idealisierenden Bild des Dänen entsprach. ${ }^{117}$ Demgegenüber sei Thorvaldsen Wagner "nicht gerade sympathisch“ gewesen, wie Urlichs festhielt. ${ }^{118}$ Nach der Lektüre von Wagners Briefen sowie vor dem Hintergrund von Thorvaldsens strategischer Selbstvermarktung und damit einhergehend von dessen Umgang mit Aufträgen wird jedoch deutlich, dass Wagners Kritik kaum, zumindest nicht in erster Linie, eine Frage mangelnder Sympathie war. Vielmehr war der Würzburger einer der wenigen Zeitgenossen, die sich nicht von dem stetig wachsenden Kult um Thorvaldsen blenden ließen und stattdessen einen nüchternen Blick auf diesen behielten. ${ }^{119}$ Seine Briefe veranschaulichen die Konstruiertheit und Stilisierung von Thorvaldsens öffentlichem Bild, weshalb sie hier etwas genauer wiedergegeben wurden. Dass Wagners Kritik durchaus rationaler Navorhebungen im Original). Siehe in diesem Zusammenhang auch Kap. IV.1.

114 Johann Martin von Wagner an Ludwig I. von Bayern, 4. Juni 1838, zit. nach von Urlichs 1887, 31. Siehe z. T. auch Wünsche 1991, 323.

115 TMA, Ref. m24 1841, nr. 34; Wünsche 1991, 323.

116 Wünsche 1991, 323.

117 Von Urlichs 1887, 3-4.

118 Ebd., 3; siehe auch Oppermann 1927, 167.

119 Siehe auch Wünsche 1991, 312. 
tur war und nicht zwingend auf einer Antipathie fußte, zeigt sich denn auch in seiner durchgehend hohen Meinung von Thorvaldsens künstlerischen Fähigkeiten.

\section{Thorvaldsens Umgang mit Bestellungen}

Um die Produktion in seinen Ateliers zu maximieren, nahm Thorvaldsen oft mehr Bestellungen entgegen, als - auch in einem so stark arbeitsteiligen Betrieb wie dem seinen ausgeführt werden konnten. Die parallele Arbeit an verschiedenen Werken kommentierte etwa Olivier in seinem 1819 erschienenen Reisebericht, wonach „man viele Statuen und unzählige Büsten in den geräumigen Werkstätten des Künstlers nach seinen Modellen in Marmor ausführen“" sah. ${ }^{120} 1820$ berichtete Jerdan, dass die Ausführung der Bestellungen trotz Thorvaldsens zahlreichen Mitarbeitern dessen ganzes Leben lang dauern würde. ${ }^{121}$ Die hier beschriebene Situation in Thorvaldsens Ateliers rächte sich noch im selben Jahr: Am 8. November 1820 brach der Boden in einer der kleineren Werkstätten unter der Last der zahlreichen Gips- und Marmorskulpturen ein, wodurch mehrere der in Arbeit befindlichen Werke zerstört oder zumindest beschädigt wurden. ${ }^{122}$ Dieser Unfall ereignete sich im Verlauf von Thorvaldsens Abwesenheit in den Jahren 1819 und 1820, während derer er die temporäre Leitung seiner Ateliers seinen beiden langjährigen Mitarbeitern Freund und Pietro Tenerani übertragen hatte. ${ }^{123}$ Dies war im Übrigen nur möglich dank der genau geregelten Arbeitsteilung in seinen Werkstätten. ${ }^{124}$ Bereits am 16. Januar 1820 hatte Tenerani seinem Meister gemeldet, dass er nicht wisse, „wie wir uns umdrehen soll-

Olivier 1819, 149. Siehe auch Wittstock 1975, 324. Zur parallelen Ausführung verschiedener Werke siehe auch Miss 2008, 32; Grandesso 2015, 27 und 166.

121 Jerdan 1820, 94.

122 Hermann Ernst Freund an Bertel Thorvaldsen, 9. November 1820, KB, Ref. NKS 1701, $2^{\circ}$ (Digitalisat im TMA). Zwei Tage später schrieb auch Tenerani einen Brief an Thorvaldsen, in dem er über den Unfall berichtete; TMA, Ref. m6 1820, nr. 49. Nachdem Tenerani und Freund nichts von ihrem Meister gehört hatten, sandte Freund am 18. November erneut einen Brief an Thorvaldsen, in dem er ihn über den Unfall unterrichtete; TMA, Ref. m6 1820, nr. 50. Siehe zu diesem Vorfall ausführlich Mrgan 2015a; auch Thiele 1852 - 1856, Bd. 1, 48-49; Grandesso 2015, 166.

123 Tesan 1998, 64; Kronberg Frederiksen 2014a; auch Jørnæs 2011, 111. Die Reise dauerte vom 14. Juli 1819 bis zum 16. Dezember 1820; Wittstock 1975, 114; Tesan 1991b, 225; Jørnæs 2011, 111. Tenerani war vor seiner Tätigkeit für Thorvaldsen Schüler bei Canova und Lorenzo Bartolini; Jørnæs 2011, 110. Thorvaldsen beauftragte Freund und Tenerani damit, ihn während seiner Abwesenheit regelmäßig über den aktuellen Stand in seinen Werkstätten zu informieren. So sind im Archiv in Thorvaldsens Museum mehrere Briefe erhalten, in denen die beiden Bildhauer ihrem Meister über die laufenden Arbeiten berichten und die darüber hinaus einen realistischen Einblick in die Werkstattpraxis geben; TMA, Ref. m6 1819, nr. 53, Ref. m6 1820, nr. 7, Ref. m6 1819, nr. 61, Ref. m6 1820, nr. 58 und Ref. m6 1820, nr. 33. Ein weiterer Bericht über die laufenden Arbeiten während Thorvaldsens Abwesenheit stammt von Brøndsted; Peter Oluf Brøndsted an Bertel Thorvaldsen, 2. Oktober 1819, TMA, Ref. m6 1819, nr. 42. Siehe außerdem Thiele 1852-1856, Bd. 2, 16 und 20.

124 Siehe auch Wittstock 1975, 114; Wittstock 1984, 105. 

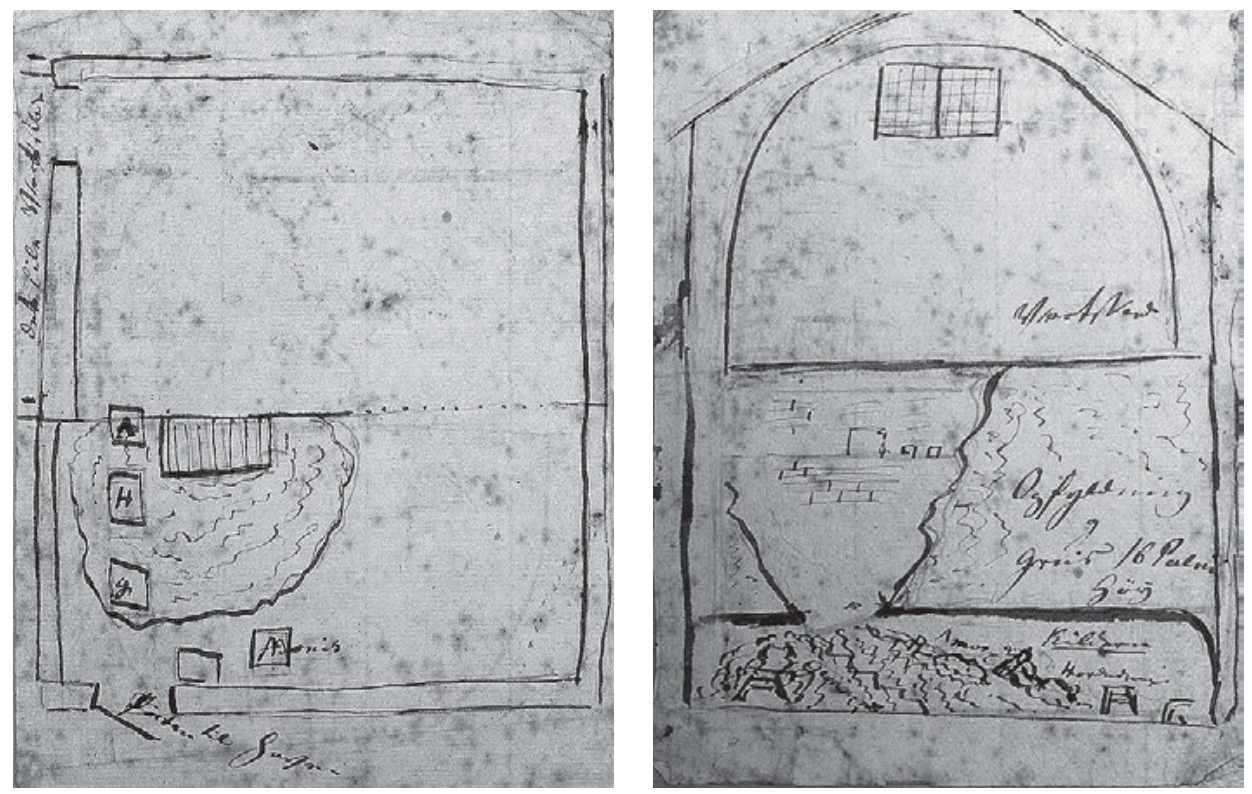

81a und 81b__Hermann Ernst Freund, Skizzen der Unfallstelle in Thorvaldsens Atelier, Beilage zum Brief von Hermann Ernst Freund an Bertel Thorvaldsen vom 9. November 1820 (recto/verso), Feder auf Papier, Kopenhagen, Det Kongelige Bibliotek, Håndskriftafdelingen (Inv.-Nr. NKS 1701, 2º

ten, so voll ist die Werkstatt ${ }^{\text {“. }}{ }^{125}$ Freund, der Thorvaldsen schließlich am 9. November 1820 über den Unfall informierte, legte seinem Brief zwei Federzeichnungen bei, auf denen er Unfallstelle und -hergang skizziert hatte (Abb. 81a und 81b). Die Buchstaben stehen für die drei beschädigten beziehungsweise zerstörten Werke: das Originalmodell des Ganymed mit Jupiters Adler (G) sowie die Marmorversionen des Hirtenjungen (H) und des Triumphierenden Amor (A). ${ }^{126}$ Bei den beiden anderen eingezeichneten, vom Unfall nicht betroffenen Skulpturen handelt es sich um Adonis und vermutlich Mars und Amor. ${ }^{27}$ Nachdem die Nachricht über den Einsturz des Bodens Thorvaldsen erst am 25. November

Pietro Tenerani an Bertel Thorvaldsen, 16. Januar 1820, TMA, Ref. m6 1820, nr. 7: „[...] non sappiamo ove rivoltarsi, per quanto è pieno lo studi[o.]“ Deutsche Übersetzung nach Tesan 1991b, 226. Siehe auch Di Majo/Susinno 1989, 17.

126 Hermann Ernst Freund an Bertel Thorvaldsen, 9. November 1820, KB, Ref. NKS 1701, $2^{\circ}$ (Digitalisat im TMA). Siehe auch Mrgan 2015a. Die beiden genannten Marmorskulpturen wurden durch den Unfall beschädigt, das Gipsmodell des Ganymed mit Jupiters Adler vollständig zerstört.

127 Mrgan 2015a. 
erreicht hatte, reiste er zwei Tage später in Wien ab, wo er sich auf seiner Rückreise von Dänemark nach Rom aufgehalten hatte. ${ }^{128}$

Die Auftragssituation in Thorvaldsens Ateliers scheint sich laufend verschärft zu haben. Bemerkenswert ist in diesem Zusammenhang die Beobachtung des Kunstkritikers Henri Delaborde, wonach Thorvaldsen um 1820 aufgehört habe, „ein Meister zu sein“, und stattdessen „kaum mehr als ein fruchtbarer Produzent“ gewesen sei. ${ }^{129}$ In dieser Einschätzung klingt deutlich die fabrikhafte Organisation von Thorvaldsens Kunstunternehmen an. In ähnlicher Weise äußerte sich auch Wagner im weiteren Verlauf der 1820er Jahre. So schrieb er am 19. Januar 1823 an Ludwig von Bayern, dass der Däne „bereits mehr Bestellungen hat, als er in seinem ganzen Leben auszuführen im stande ist“, und wenige Monate später, dass er „immer neue Sachen anfängt, die angefangenen aber hintansetzt“ . ${ }^{130}$ Am deutlichsten führte Wagner diesen Umstand schließlich in seinem Schreiben vom 22. Februar 1825 aus:

\begin{abstract}
Th. hat den bösen Grundsatz, alle nur möglichen Anträge anzunehmen. Hat er aber einmal den Kontrakt geschlossen und die erste Hälfte (?) der Zalung [sic] erhalten, so denkt er nicht weiter daran, dieselben zu vollenden. So geht es mit allen seinen Arbeiten, denn wenn er auch noch 50 Jahre leben sollte, so ist er niemals im stande, alle die Arbeiten zu vollenden, die er vertragsmässig übernommen, und auf die er die Zalung teils ganz teils zum teil [sic] schon erhalten hat. Unbedeutende Arbeiten werden noch eher befördert, weil er diese von seinen Schülern machen lässt, dabei aber nicht vergisst, sich als Thorwaldsen bezahlen zu lassen. ${ }^{131}$
\end{abstract}

Gerade aus dem letzten Satz von Wagner geht die äußerst strategische Organisation von Thorvaldsens Werkstattbetrieb klar hervor. Um sich auf dem Kunstmarkt behaupten zu können, hatte Thorvaldsen in seinen frühen Jahren die Preise seiner Skulpturen hingegen deutlich tiefer angesetzt als seine Konkurrenten: Gemäß einem Brief des Künstlers Johann Georg von Dillis an Ludwig von Bayern vom 24. März 1807 verlangte Thorvaldsen für eine Frauenstatue zehnmal weniger als Canova. ${ }^{132}$ Wie aus einem Schreiben des Bildhauers selbst ersichtlich wird, wurde jene Preispolitik ebenfalls durch den arbeitsteiligen Werkstattbetrieb ermöglicht, da günstige Arbeitskräfte einen großen Teil des Handwerks über-

128 „Thorwaldsen“ 1820, 726; auch Thiele 1852-1856, Bd. 1, 48; Tesan 1991b, 226; Jørnæs 2011, 140.

129 Delaborde 1868, 588: „[...] à partir de 1820 à peu près, Thorvaldsen, cessant dêtre un maître, n'est plus guère qu'un producteur fécond, [...]. “Siehe auch Kofoed 2014b.

130 Johann Martin von Wagner an Ludwig von Bayern (später Ludwig I.), 19. Januar und 16. April 1823, beide zit. nach von Urlichs 1887, 12. Auch bei Jacobsen 1820, 98, ist zu lesen, dass Thorvaldsen „mit Arbeiten für sein ganzes Leben überhäuft" sei.

131 Johann Martin von Wagner an Ludwig von Bayern (später Ludwig I.), 22. Februar 1825, zit. nach von Urlichs 1887, 16 (Hervorhebungen im Original). Siehe z. T. auch Oppermann 1927, 167.

132 Johann Georg von Dillis an Ludwig von Bayern (später Ludwig I.), 24. März 1807, zit. bei Wittstock 1975, 276. Siehe auch Springer, P. 1991, 214; Tesan 1991b, 225-226 und 232- 233. 
nahmen, was sich wiederum auf die Preise der fertigen Skulpturen auswirkte. ${ }^{133}$ Durch hohe Produktivität und tiefe Preise konnte Thorvaldsen seine Werke in den frühen Jahren in Rom zumindest mengenmäßig neben den damals sehr viel teureren Schöpfungen Canovas positionieren. ${ }^{134}$

Noch am 6. Februar 1815 beklagte sich Overbeck, der im Jahr zuvor als Broterwerb Thorvaldsens Reliefs nachgezeichnet hatte, dass „Thorvaldsen [...] mehrere Arbeiten an Engländer verkauft [hat], aber für bescheidne Preise, dass er sich und anderen dadurch schadet ${ }^{\text {“ }}{ }^{135}$ Damit scheint Overbeck zum einen Thorvaldsens Verlustgeschäft anzusprechen, da die Ausgaben für das künstlerische Material und dessen Transport sowie die Bezahlung der Gehilfen das Einkommen des Bildhauers bisweilen überstiegen. ${ }^{136}$ Zum anderen deuten Overbecks Worte vermutlich an, dass Thorvaldsens tiefe Skulpturenpreise die anderen Bildhauer benachteiligten, da sich diese entweder im Wettbewerb nicht durchsetzen konnten oder durch das Senken der eigenen Preise in finanzielle Engpässe gerieten. Der harte Wettbewerb unter jungen Bildhauern zeigte sich auch bei Thorvaldsen, der seit seinem Erfolg mit Jason zwar zahlreiche Bestellungen erhielt, bis zur Schaffung seiner Adonis-Statue (1808) und der Mars und Amor-Gruppe (1810) aber noch kaum finanzielle Gewinne verbuchen konnte. ${ }^{137}$ Mit seinem wachsenden Ruhm stiegen schließlich die Preise für seine Werke seit der zweiten Hälfte der 1810er Jahre deutlich an. ${ }^{138}$ Begünstigt wurde diese Entwicklung in Thorvaldsens Preispolitik zudem durch die sich nach dem Wiener Kongress und der Schlacht bei Waterloo beruhigende politische Situation und den damit einhergehenden Aufschwung im Fremdenverkehr. ${ }^{139}$

Insgesamt lässt sich festhalten, dass Thorvaldsens strategische Selbstvermarktung in Form einer hohen Produktivität durch Arbeitsteilung, vergleichsweise tiefe Skulpturenpreise und eine zuweilen opportunistische Haltung gegenüber (potenziellen) Auftraggebern und Kunden wesentlich zu seiner Etablierung als einem der führenden Künstler der Zeit beitrug. Seine dadurch gefestigte Präsenz im kulturellen Leben Roms, die durch unzählige visuelle und schriftliche Darstellungen noch verstärkt wurde, bot schließlich einen fruchtbaren Boden für den sich über Jahrzehnte entspannenden Künstler- und celebrityKult um Thorvaldsen.

Bertel Thorvaldsen an Christian Frederik Hansen, nach dem 15. Juni 1807 (Entwurf), TMA, Ref. m28, nr. 104; auch Bencard 2009; Kofoed 2014b.

134 Siehe auch Wittstock 1975, 72.

135 Friedrich Overbeck an Ludwig Vogel, 26. Mai 1814, zit. nach Wittstock 1975, 326; Friedrich Overbeck an Joseph Sutter, 6. Februar 1815, zit. nach Wittstock 1975, 326. Siehe auch Oppermann 1927, 166.

$136 \mathrm{Zu}$ Thorvaldsens finanziellen Schwierigkeiten in den frühen Jahren seiner Karriere siehe auch Springer, P. 1991, 214; Tesan 1991b, 225.

137 Siehe auch Wittstock 1975, 66-67 und 71.

138 „Thorvaldsen's Works, Prices“ 2013; auch Wittstock 1975, 116.

139 Wittstock 1975, 110; Springer, P. 1991, 214-215; Tesan 1991b, 225; Wittstock 1991, 207; Tesan 1998, 27; Myssok 2012b, 5. 


\section{Werkstatt, Verkaufsausstellung, Museum, Tempel}

Die Einführung des Gipsmodells in voller Größe vereinfachte in der bildhauerischen Praxis nicht nur den Übertragungsprozess vom Modell in den Marmor, wie im vorangegangenen Kapitel gezeigt wurde, sondern wirkte sich auch in entscheidender Weise auf die Funktionen des Ateliers und das Verhältnis zwischen dem Künstler und seinem Publikum aus. Denn im Gegensatz zum Tonmodell war das große Gipsmodell von dauerhaftem Charakter und wurde in der Werkstatt aufbewahrt. Damit diente es zum einen als Vorbild für Reproduktionen in Marmor, zum anderen als repräsentatives Exponat für das Schaffen des jeweiligen Künstlers. Dazu trug wohl auch die farbliche Ähnlichkeit von Gips und Marmor bei. ${ }^{140}$ Die neuen Funktionen und Konnotationen des Ateliers im frühen 19. Jahrhundert geben folglich einen essenziellen Einblick in das damals herrschende - beziehungsweise sich ebenfalls neu konturierende - Künstlerbild, weshalb sie im Zentrum dieses Kapitels stehen. ${ }^{141}$

Gleichzeitig stellt sich eine terminologische Frage: Lässt sich eine Verbindung zwischen dem Begriff des Ateliers und dem damaligen Kult um das schöpferisch tätige Genie feststellen, während jener der Werkstatt mehr auf die handwerkliche Arbeit fokussierte? Wie beispielsweise Eva Mongi-Vollmer gezeigt hat, trifft dies nicht zu; vielmehr wurden die beiden Begriffe in den Jahrzehnten um 1800 synonym verwendet. Der zunächst seltener vorkommende französische Begriff wurde im Laufe des 19. Jahrhunderts zunehmend in andere Sprachen übernommen, jedoch weiterhin in gleicher Weise benutzt wie jener der Werkstatt. Als Unterschied könnte man höchstens festhalten, dass seit Diderots Encyclopédie der Begriff des Ateliers grundsätzlich häufiger den Arbeitsbereich eines Künstlers und jener der Werkstatt den Wirkungsort einer rein handwerklich oder gewerblich tätigen Person benannte. ${ }^{142}$ Diese Konnotation des Atelierbegriffs sollte sich aber erst ab der zweiten Hälfte des 19. Jahrhunderts endgültig durchsetzen. ${ }^{143}$ Dasselbe bestärken auch die Quellen zu Thorvaldsen, in denen kein prinzipieller Unterschied im Gebrauch der Begriffe des Ateliers, der Werkstatt (dän. voerksted) und ferner des Studios erkennbar ist, sondern sicherlich auch zugunsten der sprachlichen Abwechslung gleichbedeutend vorkommen. Da den genannten Begriffen für die hier relevante Zeit keine divergierenden Konzepte des damit bezeichneten Innenraumes zugrunde liegen, werden sie im vorliegenden Buch ebenfalls synonym verwendet.

140 Siehe auch Springer, P. 1991, 213 und 216; Myssok 2010, 281; Myssok 2017, 144.

141 Siehe dazu auch Schindler 2019.

142 Encyclopédie 1751-1772, Bd. 1, 839. Zur Begriffsgeschichte generell siehe Mongi-Vollmer 2004, 29-40; Griener 2014.

143 Mongi-Vollmer 2004, 34-35. 
Hohe Besuche I: Ditlev Martens' Darstellung von Papst Leo XII. bei Thorvaldsen In dem bereits mehrfach erwähnten Gemälde von 1828-1829 hielt Martens den am 18. Oktober 1826 erfolgten Besuch des Papstes Leo XII. in Thorvaldsens studio grande fest (Taf. II). Das Kirchenoberhaupt hatte den Bildhauer am Lukastag jenes Jahres aufgesucht, um die Fortschritte der Arbeit am Grabmonument für seinen Vorgänger Pius VII. in Augenschein zu nehmen. ${ }^{144}$ Dementsprechend ist dieses Werk, das 1831 vollendet und im Petersdom aufgestellt werden sollte, in Martens' Gemälde in den Fokus gerückt. ${ }^{145}$

Das Motiv des hohen Besuchs im Atelier war bereits in der antiken Künstlergeschichte angelegt worden und etablierte sich - abgesehen von der schon früher oft verbildlichten Legende des Besuchs von Alexander dem Großen in Apelles' Werkstatt - besonders im frühen 19. Jahrhundert zu einem beliebten Thema in gemalten Atelierdarstellungen. Dabei zeigt sich eine zuweilen aufgeweichte Hierarchie zwischen Herrscher und Künstler, da der Potentat mit seinem Besuch den Künstler zwar ehrt und nobilitiert, gleichzeitig aber dessen Genie huldigt. ${ }^{146}$ Diese sich in den Bildern, so auch bei Martens, manifestierende Machtverschiebung ist als Folge der Französischen Revolution zu sehen. ${ }^{147}$ Ein brisanter Aspekt in Martens' Gemälde ist indessen der konfessionelle Zusammenprall: Thorvaldsen trug als einziger protestantischer, laut manchen Stimmen gar heidnischer Bildhauer zur skulpturalen Ausstattung des Petersdoms als der katholischen Hauptkirche bei, was unter den Zeitgenossen durchaus auch Unmut erregte. ${ }^{148}$ Besonders Thorvaldsens Aussage: „Ich glaube ja [auch] nicht an die griechischen Götter - aber ich kann sie dennoch darstellen“, wurde sowohl von Zeitgenossen als auch in der späteren Literatur wiederholt zitiert, um seine Zurückhaltung hinsichtlich seiner religiösen Überzeugung zu illustrieren. ${ }^{149}$ Diese Reserviertheit dürfte - wie im Kapitel I.2 angeschnitten wurde - hauptsächlich strategischer Natur gewesen sein, führte Thorvaldsen doch für den Petersdom wie für die Frauenkirche als reformierte Hauptkirche Kopenhagens gleichermaßen monumentale Aufträge aus.

Nachdem Martens seinem ehemaligen Lehrer Eckersberg bereits im Juli 1827 von seinen Ideen zu dem hier vorgestellten Gemälde berichtet hatte, erläuterte er seine Darstellung in einem ausführlichen Brief vom 20. August 1828 an die Kopenhagener

144 Thiele 1852-1856, Bd. 2, 163; Hartmann 1971, 36; Helsted 1982a, 52; Jørnæs 1991c, 90; Kat. Nürnberg/ Schleswig 1991, 529; Mildenberger 1991, 195; Randolfi 2010, 81; Jørnæs 2011, 181.

145 Kat. Nürnberg/Schleswig 1991, 529.

146 Siehe auch Mildenberger 1991, 195; Kanzenbach 2007, 185; Warnke 2008, 79. Spezifisch zum Bildtyp der Hommage siehe bspw. Gohr 1975.

147 Siehe auch Mildenberger 1991, 195.

148 Thiele 1852-1856, Bd. 2, 105; Mildenberger 1991, 195; Bogh 1997, 53; Henderson 2005, 60; Jørnæs 2011, $169-171$.

149 Zit. nach Bernhard Severin Ingemann an Just Mathias Thiele, 22. September 1851, TMA, Ref. m31, nr. 71: „Jeg tror jo ikke paa de græske Guder - men jeg kan dog gjøre dem!“ 
Kunstakademie. ${ }^{150}$ Da dieses Schreiben äußerst aufschlussreichen Einblick in künstlerische Überlegungen, in die zeitgenössische Beurteilung von Thorvaldsens Skulpturen sowie in den Kult um den Bildhauer gewährt, soll es hier in weiten Teilen wiedergegeben werden. Aus dem Brief wird zunächst ersichtlich, dass der Fokus des Gemäldes auf dem christlichen Glauben liegt, den Martens als Ursprung für eine neue Blüte der Kunst betrachtete:

Im Hintergrund ist Pius VII. als Oberhaupt der christlichen Religion die dominierende Figur; diese Figur verdeckt mit der dreifachen Krone die Figur Christi auf dem Basrelief, das die Gründung des Papsttums darstellt, indem Christus Petrus die Schlüssel zum Himmel übergibt; dem zur Seite ist angebracht die Allegorie auf das griechische Kunstzeitalter, als die Götter noch den Olymp bewohnten, nämlich das Basrelief, auf dem die Musen zu Apollos Lyraspiel die Grazien umtanzen; darunter sieht man die Nacht, wobei ich mir in diesem Zusammenhang noch ein früheres Zeitalter gedacht habe; dicht daneben habe ich den Tag plaziert, und meinte durch das Anbringen dieses Basreliefs hinter der Figur des Papstes die Bedeutung zu unterlegen, dass die fromme Lehre des Christentums, indem sie Raffael, Michelangelo, Tizian und andere vom Papst geförderte Künstler begeisterte, die von den Griechen sicher nicht der Überlegung für wert gehalten würden, sie in ihre Mitte aufzunehmen, die Morgenröte der Kunst von neuem erwachen ließ..$^{151}$

Während sich Martens in diesen Zeilen als der nazarenischen Romantik nahestehend zu erkennen gab, hob er in seinem Gemälde ein Werk Thorvaldsens mit antikem Inhalt, das Relief Priamos bittet Achilles um Hektors Leichnam von 1815, besonders hervor:

Die Karyatiden, die für den Thron des Königs bestimmt sind, sind dekorationshalber auf jeder Seite der Tür angebracht, über welcher das Basrelief hängt, auf dem Priamos von Achilles den Leichnam Hektors erfleht. Ich habe es als kolossal angenommen, aus keinem anderen als einem individuellen Grund, da dieses Basrelief mich allzeit vor allen anderen so unendlich interessierte; wobei die Akademie den Grund selbst wird beurteilen können, da ich bei nächster Gelegenheit einen Gipsabguss nach Kopenhagen senden werde, den Thorvaldsen mir geschenkt hat. ${ }^{152}$

Durch die vergrößerte Darstellung des Reliefs betonte Martens mittels künstlerischer Freiheit seine Bewunderung für das genannte Werk, ohne jedoch die Gründe seiner subjektiven Hochschätzung zu nennen. Im Bildmittelgrund dominieren erneut biblische Themen:

Die Hauptebene oder den Mittelgrund nehmen Christus mit den Aposteln und Johannes, der in der Wüste predigt, sowie die lebenden Personen, Thorvaldsen und der Papst mit seiner Prälaten-Suite und Ehrengarde, ein, die so angeordnet sind, dass der Erlöser ihnen gegenüber segnend die Arme öffnet.

150 Ditlev Martens an die Kunstakademie Kopenhagen, 20. August 1828, zit. bei Glarbo 1944, 56 -58; Kat. Nürnberg/Schleswig 1991, 529-531.

151 Ditlev Martens an die Kunstakademie Kopenhagen, 20. August 1828, zit. nach Kat. Nürnberg/Schleswig 1991, 529.

152 Ebd. 
Christus, der für die Menschen den Tod erlitt, verdeckt den Tod und die Sterbende auf dem bekannten Grabmal-Basrelief, und so habe ich mit Überlegung Johannes, den Vorgänger und Verkünder des Messias, so aufgestellt, dass er von der Christus-Figur verdunkelt wird. ${ }^{153}$

Bei dem genannten Grabmal-Relief handelt es sich um jenes für Auguste Böhmer, die Tochter der Schriftstellerin Caroline Schelling, das Thorvaldsen zwischen 1811 und 1812 modelliert hatte. ${ }^{154}$ Auf der teilweise im Schatten liegenden vordersten Bildebene sind schließlich einige der erfolgreichsten Werke des Bildhauers angeordnet:

Im Vordergrund sieht man Prinz Poniatowskis Reiterstatue und die kolossalen Nebenfiguren für das Grabmal Pius' VII., die [göttliche] Stärke direkt gegenüber der Poniatowski-Figur und die [himmlische] Weisheit bescheiden zur Seite, nur Haupt und Bauch der Weisheit beleuchtet. Ein Teil von Alexanders Triumpf [sic] - ganz im Schatten - dient dazu, die Masse [der Skulpturen] im Vordergrund zu schließen, unmittelbar hinter der Rückseite befinden sich die [Göttin der] Hoffnung und die drei Grazien. ${ }^{155}$

Hier ist anzumerken, dass der Alexanderzug von 1812 nicht nur die Werke im Bildvordergrund zusammenhält, sondern sich über die gesamte Länge des Atelierraumes erstreckt. Dadurch schafft er einen Rahmen für sämtliche ausgestellte Skulpturen, unterstreicht die räumlichen Dimensionen von Thorvaldsens Werkstatt und verleiht Martens' Gemälde Tiefenwirkung. Außerdem handelte es sich bei diesem Fries um dasjenige Werk in Thorvaldsens Künstlerbiografie, das diesen als führenden Reliefbildhauer der Zeit etabliert und ihm den Übernamen patriarca del bassorilievo eingebracht hatte, weshalb eine die Monumentalität des Reliefs unterstreichende Positionierung im Bild durchaus naheliegend erscheint. ${ }^{156}$ Direkt hinter dem rechts in Martens' Gemälde wiedergegebenen Teilstück des Alexanderzuges steht, wie im Zitat erwähnt, Thorvaldsens archaisierende Göttin der Hoffnung von 1817, mit der sich der Bildhauer 1839 in seiner lebensgroßen Selbstporträtstatue darstellen sollte (Abb. 32 und 34). ${ }^{157}$ Ebenfalls im rechten Bildvordergrund hat Martens die 1824 von Thorvaldsen geschaffene Porträtbüste des im selben Jahr verstorbenen Kardinals Ercole Consalvi mit folgender Begründung dargestellt:

Consalvis Büste befördert den Übergang zwischen Licht und Schatten. Es scheint mir, dass die Büste dieses Mannes zur Einleitung oder zum Vordergrund gehört, da dieser treue Freund und Beschützer des

153 Ditlev Martens an die Kunstakademie Kopenhagen, 20. August 1828, zit. nach Kat. Nürnberg/Schleswig 1991, $529-531$.

154 Kopenhagen, Thorvaldsens Museum (Inv.-Nr. A614,1-A614,3). Die 1814 ausgeführte Marmorversion dieses Reliefs für das nicht vollendete Grabmal für Auguste Böhmer befindet sich ebenda (Inv.-Nr. A700 - A702).

155 Ditlev Martens an die Kunstakademie Kopenhagen, 20. August 1828, zit. nach Kat. Nürnberg/Schleswig 1991, 531.

156 Siehe dazu Kap. I.2.

157 Siehe dazu Kap. I.3. 
Künstlers bis zu seinem Tod die Verdienste in Ehren hielt, die Canovas übrige Landsleute dem hochbegabten Transmontanen so ungern einräumten. ${ }^{158}$

Es war Consalvi, dem Thorvaldsen den Auftrag für das auf der hintersten Bildebene gezeigte Grabmonument für Papst Pius VII. maßgeblich zu verdanken hatte. ${ }^{159}$ Insofern bildet seine Büste nicht nur den visuellen Einstieg in Martens' Gemälde, sondern die Bemühungen des Kardinals waren überhaupt die Basis für Thorvaldsens Auftrag und damit den bei Martens dargestellten Papstbesuch. Zusammen mit einem 1825 ebenfalls von Thorvaldsen ausgeführten Relief schmückt die Büste des Kardinals bis heute dessen Grabdenkmal im Pantheon in Rom.

An den Sockel von Consalvis Büste ist schließlich „ein Zeichenbrett mit einer Contour vom Jason gelehnt, der Thorvaldsens Renommé außerhalb seines Geburtslandes etablierte“ ${ }^{160}$ Martens dürfte also ganz bewusst zwei Werke als räumlichen Einstieg in das Gemälde gewählt haben, die für Thorvaldsens Künstlerbiografie von essenzieller Bedeutung waren: Während dem Bildhauer mit seiner Jason-Statue 1803 der künstlerische Durchbruch gelang, festigte der Alexanderzug seinen internationalen Ruhm und seine zentrale Stellung im kulturellen Leben Roms. ${ }^{161}$

Zusätzlich zu seinen Überlegungen zur Darstellung von Thorvaldsens Werken im Gemälde hat Martens auch die Lichtführung genau komponiert:

Die Beleuchtung betreffend habe ich mit Rücksicht auf den für die plastische Kunst gegebenen schönen Zeitpunkt ein frühes Tageslicht gewählt. Christus erhält das Hauptlicht, Poniatowski den Hauptschatten, die Grazien ein weiches, Merkur hingegen ein großes und kaltes Licht, die Hoffnung in grünlicher Farbe, der Taufstein für Island ein warmes Licht. ${ }^{162}$

Der zuletzt erwähnte Taufstein von 1805-1807 ist von jener Seite gezeigt, die mit dem Relief Maria mit Jesus und Johannes geschmückt ist. ${ }^{163}$ Folglich schließt sich auch hier -

158 Ditlev Martens an die Kunstakademie Kopenhagen, 20. August 1828, zit. nach Kat. Nürnberg/Schleswig 1991, 531. Das originalgroße Gipsmodell der Consalvi-Büste befindet sich in Thorvaldsens Museum in Kopenhagen (Inv.-Nr. A271).

159 Siehe bspw. Nyeste Skilderie af Kjøbenhavn, 8. Juni 1824, Sp. 733; Nyt Aftenblad, 27. August 1825, 303; Archiv for Psychologie, Historie, Literatur og Kunst, 7:6, 1827, 388; Kjøbenhavns-Posten, 5:182, 1831, o. S. [Titelseite]; Thiele $1852-1856$, Bd. 2, 104-105.

160 Ditlev Martens an die Kunstakademie Kopenhagen, 20. August 1828, zit. nach Kat. Nürnberg/Schleswig 1991, 531.

161 Siehe dazu die Kap. I.1 und I.2.

162 Ditlev Martens an die Kunstakademie Kopenhagen, 20. August 1828, zit. nach Kat. Nürnberg/Schleswig 1991, 531.

163 Es handelt sich dabei um den ursprünglich für die Kirche Brahetrolleborg geschaffenen Taufstein, von dem Thorvaldsen zwischen 1822 und 1827 eine weitere Marmorversion für die Kathedrale von Reykjavik ausführte. Das originalgroße Gipsmodell befindet sich in seinem Museum in Kopenhagen (Inv.-Nr. A555). 
wie mit dem Alexanderzug in räumlicher und mit dem päpstlichen Grabmonument und der Consalvi-Büste in auftragsspezifischer Hinsicht - ein Kreis in Martens' Darstellung: Christus und Johannes der Täufer bestimmen sowohl die vorderste als auch die hinterste Bildebene und schaffen dadurch einen allumfassenden inhaltlichen Rahmen innerhalb des Gemäldes. Darin wird erneut die Bedeutung evident, die Martens den biblischen Themen in Thorvaldsens Werk einräumte: Zusammen mit jenen der griechischen Antike wies er sie als Referenzpunkte im Schaffen seines berühmten Landsmannes aus. ${ }^{164}$ Martens' vier Jahre zuvor entstandenes, im Kapitel I.2 vorgestelltes Gemälde des Antikensaals in der Kunstakademie Kopenhagen verankert Thorvaldsen indessen noch klar in der antiken Kunst (Abb. 14). ${ }^{165}$ Trotz der ausführlichen Beschreibung zu seinem Gemälde des studio grande ließ Martens einige darin vorkommende Elemente unerwähnt. Dazu gehören vereinzelte Reliefs und Büsten, die teilweise in die Knie gefallenen Staffagefiguren im Vorderund Mittelgrund des Bildes - und sein eigenes Porträt. Denn es ist der Maler selbst, der im rechten Vordergrund mit der Zeichenmappe unter dem Arm das Bild und damit Thorvaldsens Atelier betritt und sich so als Zeuge des hohen Besuchs des Kirchenoberhaupts darstellte..$^{166}$

\section{Ausstellungs- und Verkaufsraum}

Martens' Gemälde veranschaulicht exemplarisch, dass Thorvaldsens studio grande weniger der Herstellung von Skulpturen als vielmehr deren Ausstellung sowie der Repräsentation des Bildhauers diente. ${ }^{167}$ Damit spiegelt es zugleich einen Aspekt des noch jungen anonymen Kunstmarkts im Rom des frühen 19. Jahrhunderts wider: Parallel zu den damals erst aufkommenden Akademieausstellungen wurden Kunstwerke vor allem in Kirchen sowie zunehmend in den individuellen Ateliers öffentlich präsentiert. ${ }^{168} 1829$ wurde in der Ewigen Stadt ein Kunstverein gegründet, die Società degli Amatori e Cultori di Belle $A r t i$, die fortan für die Organisation von jährlichen Ausstellungen zwischen November und Mai, der damaligen ,Hochsaison der Romreisenden, zuständig war. ${ }^{169}$ Einen Einblick in die Ausstellungspraxis im Rom der frühen 1830er Jahre gibt etwa der württembergische Gesandte und Kunstsammler Christoph Friedrich Karl von Kölle in seinem 1834 publizierten Reisebericht:

Siehe auch Jørnæs 1991c, 90; Mildenberger 1991, 195.

Siehe auch Mildenberger 1991, 195.

Siehe auch Kat. Nürnberg/Schleswig 1991, 531. Martens hielt sich zum Zeitpunkt des Papstbesuchs bei Thorvaldsen zwar in Rom auf, es ist jedoch nicht bekannt, ob er tatsächlich Augenzeuge jenes im Gemälde verewigten Ereignisses war.

Siehe auch Tesan 1991b, 233.

Siehe bspw. Oppermann 1927, 123; Springer, P. 1991, 212; Tesan 1991b, 228.

Springer, P. 1991, 213. 
Wenn ein Kunstwerk von Bedeutung fertig geworden ist, so wird es gewöhnlich einige Zeit hindurch dem Publicum gezeigt. Bei der Porta del popolo ist ein eigenes Local für Ausstellungen; auch im Pantheon werden zuweilen fertig gewordene Kirchenbilder ausgestellt. Der Kunstverein sorgt ebenfalls für ein Local für die Zeit, in welcher die meisten Fremden in Rom sind. ${ }^{170}$

Allerdings, so hielt Kölle fest, stellten die „ersten Künstler in jedem Fache [...] in der Regel nur in ihren Studien aus“. ${ }^{\text {"171 }}$ Dabei war es gerade unter den Künstlern selbst üblich, sich gegenseitig bei der Arbeit zu besuchen, zu beraten und dabei zu lernen. Dementsprechend schrieb Kölle, dass die Künstler um Besuche von Kollegen und Kunstverständigen baten, während sie „noch etwas am Kunstwerke ändern können, und die ersten Sterne des hiesigen Kunsthimmels erleuchten sich wechselseitig“.172

Der erste Künstler, der in Rom eine öffentliche Ausstellung seiner eigenen Werke organisiert hatte, dürfte Carstens gewesen sein. ${ }^{173}$ Obgleich dessen Ausstellung von 1795 nicht in seinem Atelier, sondern in eigens dafür gemieteten Räumlichkeiten zu sehen war, häuften sich individuelle Atelierausstellungen in den darauffolgenden Jahrzehnten zusehends. Die öffentliche Präsentation von Werken war eine neue Funktion des Künstlerateliers um 1800, in der sich zugleich das Bild des modernen Künstlers - oder nach Bätschmann des Ausstellungskünstlers - manifestierte. ${ }^{174}$ Wolfgang Ruppert und Michael Diers datieren die Neukodierung des Künstlerateliers als öffentlichem Ort des Künstlerkults und -mythos in die zweite Hälfte des 19. Jahrhunderts. ${ }^{175}$ Thorvaldsens Beispiel zeigt jedoch, dass sich jene Entwicklung bis in die Jahrzehnte um 1800 zurückverfolgen lässt. Gerade in Rom behielten die Atelierbesuche ihre Bedeutung für die künstlerische Praxis und Sichtbarkeit auch im weiteren 19. Jahrhundert bei, wohingegen sie in Paris und London immer mehr durch regelmäßig stattfindende Salons und Ausstellungen der dortigen Akademien abgelöst wurden. ${ }^{176}$

$$
1850
$$
neue Assoziationen mit dem Künstler auf, die zu Thorvaldsens Lebzeiten noch kaum thematisiert worden waren, wie etwa das Bild des zerstreuten, chaotischen Künstlers, sowie ein psychologisierendes oder gar pathologisierendes Verständnis von dessen Persönlichkeit, die sich im Atelier und den Werken widerspiegle; siehe dazu Junod 1998, 86-90.

176 Joachimides 2008, 39 - 40; Kernbauer 2011; Esner 2014, 7; Séverine Sofio, in: Guillouët u. a. 2014 , 39. 
Entsprechend jener neuen Funktion des Künstlerateliers als Ausstellungsraum bezeichnete Molbech Thorvaldsens Werkstätten, die er 1820 besucht hatte, als „öffentliche Ausstellung, da sie für jeden anständigen Fremden zugänglich“ waren. ${ }^{177}$ Molbech betonte damit zugleich den öffentlichen Charakter jener Arbeitsräume. Diese waren ferner nicht wie üblich einmal in der Woche, sondern Tag und Nacht für Besucher geöffnet. ${ }^{178}$ Diese radikale Öffnung von Thorvaldsens Werkstätten trug zusammen mit der durch das arbeitsteilige Verfahren erreichten Produktivität und einer geschickten Preispolitik wesentlich zur Sichtbarkeit des Bildhauers auf dem anonymen Kunstmarkt bei, die sowohl für seinen künstlerischen Erfolg als auch seinen celebrity-Status essenziell war.

In engster Verbindung mit der Funktion des Ateliers als Ausstellungsraum steht dessen Funktion als Treffpunkt des kunstinteressierten und kaufkräftigen Publikums - das Atelier wurde folglich zum Verkaufsraum. ${ }^{179}$ Mit der Einführung des Gipsmodells in voller Größe und dessen öffentlicher Präsentation im Bildhaueratelier wandelte sich auch der Umgang des Künstlers mit seinem Publikum: Abgesehen vor allem von Denkmälern bestellten die kaufkräftigen Zeitgenossen nicht mehr Werke nach eigenen Vorstellungen, sondern entschieden sich nach Besichtigung der verschiedenen Ateliers für die Marmorversion einer bereits modellierten Skulptur. ${ }^{180}$ Noch vor der Jahrhundertwende hatte Thorvaldsen mit der Herstellung von Porträtbüsten „auf Spekulation“ begonnen, wie er am 25. Februar 1804 rückblickend an Abildgaard schrieb. ${ }^{181}$ In diesem Brief kommt die taktische Denk- und Arbeitsweise des jungen Bildhauers klar zum Ausdruck, die ihm 1803 mit der gleichsam durchkalkulierten Jason-Statue den künstlerischen Durchbruch sowie kurz darauf mit der im vorangegangenen Kapitel thematisierten Arbeitsteilung und Preispolitik die Etablierung im römischen Kunstmarkt ermöglichte. Thorvaldsens Strategie schien aufzugehen: Im Jahr 1817 schrieb Rasmus Emil Bruun, dass sich Thorvaldsens „größter Wunsch, nach freier Wahl und ohne Aufträge zu arbeiten“, wohl erfüllen werde, „denn seine Kunst hat ihm Unabhängigkeit verschafft, und sein Name ist in allen kultivierten Ländern berühmt “. ${ }^{182}$ Mit jener Umkehrung im Schaffensprozess eröffnete sich die Möglichkeit zur mehrfachen Ausführung ein und desselben Werks für verschiedene Konenhver anstændig Fremmed. "Siehe auch Wittstock 1975, 110; Helsted 1977, 13; Springer, P. 1991, 213. Davon berichtete etwa Ponzano y Gascón zwischen 1832 und 1838, zit. bei Hartmann 1971, 39. Siehe auch Plon 1867, 40; Pfundheller 1886, 223; Tesan 1991b, 227.

179 Siehe auch Oppermann 1927, 123; Springer, P. 1991, 212; Tesan 1991b, 226 - 230.

180 Bott, K. 1991, 154; Kluxen 1991, 282; Springer, P. 1991, 213 und 216; Jørnæs 2011, 51; Myssok $2017,144$.

181 Bertel Thorvaldsen an Nicolai Abildgaard, 25. Februar 1804, KB, Ref. NKS 2337, 2 (Transkript im TMA): „Bysterne vare alle gjorde paa Spekulasion [...].“ Siehe auch Thiele 1852-1856, Bd. 1, 71; Springer, P. 1991, 214 und 218.

182 Bruun, R.E. 1817, 541: „Hans kaereste Ønske er, at kunne arbejde efter frit Valg og uden Bestillinger; og dette vil han vel ogsaa kunne opnaae; thi hans Konst har skaffet ham Uafhængighed, og hans Navn er berømt i alle cultiverede Lande.“ 
texte. ${ }^{183}$ Wie mit Bezug auf Thorvaldsens Alexanderzug gezeigt wurde, sind die Schöpfungen des Dänen folglich durch eine Aufhebung der die Skulptur lange bestimmenden Ortsgebundenheit charakterisiert, was ihnen und vor allem ihrem Schöpfer zusätzliche Sichtbarkeit, Reichweite und Bekanntheit verlieh. ${ }^{184}$

\section{Museum und Tempel}

Im Vergleich mit früheren Atelierausstellungen erhielten jene von Bildhauern wie Canova und Thorvaldsen eine neue Dimension: Durch die Ansammlung der Originalmodelle gaben ihre Werkstätten nicht nur Einblick in das aktuelle Schaffen, sondern wurden zum Spiegel des Gesamtwerks jener Künstler. ${ }^{185}$ Dies kommt in Martens' Beschreibung zu seinem Gemälde von Thorvaldsens studio grande deutlich zum Ausdruck: „[...] es war mein Plan, Thorvaldsens sämtliche Arbeiten zu einem Ganzen zu vereinen. "186 Auch nach Thiele hatte man wenige Monate nach Vertragsabschluss für das ehemalige barberinische Stallgebäude im Oktober 1822

die schon fertigen großen Modelle hierher gebracht, und da die Figuren für das Fronton der Frauenkirche zu Kopenhagen nun auch vollendet waren, wurden sie aus den verschiedenen Studien ebenfalls hier auf-, und zum ersten Male als ein Ganzes in der Composition zusammengestellt. ${ }^{187}$

Als gleichsam physisches Euvreverzeichnis wollte die Werkpräsentation in den Ateliers entsprechend gepflegt sein. Für Thorvaldsen ist beispielsweise bekannt, dass er mit einigen frühen Skulpturen später nicht mehr einverstanden war und die Modelle des Bacchus von 1804 und des Apoll von 1805 aus der Ausstellung in seinem Atelier und somit faktisch aus seinem CEuvre entfernte. ${ }^{188}$ Weiter ersetzte er ältere durch ,korrigierte‘ Modelle, wie jene von Ganymed (1804/1816), Venus (1804-1805/1813-1816), Hebe (1806/1815-1816) oder dem Tanz der Musen auf dem Helikon (1806/1816). ${ }^{189}$

Wegen der schieren Anzahl der aufgestellten Werke hinterließen die Ateliers des Dänen, besonders das studio grande, einen tiefen Eindruck bei den Besuchenden. So beschrieb Ponzano y Gascón jenen Raum als „Arsenal“, während Thorvaldsens späterer Assistent Johann Scholl vom Anblick des Ateliers derart überwältigt war, dass er „von dem ungeheuren Reichthum an herrlichen Werken ganz verwirrt geworden u Kopfweh heim-

183 Siehe auch Kluxen 1991, 282 - 284.

184 Zum Alexanderzug siehe Kap. I.2.

185 Siehe auch Helsted 1982a, 52; Miss 1991, 351; Springer, P. 1991, 213; Tesan 1991b, 230.

186 Ditlev Martens an die Kunstakademie Kopenhagen, 20. August 1828, zit. nach Kat. Nürnberg/Schleswig 1991, 529.

187 Thiele $1852-1856$, Bd. 2, 90.

188 Molbech 1822, 224-225; auch Wittstock 1975, 65.

189 Siehe bspw. Thiele 1852 - 1856, Bd. 1, 265; Wittstock 1975, 65; auch Jørnæs 2011, 91. 
gebracht" habe. ${ }^{190}$ Die möglichst vollständige Ausstellung von Thorvaldsens Originalmodellen veranlasste überdies bereits Zeitgenossen, dessen Ateliers mit einem Museum zu vergleichen, wie es etwa für Molbech, den Bildhauer Ernst Rietschel, den Schriftsteller Ernst August Hagen und Thiele belegt ist. ${ }^{191}$ In diesem Zusammenhang ist ferner beachtenswert, dass der dänische Kronprinz Christian Frederik bereits 1820 nach einem Besuch in Thorvaldsens römischen Werkstätten verkleinerte Modelle von zehn Statuen bestellte, die anschließend von Wilhelm Hopfgarten in München in Bronze gegossen und vergoldet wurden. ${ }^{192}$ Diese 1825 vollendeten Tafelaufsätze dienten dem Kronprinzen gemäß Thiele dazu, „sich den Eindruck von den Ateliers unsers Künstlers [...] zu bewahren“. ${ }^{193}$

Mit der Bezeichnung von Thorvaldsens Arbeitsstätte als „ein eigenes Museum, in das ich oft zurückkehren werde“, charakterisierte Rietschel das Künstleratelier auch als ,auratischen' Ort des romantischen Geniekults. ${ }^{194}$ In Anlehnung an Benjamins Definition der Aura eines Kunstwerks kann das Atelier als Raum gedeutet werden, der durch die Untrennbarkeit vom dort wirkenden Künstler mit Kult- und Originalitätswert belegt ist. ${ }^{195}$ In diesem Sinn ist auch die Vergrößerung der räumlichen Dimensionen von Thorvaldsens

190 Ponciano Ponzano y Gascón, „Studio o arsenale dello scultore Thorwaldsen“, zwischen 1832 und 1838, zit. nach Hartmann 1971, 37; Johann Scholl, 2. Januar 1835, zit. nach Bott, G. 1991, 147.

191 Molbech 1822, 208: „Det ligner mere et heelt Museum, end en eneste Mands Frembringelser.“; Hagen 1844, 28: „das Ansehen eines Museums“; Thiele 1852 - 1856, Bd. 2, 182: „köstliches Museum“.

192 Siehe dazu ausführlich Kronberg Frederiksen 2014a; auch Thiele 1852-1856, Bd. 2, 54; Springer, P. 1991, 217. Es handelte sich dabei um den Hirtenjungen, den Triumphierenden Amor, Venus mit dem Apfel, Merkur, den Frieden bringenden Mars, die Drei Grazien, Jason mit dem goldenen Vlies, Hebe, das Tanzende Mädchen und Adonis. Den genannten Tafelaufsätzen war 2015 die Ausstellung Det Gyldne Tableau auf Amalienborg in Kopenhagen gewidmet.

193 Thiele $1852-1856$, Bd. 2, 54.

194 Ernst Rietschel an Christian Daniel Rauch, 4.10.1830, zit. nach Haufe 1965, 287. Siehe auch Wittstock 1975, 111; Springer, P. 1991, 218.

195 Zum Begriff der Aura eines Kunstwerks siehe Benjamin 1977, 11-20, und zu dem mit dem Geniekult verbundenen Originalitätskult in den Jahrzehnten um 1800 siehe Krieger 2007, 38-39. Es ist hier bewusst nicht von Authentizitätswert die Rede, den anzufügen man rasch versucht wäre. Insgesamt scheint jedoch die Frage nach künstlerischer Authentizität - auch nach einer paradoxen Inszenierung derselben - mit Blick auf Thorvaldsens Werkstattpraxis und Selbstvermarktung weder besonders relevant noch ergiebig zu sein: Die Arbeitsteilung in seinen Ateliers wurde von den Zeitgenossen nur vereinzelt kritisiert und stattdessen als die neue - revolutionäre - Form der Skulpturproduktion akzeptiert und bisweilen bewundert. Was Thorvaldsens Selbstvermarktung betrifft, so lässt sich gerade seine opportunistische Haltung gegenüber (potenziellen) Auftraggebern und Kunden nicht mit dem Wert künstlerischer Authentizität vereinbaren. Ebenso wenig wurde jene Haltung kritisiert, weshalb hier auch kein Diskurs über ,Inauthentizität' vorliegt. Diesbezüglich steht Thorvaldsen einem Künstler wie Carstens diametral gegenüber, der großen Wert auf seine künstlerische Autonomie legte und für diese gar den Ausschluss aus der Berliner Akademie riskierte. Für eine detaillierte Untersuchung zum schwer greifbaren Begriff der künstlerischen Authentizität siehe Wenninger 2009, die auch auf die Problematik der romantischen Prägung des Terminus hinweist. 
studio grande durch Martens zu verstehen (Taf. II). ${ }^{196}$ Die idealisierende Darstellung des Ateliers begründete der Maler selbst mit dem oben zitierten Wunsch, möglichst viele von Thorvaldsens Arbeiten wiederzugeben. Die monumentalen Ausmaße dieses Raumes manifestieren sich hier zudem im Kontrast zu den winzig erscheinenden Besucherinnen und Besuchern. Außerdem veranschaulicht Martens' Darstellung eine Problematik, die Rachel Esner mit Blick auf Atelierbilder des 20. und 21. Jahrhunderts festgestellt hat - „den Konflikt zwischen Autonomie und Auftrag, zwischen den Anforderungen des Diskurses um den modernen Künstler und der tatsächlichen Realität desselben“.197 Auch für das frühe 19. Jahrhundert gilt, dass Thorvaldsens fast märchenhafte Laufbahn und sein zeitweise kaum überschaubarer Werkstattbetrieb zwar durchaus der veränderten Vorstellung, jedoch keineswegs der Realität der meisten Künstler entsprach. ${ }^{198}$ Als Gegenbeispiel zum ,Künstlerfürsten` Thorvaldsen kann dessen frühes Vorbild Carstens herangezogen werden, der sich zwar seine künstlerische Autonomie erkämpft und unbeirrbar an ihr festgehalten hatte, jedoch nicht zuletzt aufgrund seiner Unangepasstheit finanziell scheiterte. ${ }^{199}$ Einen ebenso auf tradierten Topoi basierenden wie ernüchternd-realistischen Blick auf das Künstlerdasein zeigt schließlich Adolph von Menzels Lithografie-Serie Künstlers Erdenwallen von 1833/1834, die besonders den Kontrast zwischen der von Einsamkeit und den Gesetzen des Kunstmarkts geprägten Künstlerexistenz zu Lebzeiten einerseits und dem zuweilen fast ins Absurde getriebenen Nachruhm andererseits herausstreicht. ${ }^{200}$

Martens' verklärendes Gemälde findet seine schriftliche Entsprechung in Thieles Beschreibung des gezeigten Ateliers, das der Biograf nicht nur mit einem Museum, sondern überdies mit einer Kirche assoziierte. Die Gegenüberstellung von Thieles auf das Jahr 1824 verweisendem Zitat und Martens' 1828 -1829 geschaffenem Gemälde lässt ferner - tatsächlich erfolgte oder durch Martens fingierte - Veränderungen in der Skulpturpräsentation im studio grande erkennen:

Der gesamte Raum, der, was seine Größe betrifft, fast mit einer Kirche zu vergleichen ist, wird durch herabhängende Vorhänge in drei Teile geteilt.

Im ersten Teil sah man im Jahre 1824, gleich am Eingang, zwei in Marmor gehauene Karyatiden und zwei Figuren, die bestimmt waren für die Metropolitan-Kirche zu Kopenhagen, nämlich ein stehender Krieger mit Helm und Schild und eine sitzende männliche Figur. Weiterhin sah man die vier Basreliefs für das Schloss Christiansborg, dann eine Venus, den kolossalen Mars mit Amors Pfeil in seiner Hand, in Marmor, und das Modell des Kopernikusmonumentes.

Zu den bei Martens vergrößerten Dimensionen des Atelierraumes siehe auch Jørnæs 1991c, 90; Jørnæs 2011, 181.

197 Esner 2014, 8. Eine ähnliche Aussage findet sich bei Holsten 1978, 74.

198 Siehe auch Wittstock 1975, 39 - 40; Tesan 1991b, 223; Ruppert 1998, 194, 322 und 579; Bogh 2006, 284.

199 Tesan 1991b, 223. Ein ähnliches Autonomiebestreben ist auch für Joseph Anton Koch bekannt; Maaz 2008, $17-18$.

200 Siehe dazu bspw. Holsten 1978, 64 - 65; Maaz 2008, 11; Kat. Göttingen/Rom 2015, 354 - 359. 
In der zweiten Abteilung: Das stolze Ross in natürlicher Größe vom Fürst-Poniatowsky-Monument, eine Replik des Taufbeckens von Brahe-Trolleborg, die Porträtstatue der Gräfin Ostermann, die Tänzerin, den Hirtenknaben, Merkur und den stehenden Taufengel und außerdem eine große Anzahl Basreliefs und Büsten.

Im inneren Teil, dem Allerheiligsten der Studios die Christusstatue und die Apostel. Hinter ihnen die Komposition Johannes der Täufer in der Wüste. In diesem Raum wurde später auch, außer den genannten Statuen, das fertige Modell des Denkmals von Papst Pius VII. aufgestellt.

Durch diese drei Teile hindurch, von deren Größe man sich am leichtesten eine Vorstellung macht, wenn man bedenkt, was alles hier aufgestellt war, schuf das fast fertige Exemplar von Alexanders Triumphzug in Marmor eine Verbindung, indem es die gesamte Länge einnahm am Fußboden entlang, linkerhand des Eintretenden. ${ }^{201}$

Im Kontext des Geniekults um Thorvaldsen und des Ateliers als auratischem Ort sind vor allem Thieles Vergleich der Künstlerwerkstatt mit einer Kirche und die Bezeichnung eines Bereichs des Ateliers als dem Allerheiligsten signifikant. In seiner späteren Biografie über Thorvaldsen wiederholte der Kunsthistoriker diese Assoziation in einer Formulierung, die stark der einleitend erwähnten ,Kunstreligion' jener Zeit verpflichtet war:

Das große Atelier, in welchem die Heiligen-Statuen in Reihen vor den mächtigen herabwallenden Draperien, die von der hohen Decke aus den Raum in mehrere Abtheilungen bis auf das Allerheiligste theilten, standen, war in Rom mein protestantischer Tempel, und Sonntags fehlte es nicht, daß irgend ein fleißiger Arbeiter, welcher den Ruhetag zur Hilfe nahm, die Marmorglocken zu dem stillen Gottesdienst klingen ließ. ${ }^{202}$

201 Thiele 1831-1850, Bd. 2, 131-132: „Det hele Rum, der, ihenseende til Størrelse, nærmest er at ligne med en Kirke, er ved nedhængende Dækker adskildt i tre Dele. / I den første Afdeling saae Man i Aaret 1824, strax ved Indgangen, de tvende i Marmor udførte Caryatider og to, af Frontonen til Metropolitankirken i Kiøbenhavn udskudte, Figurer, nemlig en staaende Kriger med Hjelm og Skjold og en siddende, mandlig Figur. Endvidere saae Man her de fire runde Basrelieffer til Christiansborgslot, Venus, den colossale Mars, som veier Amors Piil, i Marmor, og Modellen til Monumentet over Kopernikus. / I den anden Afdeling: Den vælige Hest i naturlig Størrelse til Monumentet over Fyrst Poniatowsky, en Gjentagelse af Døbefonten til Brahe-Trolleborg, Portraitstatuen af Grevinde Ostermann, Dandserinden, Hyrdedrengen, Merkur og den staaende Daabens Engel, foruden et stort Antal Basrelieffer og Buster. / I den inderste Afdeling, Studiernes Allerhelligste, Christusstatuen og Apostlene ; bagved disse Compositionen Johannes den Døber i Ørkenen. I dette Rum opstilledes senere, foruden de nævnte Statuer, ogsaa den færdige Model til Monumentet over Pave Pius den Syvende. / Igjennem disse tre Afdelinger, om hvis Størrelse Man lettest gjør sig den rigtige Forestilling, naar Man bemærker, hvad der i hver var opstillet, udgjorde det næsten færdige Exemplar af Alexanders Triumphtog i Marmor en Forbindelse ved at indtage den hele Længde, langsmed Gulvet, paa den Indtrædendes venstre Side.“ Deutsche Übersetzung nach Jørnæs 1991c, 90; Anpassung der Schriftarten an das Original durch T. S.

202 Thiele 1852-1856, Bd. 2, 141. Der Begriff und das Phänomen der Kunstreligion sind in der Einleitung des vorliegenden Buches kurz umrissen. 
Über diese Sakralisierung des Ateliers hinaus verherrlichte Thiele auch Thorvaldsens Werke, die ihn erst „sehen gelehrt" hätten. ${ }^{203}$ Der Biograf war indessen keineswegs der einzige Zeitgenosse, den Thorvaldsens Ateliers an heilige Räume erinnerten. Schon 1819 hatte der Komponist Rudolph Bay eine frühere Werkstatt des Bildhauers als „wahren Tempel der Kunst" bezeichnet, während Seidler ungefähr zeitgleich die Größe einer der Arbeitsstätten mit jener einer „kleine[n] Kirche“ verglich. ${ }^{204}$

Generell bildet die Sakralisierung des Künstlerateliers eine Konstante in der dem damaligen Geniekult verpflichteten Kunstliteratur des frühen 19. Jahrhunderts. Im selben Zusammenhang ist auch die zunehmende Betrachtung von Atelier und Künstler als einer untrennbaren Einheit sowie der Arbeitsstätte als Spiegelbild des darin Wirkenden zu sehen. ${ }^{205}$ Dementsprechend versteht Philippe Junod mit Fokus auf das ausgehende 19. und beginnende 20. Jahrhundert das Künstleratelier gleichsam als ein Kunstwerk für sich und als Selbstbildnis des darin schaffenden Künstlers. ${ }^{206}$ Diese Beobachtung lässt sich auf die Zeit um 1800 und Atelierdarstellungen wie jene von Martens ausweiten: Die Werkstatt erscheint bereits hier als Porträt des betreffenden Künstlers. In Martens' Gemälde nobilitieren sowohl der Papstbesuch als auch die verzerrten Größenverhältnisse, die den Raum in der Tat wie ein Kirchenschiff erscheinen lassen, das Atelier ebenso wie den Bildhauer selbst. Thorvaldsens galante Pose und vornehme Kleidung verdeutlichen überdies, dass das Atelier seit dem frühen 19. Jahrhundert immer mehr zum Ort der offiziellen Repräsentation, strategischen Selbstvermarktung und effektiven Selbstdarstellung des Künstlers wurde. ${ }^{207}$

\section{Hohe Besuche II: Luigi oder Fabio Ricciardellis Darstellung von}

\section{Ludwig I. bei Thorvaldsen}

Martens' Idealisierung und Sakralisierung von Thorvaldsens studio grande treten im Vergleich mit der fast zur gleichen Zeit entstandenen Zeichnung desselben Ateliers durch Luigi oder Fabio Ricciardelli besonders deutlich zutage (Abb. 82).208 Das Atelier ist hier von der anderen Seite dargestellt: Der Alexanderzug läuft der rechten Wand unterhalb der Fenster entlang, und im Vordergrund befinden sich mit dem Papstgrabmal und der Christus-Statue Werke, die bei Martens die hintere Bildebene prägen. Die bauliche Konstruktion mit dem Holzgebälk sowie die Unterteilbarkeit des Raumes mittels Vorhängen ent-

204 Rudolph Bay, 8. Mai 1819, zit. nach Wittstock 1975, 243: „kunstens sande tempel“; Erinnerungen der Malerin Louise Seidler 1922, 122. Zur Sakralisierung von Thorvaldsens studio grande siehe außerdem Tesan 1991b, 233. Junod 1998; Schneemann 1998, 13 - 14; Diers 2010, 3; Esner 2014, 7.

207 Séverine Sofio, in: Guillouët u. a. 2014, 39.

208 Siehe auch Jørnæs 1991c, 91; Jørnæs 2011, 181. 


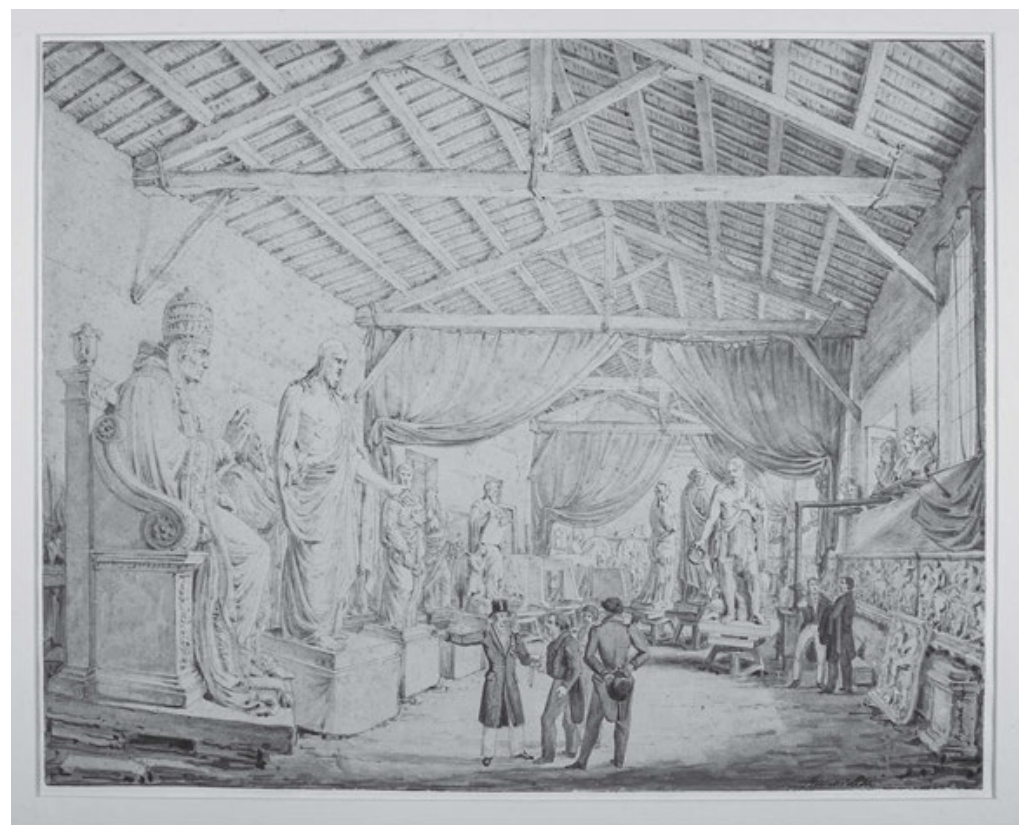

82_Luigi oder Fabio Ricciardelli, Ludwig I. von Bayern besucht Thorvaldsens großes Atelier nahe der Piazza Barberini am 18. Februar 1829, 1829, Bleistiftzeichnung braun laviert auf Papier, $279 \times 351 \mathrm{~mm}$, Kopenhagen, Thorvaldsens Museum (Inv.-Nr. D1771)

sprechen der Wiedergabe bei Martens, obschon das Atelier bei Ricciardelli insgesamt schmaler und niedriger wirkt.

Den Vordergrund von Ricciardellis Zeichnung bestimmt die Figurengruppe um Thorvaldsen, der den bayerischen König Ludwig I. durch seine Werkstatt führt und diesem im festgehaltenen Moment sein Grabmal für Papst Pius VII. zeigt. Sicherlich im Zusammenhang mit dem Besuch des Königs hat Ricciardelli der 1827 modellierten Statue von Eugène de Beauharnais, dem Schwager von Ludwig I., einen prominenten Platz im Mittelgrund des Bildes eingeräumt. Dieses Standbild für Beauharnais' Grabmal war einer von mehreren Aufträgen aus München, denen eine intensive Korrespondenz zwischen Ludwig I. und dessen Kunstagenten Wagner sowie ein langwieriger Arbeitsprozess in Thorvaldsens Werkstätten folgten (Abb. 83). ${ }^{209}$

Bestellt wurde das Beauharnais-Monument am 24. April 1824 durch Klenze, der Thorvaldsen genaue Vorgaben für das Werk machte. ${ }^{10}$ Dem Dänen scheint es indessen schon stellte und erst 1831 gelieferte Adonis-Statue; siehe dazu Kap. II.1 und III.1.

210 Von Urlichs 1887, 13. 


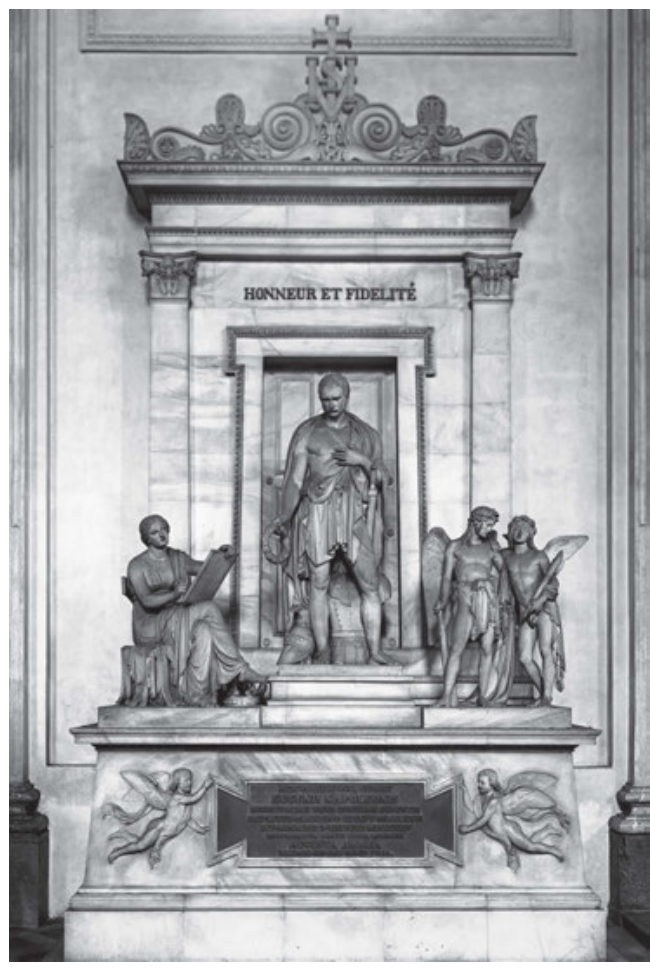

83_Bertel Thorvaldsen, Grabmal für Eugène de Beauharnais, 1827 - 1829, Marmor, Höhe: $275 \mathrm{~cm}$, München, Sankt Michaels Kirche

seit langer Zeit widerstrebt zu haben, die Ideen anderer auszuführen. Dementsprechend schrieb Wagner am 25. Mai 1824 an den damaligen Kronprinzen Ludwig: „Dass Th. diesen Antrag annehmen werde, daran ist kein Zweifel. Nur ist er nicht ganz mit dem ihm vorgeschlagenen Entwurf, noch weniger mit der ihm gesetzten Zeitfrist (2 Jahre) einverstanden. “211 Am 22. Juli desselben Jahres informierte Wagner den Kronprinzen über Thorvaldsens Unmut bezüglich der klaren Vorgaben von Seiten Klenzes:

Etwas machen, was gegen seine Ueberzeugung sei, könne er [Thorvaldsen], wenn einmal dieses Monument unter seinem Namen vor der Welt ausgestellt werden solle, deswegen nicht, weil das Lob oder der Tadel ihn allein treffe. Deswegen könne er dieses Denkmal nicht anders unternehmen, als wenn man ihm freie Hand lasse [...]..$^{212}$

211 Johann Martin von Wagner an Ludwig von Bayern (später Ludwig I.), 25. Mai 1824, zit. nach von Urlichs 1887, 13 (Hervorhebungen im Original).

212 Johann Martin von Wagner an Ludwig von Bayern (später Ludwig I.), 22. Juli 1824, zit. nach von Urlichs 1887,14 . 
Ludwig zeigte sich hierauf damit einverstanden, dass Thorvaldsen einen eigenen Entwurf für das Grabmal von Beauharnais zeichne. ${ }^{213}$ Der Bildhauer war nun jedoch nicht mehr abgeneigt, das Monument nach Klenzes Skizzen auszuführen. Am 22. Februar 1825 berichtete Wagner dem Kronprinzen, Thorvaldsen habe ihm mitteilen lassen,

dass er zwar nicht gewohnt sei, nach Entwürfen anderer zu arbeiten, da er aber die Idee des Herrn v. Kl. so vortrefflich fände so mache er sich eine Ehre daraus, diese Arbeit zu übernehmen und werde es sich zur Pflicht machen, diese Arbeit sich vorzüglich angelegen sein zu lassen und zu einer seiner ersten zu machen. ${ }^{214}$

Da sich Thorvaldsen offenbar kurz zuvor noch bei Wagner über die Vorgaben aus München beschwert hatte, erklärte er ihm seinen Sinneswandel damit, dass

er geglaubt habe, dadurch am ersten [ehesten?] zum Ziele zu gelangen, und dass, wenn er dem Hrn. $v$. $\mathrm{Kl}$. solche Lobsprüche über seine Ideen mache, er auch hoffen dürfe, dass $\mathrm{Kl}$. auch ihm von seiner Seite etwas nachgeben würde. ${ }^{215}$

Das Grabmal für Beauharnais wurde schließlich von Thorvaldsen und Tenerani gemeinsam ausgeführt, wobei Thorvaldsen für die Hauptfigur, die Porträtstatue des Verstorbenen, verantwortlich war. ${ }^{216}$ Das Werk wurde im Herbst 1829 vollendet und nach München versandt, wo es in der St.-Michaels-Kirche aufgestellt und am 12. März des darauffolgenden Jahres enthüllt wurde. ${ }^{217}$

Gemäß Thiele handelte es sich bei der von Ricciardelli gezeichneten Anwesenheit Ludwigs I. im studio grande um einen Überraschungsbesuch, der aber dennoch offiziellen Charakter hatte: Der König überreichte Thorvaldsen am 18. Februar 1829 das Kommandeurskreuz der bayerischen Krone. Für seine unkonventionelle Art bekannt, soll Ludwig I. die Wahl des Ortes mit folgenden Worten begründet haben: „Den Soldaten zeichnet man auf dem Schlachtfelde, den Künstler unter seinen Werken aus!“218 Wie im Kapitel II.1 ausgeführt wurde, hatte Ludwig schon seit Jahrzehnten zu Thorvaldsens eifrigsten Bewunderern gezählt. Noch während eines erneuten Aufenthalts in Rom in den Jahren 1841 und 1842 soll der bayerische König zur Baronin Stampe gemeint haben: „[V]on Könige giebt es

Von Urlichs 1887, 14.

Johann Martin von Wagner an Ludwig von Bayern (später Ludwig I.), 22. Februar 1825, zit. nach von Urlichs 1887, 15 (Hervorhebung im Original).

Ebd., 16 (Hervorhebungen im Original).

Während des Entstehungsprozesses dieses Monuments zerstritten sich die beiden Bildhauer; siehe dazu Helsted 1977, 10; Tesan 1998, 65 - 66; Jørnæs 2011, 176-180.

Siehe dazu bes. Kjøbenhavns-Posten, 4:110, 11. Mai 1830, o. S. [Titelseite].

Thiele 1852-1856, Bd. 2, 203. Siehe auch Thiele 1831-1850, Bd. 3, 25; Hubbard 1902, 100; Hartmann 1971, 37; Jørnæs 1991c, 91; Kat. Nürnberg/Schleswig 1991, 534; Mildenberger 1991, 195; Peters 1991, 165; Kanzenbach 2007, 185. 
viele, aber nur ein Thorvaldsen“.219 Mit dieser Aussage bestätigte Ludwig den oben erwähnten, durch die Französische Revolution ausgelösten Wandel des gesellschaftlichen Status von Monarchen einerseits und Künstlern andererseits, was sich in Atelierdarstellungen des frühen 19. Jahrhunderts in einer unklar gewordenen Hierarchie niederschlug.

\section{Thorvaldsens römische Ateliers als Sehenswürdigkeiten}

Sowohl bei Martens als auch bei Ricciardelli ist Thorvaldsens studio grande nicht etwa durch den bildhauerischen Arbeitsprozess, sondern durch eine repräsentative, gleichsam museale Wirkung geprägt. Damit stehen diese Darstellungen beispielsweise Francesco Chiarottinis um 1786 entstandener Zeichnung von Canovas Atelier entgegen, die verschiedene Schritte im bildhauerischen Arbeitsprozess beleuchtet (Abb. 84). Angesichts des ähnlichen Bildaufbaus dürfte Chiarottinis Blatt Ricciardelli nicht nur bekannt gewesen sein, sondern darüber hinaus als Vorlage gedient haben. Dass die handwerkliche Arbeit bei Ricciardelli ausgeblendet ist, wurzelt weniger in dessen nobilitierendem Bestreben gegenüber Thorvaldsen als vielmehr in der damaligen Wirklichkeit. Dementsprechend konstatierte etwa Ponzano y Gascón, dass in Thorvaldsens großem Atelier „keine einzige Skulptur gearbeitet wurde“.220 In der Tat diente das studio grande, wie erwähnt, hauptsächlich der Ausstellung, der Repräsentation und dem Verkauf. ${ }^{221}$ Außerdem fanden hier soziale Anlässe wie Betrachtungen der Skulpturen bei Fackellicht, illustre Abendgesellschaften oder Konzerte statt. ${ }^{222}$

Thorvaldsens Werkstätten waren folglich nicht nur öffentlich zugänglich, sondern etablierten sich schon kurz nach dem künstlerischen Durchbruch des Bildhauers mit der Jason-Statue 1803 als gesellschaftlicher Treffpunkt und als eine der wichtigsten Sehenswürdigkeiten für Romreisende im frühen 19. Jahrhundert. ${ }^{223}$ So liest man bereits am 5. April 1804 in Pauline Dorothea Frischs Reisetagebuch, dass

Thorwaldsends [sic] Werkstätte [...] etwas von dem ersten [war,] was wir besahen. Mit [R]ücksicht auf das, was dieser Mann schon geliefert hat, glaube ich dass er ein vorzüglicher Arbeiter in seiner Kunst werden muss. Seine Bescheidenheit scheint dafür Bürge zu seyn. ${ }^{224}$

Jahre später hielt Scavenius während seines Romaufenthalts von 1819 in seinem Reisetagebuch fest, dass Thorvaldsens Ateliers „von Morgends bis Abends von Fremden überlau-

Zit. nach Baronesse Stampes Erindringer 1912, 191 (orthografische und Kasus-Fehler im Original). Siehe auch Repholtz 1911, 113.

220 Zum Zitat von Ponzano y Gascón siehe Tesan 1991b, 233; auch Hartmann 1971, 37.

221 Tesan 1991b, 233.

222 Hartmann 1966, 18; Tesan 1991b, 227 - 228.

223 Otto 1869, 665; Wittstock 1975, 56 - 57 und 110; Helsted 1982a, 52; Springer, P. 1991, 213; Tesan 1991b, 227; Wittstock 1991, 203 und 208; Randolfi 2010, 81.

224 Frisch 1816, 363. Siehe auch Wittstock 1975, 55; Kofoed 2009a. Eine ähnliche Formulierung findet sich auch in Rudolph Bays Tagebucheintrag vom 8. Mai 1819, zit. bei Wittstock 1975, 243. 
84_Francesco Chiarottini, Canovas Atelier in der Via San Giacomo in Rom, um 1786, Tinte und Wasserfarbe auf Papier, $385 \times 560$ mm, Udine, Museo Civico

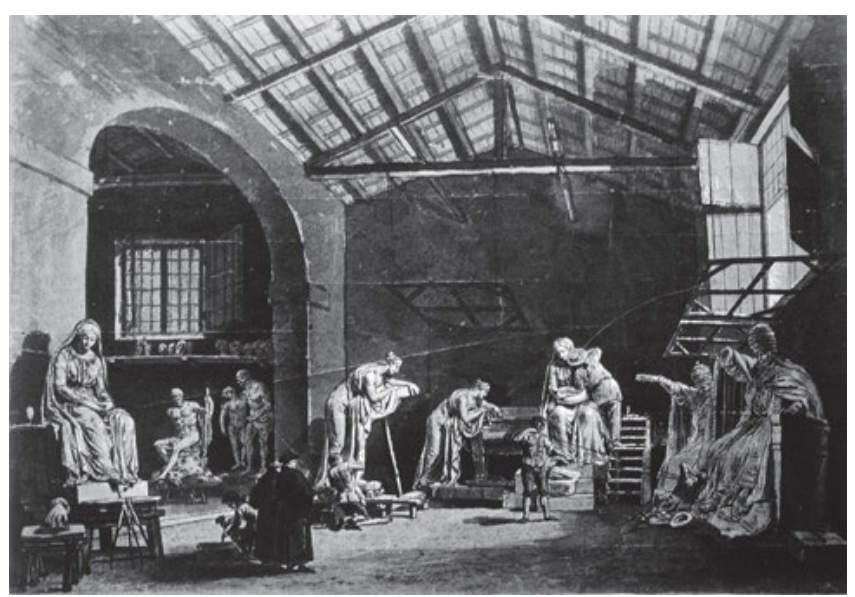

fen“ seien. ${ }^{225}$ Dabei verkehrten keineswegs nur Kunstkenner in den Werkstätten des Dänen, wie ebenfalls aus Scavenius' Tagebucheintrag hervorgeht: „Ein Reisender kam herein mit seinen Cicerone, wusste nicht einmal, wo er war. ${ }^{\text {“226 }}$ Aus diesen Zitaten geht erneut Thorvaldsens celebrity-Status hervor, denn sie veranschaulichen, dass seine Ateliers auch als feste Programmpunkte auf dem Reiseplan derjenigen Romtouristen standen, die sich offenbar nicht näher mit dem aktuellen Kunstleben in der Ewigen Stadt befassten. Dementsprechend bemerkte der Autor Hans Peter Holst in seiner 1850 verfassten „biografischen Skizze “ über den dänischen Bildhauer:

Thorvaldsens Berühmtheit festigte sich von Jahr zu Jahr. Bald wurde sein Name der populärste Künstlername von Italien und sein Atelier das meistbesuchte von allen [...]. In Rom war er beinahe so bekannt und verehrt wie der Pontifex Maximus.227

Peder Brønnum Scavenius, 13. April 1819, RA, Peder Brønnum Scavenius’ privatarkiv (Digitalisat im TMA): „Thorvaldsen overløbes i denne Tid fra Morgen til Aften af Fremmede.“ Siehe auch Plon 1867, 40; Pfundheller 1886, 223; Wittstock 1975, 111; Springer, P. 1991, 213; Wittstock 1991, 208.

226 Peder Brønnum Scavenius, 13. April 1819, RA, Peder Brønnum Scavenius’ privatarkiv (Digitalisat im TMA): „En Reisende kom derind med sin Cicerone, vidste ei engang hvor han var.“ Siehe auch Wittstock 1975, 337. Bereits am 8. April 1813 hatte Peder Malling an Christian Frederik von Dänemark (später Christian VIII.) geschrieben, dass Thorvaldsens Atelier jeden Tag „von Römern und auswärtigen Künstlern und Dilettanten“ besucht würde, um die in Entstehung begriffenen Karyatiden für Schloss Christiansborg zu sehen; zit. nach Linvald/Fabritius 1965, 106: „Dagligen besøges hans Attelier af Rommere og fremmede Kunstnere og Dilettanter for at beundre dette Mesterværk. “ Auch gemäß Gibson war Thorvaldsens Atelier „die Zuflucht von Künstlern und Kunstliebhabern aller Nationen“, zit. nach Matthews, T. 1911, 81: „His studio was the resort of artists and lovers of art from all nations.“

227 Holst 1865/1866, 26: „La célébrité de Thorvaldsen s'accrut d’année en année. Bientôt son nom devint le nom d'artiste le plus populaire de l'Italie et son atelier le plus fréquenté de tous [...]. A Rome, il était connu et vénéré presque à l'égal du souverain Pontife.“ 
Nebst seinem Erfolg mit der Jason-Statue 1803 profitierte Thorvaldsen in den Jahren danach von der - im Vergleich mit den napoleonischen Kriegen in Mitteleuropa und der britischen Zerstörung Kopenhagens - relativ ruhigen politischen Situation in Rom, die den dortigen Kunstmarkt begünstigte. ${ }^{228}$ Im selben Zusammenhang berichtet Thiele in seiner Biografie über den Bildhauer:

Nun erst, ungefähr mit dem Anfang des Jahres 1805, als die Stürme sich einigermaßen gelegt hatten, als er ehrlich kämpfend einen angesehenen Namen errungen, als bereits nicht wenige Arbeiten sich in seinem Studio gruppirten, welches kein Reisender unbesucht ließ, - jetzt erst stand er freier und selbstständiger da, und die schöpferische Thätigkeit, die er jetzt entfaltete, wurde auch der Anfang des großartigen römischen Lebens, durch welches er bald über die ganze Welt, und zwar unter dem Namen ,Thorvaldsen in Rom bekannt wurde. ${ }^{229}$

Dass die Besichtigung von Künstlerateliers zu den festen Programmpunkten der Romreisenden zählte, zeigt sich schließlich auch in der damals jungen Literaturgattung der Atelierführer. ${ }^{230}$ Neben den Adressen der Werkstätten enthalten sie Werbeanzeigen einzelner Künstler. Frühe Beispiele für Rom sind die zwischen 1830 und 1841 erschienenen Verzeichnisse von Heinrich (Enrico) Keller, der um 1803 selbst in Thorvaldsens Atelier gearbeitet hatte, Giuseppe Brancadoro und William Hawks Le Grice. ${ }^{231}$ All diese Führer sind alphabetisch nach Künstlernamen aufgebaut; ausgenommen sind Thorvaldsens Werkstätten, die jeweils an erster Stelle der Bildhauerateliers erscheinen. ${ }^{232}$ So führte Keller seinen früheren Meister nicht unter seinem Nachnamen, sondern einfallsreich unter seinem italianisierten Vornamen Alberto auf („A. Torvaldsen“), wodurch sich sein prominenter Platz auch alphabetisch zu legitimieren schien. ${ }^{233}$ Derweil widmete Le Grice gar die ersten fünfzig Seiten seines zweibändigen Werks Thorvaldsen, dem „ersten der lebenden Bildhauer“. ${ }^{234}$ Diese Ausführungen vermitteln einen exemplarischen Eindruck davon, in welchem Ausmaß die Künstler in Rom von der Tradition der Grand Tour abhängig waren. ${ }^{235}$ Den größten Teil der Besucher in Thorvaldsen Werkstätten machten Reisende aus Dänemark, Deutschland, England, Polen und Russland aus, was sich in den Bestellungen und Aufträgen an den Bildhauer aus diesen Regionen widerspiegelte.

230 Tesan 1991b, 226; Tesan 1998, 74.

231 Keller, E. 1830; Brancadoro 1834; Le Grice 1841. Zu Kellers Tätigkeit bei Thorvaldsen siehe Kofoed 2014c.

232 Siehe auch Kat. Nürnberg/Schleswig 1991, 536 - 537; Tesan 1991b, 226.

233 Keller, E. 1830, 92. Bei Keller sind zusätzlich zu den Künstlerateliers unterschiedlichster Art auch die verschiedenen Akademien, Geschäfte für Kunsthandwerk, spezielle Gottesdienste, Bibliotheken und Öffnungszeiten von Museen aufgelistet.

234 Le Grice 1841, 7: „We begin our ,Walks" with the studio of the first of living sculptors, Thorwaldsen.“ Siehe auch Kat. Nürnberg/Schleswig 1991, 537; Tesan 1991b, 226.

235 Siehe auch Tesan 1991b, 226 und 229 - 230; Zeitler 1991, 25 - 26; Junod 1998, 85. 


\section{Thorvaldsen auf Schloss Charlottenborg}

In der Kopenhagener Kunstakademie auf Schloss Charlottenborg war für Thorvaldsen bereits ab 1805 ein Atelier eingerichtet worden, obwohl sich der Künstler nicht dort befand, was die frühe Verehrung für den Bildhauer durch seine Landsleute veranschaulicht. ${ }^{236}$ Dieses Atelier übte schon während des lang ersehnten Besuchs des Bildhauers in Kopenhagen in den Jahren 1819 und 1820 große Anziehungskraft aus. Daran erinnert sich Thiele in seiner Biografie über den Künstler:

Ihn [Thorvaldsen] arbeiten zu sehen, war ein allgemeiner Wunsch der Vielen, deren erster Wunsch, ihn zu sehen, in Erfüllung gegangen war. [...] Alle Welt, Jeder, der sich Zutritt verschaffen konnte, strömte nun nach seinem Atelier in Charlottenburg, um diese neuen Arbeiten in Augenschein zu nehmen. ${ }^{237}$

Ähnlich den Werkstätten Thorvaldsens in Rom hatte auch sein Atelier in der Kopenhagener Kunstakademie bereits vor der Rückkehr des Bildhauers in seine nordische Heimat im Herbst 1838 den Wert einer allgemeinen Sehenswürdigkeit angenommen, wie etwa aus einem am 8. April 1838 verfassten Brief von Bødtcher an Thorvaldsen hervorgeht. ${ }^{238}$ Ebenso wenig beschränkte sich die Bestimmung des Künstlerateliers als Ausstellungs- und Repräsentationsraum auf Thorvaldsens studio grande in Rom: Dieselbe Funktion erfüllte nach seiner Rückkehr nach Kopenhagen seine Charlottenborger Werkstatt. Die von dieser erhaltenen Gemälde zeigen, dass Thorvaldsens Kopenhagener Atelier aus mindestens zwei Räumen bestand, wovon einer vermutlich mehr der bildhauerischen Arbeit und der andere mehr der Ausstellung diente. Mit der Einrichtung des letzteren Raumes war vermutlich bereits ab $1833 \mathrm{im}$ Zuge der Vergrößerung der für Thorvaldsen vorgesehenen Zimmer auf Charlottenborg begonnen worden. ${ }^{239}$ Anlass für diese Umgestaltung war sicherlich Thorvaldsens ab 1828 geäußerter und 1830 erstmals testamentarisch festgelegter Entschluss, seine sämtlichen Sammlungen seiner Geburtsstadt zu hinterlassen, worauf im nächsten Teil näher eingegangen wird.

236 Siehe bspw. Thiele 1831 - 1850, Bd. 4, 55; Thiele 1852-1856, Bd. 3, 40; Bjarne Jørnæs, in: Wilckens 1973, 181; Kat. Nürnberg/Schleswig 1991, 699; Jørnæs 2011, 205 - 216.

237 Thiele 1852-1856, Bd. 2, 22 - 23. Die genannten neuen Arbeiten waren die 1820 modellierten Basreliefs der Taufe Christi und des Abendmahls für die Kopenhagener Frauenkirche (Kopenhagen, Thorvaldsens Museum, Inv.-Nr. A557 und A558).

238 Ludvig Bødtcher an Bertel Thorvaldsen, 8. April 1836, TMA, Ref. m21 1836, nr. 17: „Hele Kiøbenhavn strømmer daglig til Charlottenborg [gemeint sind spezifisch Thorvaldsens Räume auf Schloss Charlottenborg] for at glæde sig ved Synet af dem i Udstillingstiden, [...].“

239 Zur Vergrößerung der für Thorvaldsen vorgesehenen Wohnung auf Schloss Charlottenborg siehe Kronberg Frederiksen 2014b. Jene Wohnung war bereits seit 1805 nach der Berufung Thorvaldsens auf die Bildhauereiprofessur an der Kopenhagener Kunstakademie für ihn freigehalten worden; siehe dazu bspw. Thiele 1831-1850, Bd. 4, 55; Thiele 1852-1856, Bd. 3, 40; Bjarne Jørnæs, in: Wilckens 1973, 181; Kat. Nürnberg/Schleswig 1991, 699; Jørnæs 2011, 205-216. 


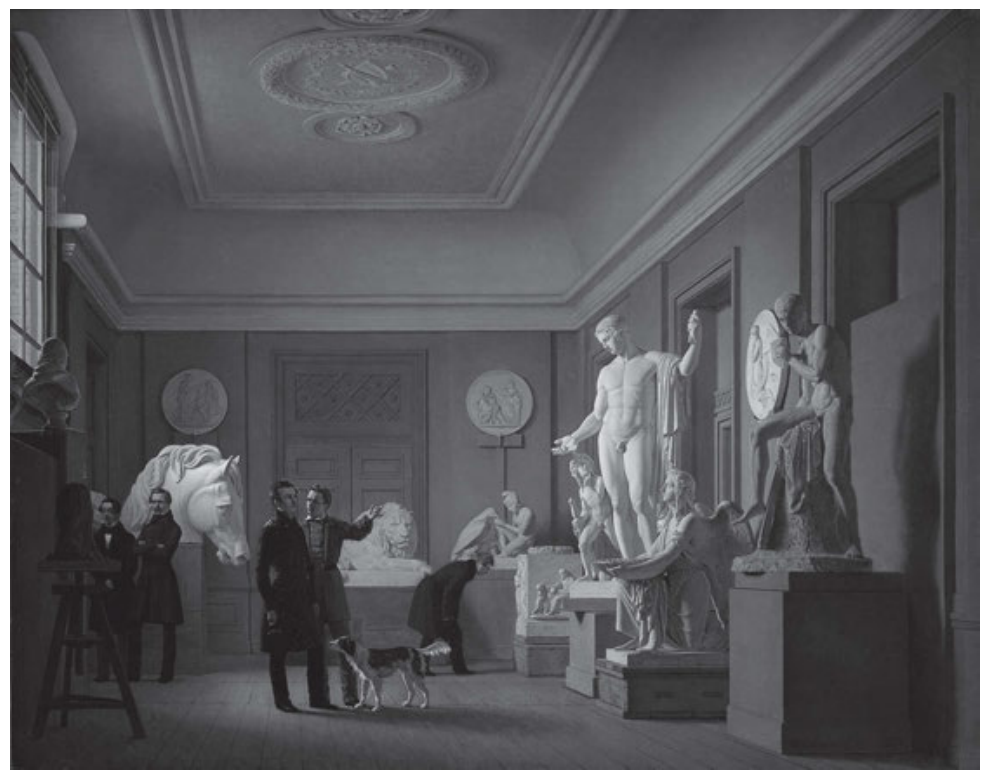

85_Johan Vilhelm Gertner, Thorvaldsens Atelier in der Kunstakademie Kopenhagen, 1836, Öl auf Leinwand, $64 \times 79 \mathrm{~cm}$, Kopenhagen, Statens Museum for Kunst (Inv.-Nr. KMS296)

Jenes als Ausstellungsraum für Thorvaldsens Werke eingerichtete Zimmer hielten Gertner und Peter Julius Larsen 1836 und 1837 in zwei Gemälden fest (Abb. 85 und 86). Zwischen orangefarbenen Wänden und unter einer leicht gewölbten Stuckdecke ist eine Reihe von originalgroßen Gipsabgüssen nach Thorvaldsens Skulpturen aufgestellt. Bei Gertner sieht man von links im Uhrzeigersinn die von hinten abgebildete Consalvi-Büste (1824), den spiegelverkehrten monumentalen Kopf des Pferdes für das Reiterstandbild des polnischen Fürsten Józef Poniatowski (1826 - 1827), den Liegenden Löwen (1825), Ganymed mit Jupiters Adler (1815-1817), den Taufstein für Brahetrolleborg (1805-1807), Mars und Amor (1810), den Knienden Taufengel (1827-1828) und Merkur (1818). Die Wände zieren die Relieftondi Hygieia und Äskulap (1808), Nemesis und Jupiter (1810) und Nacht (1815; Abb. 2). Durch die Wahl des Türdurchblicks als Darstellungsform liegt Larsens Fokus hingegen auf nur drei der ausgestellten Werke. Abweichend von Gertner erscheint bei Larsen das Relief der Nacht außerhalb der Türe passenderweise vollständig im Schatten. Auf der vordersten Bildebene befindet sich zudem die kleine, punktuell erhellte Figurengruppe Bacchus und Ariadne (1798) aus Thorvaldsens Frühwerk. An deren Sockel ist eine leere, aufgespannte Leinwand gelehnt, die auf die Funktion von Thorvaldsens Atelier als Studienraum für die jungen Künstler hinweisen könnte. Einige der bei Gertner und Larsen wiedergegebenen Werke stehen auf drehbaren Podien, wie sie ab den späten 1820er Jahren in den 
86__Peter Julius Larsen, In der Kunstakademie Kopenhagen (Thorvaldsens Atelier), 1837, Öl auf Leinwand, 71,5 $\times 53 \mathrm{~cm}$, Kopenhagen, Thorvaldsens Museum (Inv.-Nr. B452)

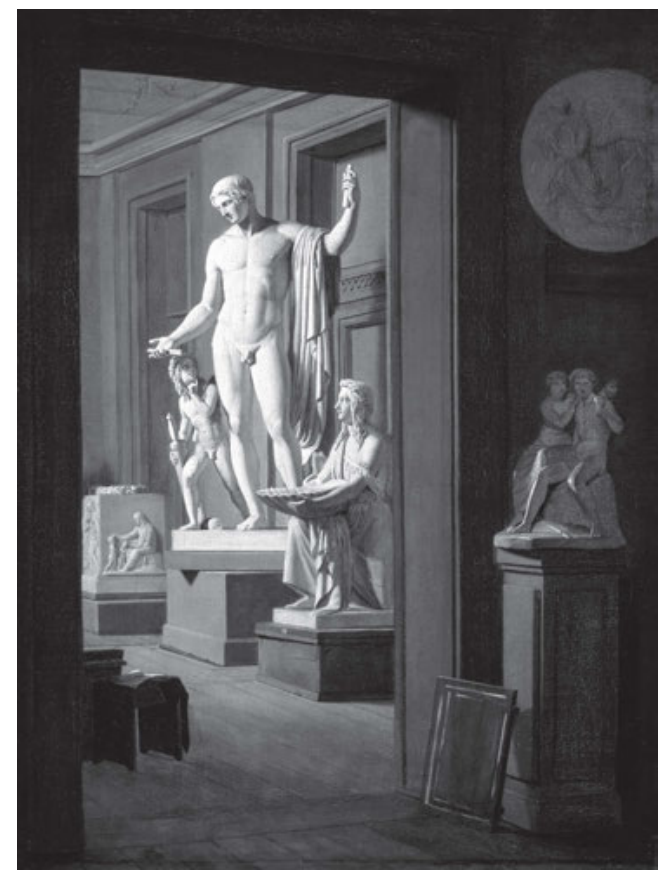

Ausstellungsräumen der Kopenhagener Kunstakademie eingeführt worden waren. ${ }^{240}$ Während bei Gertner einzig das auf einem Kavalett platzierte, mit einem Tuch bedeckte Tonmodell einer Büste das dargestellte Interieur als Werkstatt zu erkennen gibt, veranschaulichen die anwesenden Betrachter die zusätzliche Funktion des Ateliers als Ausstellungsraum.

Das einzige Gemälde von Thorvaldsen in seinem Atelier auf Charlottenborg scheint das 1840 entstandene Bild von Richardt zu sein (Abb. 76). Hier sitzt der Bildhauer sinnierend inmitten einer Auswahl seiner Schöpfungen. Unter den Gipsmodellen in reduzierter und voller Größe sind beispielsweise sein Selbstbildnis mit der Statue der Hoffnung (1839; Abb. 32), zwei Abgüsse der Hebe (1816), das Relief der Grazien, Amors Lied lauschend (1821), Mars und Amor (1810), der Kniende Engel (1839), die Büste des Dichters Ludvig Holberg (1835), die Hirtin mit Amorettennest (1831) und die Christus-Statue (1821; Abb. 3) deutlich zu erkennen. Auf den Holzgestellen neben Thorvaldsen liegen seine Werkzeuge, während er in der linken Hand ein Modelliereisen hält. Die Treppe im Hintergrund führte vom Atelier in die Wohnräume des Bildhauers. ${ }^{241}$ 
Thorvaldsen hat in Richardts Darstellung dieselbe Machtpose eingenommen wie auf den Gemälden von Blunck und auf Neubourgs Daguerreotypieporträt (Abb. 58-60 und 69). ${ }^{242}$ Es wurde bereits erwähnt, dass der Bildhauer oft selbst bestimmte, wie er in Porträts dargestellt wurde. Allerdings blieb es nicht immer bei der mündlichen Mitsprache: Nach verschiedenen Überlieferungen korrigierte der Bildhauer in Entstehung begriffene Darstellungen von sich gelegentlich eigenhändig. ${ }^{243}$ Einer der Maler, der solche künstlerischen Eingriffe erfuhr, war Richardt. Über eine Sitzung für ein nicht mehr bekanntes Porträt berichtet die Baronin Stampe im Manuskript zu ihren Memoiren, dass Thorvaldsen sein Bildnis missfiel und Richardt um eine Korrektur bat. Als dieser seine Darstellung trotz Thorvaldsens Aufforderung nicht überarbeitete, soll der Bildhauer sein Porträt schließlich mit dem Finger verwischt und gedroht haben, das Gemälde von der Polizei entfernen zu lassen. ${ }^{244}$ Er fühlte sich offenbar durch Richardt ungerecht behandelt, da er den Maler zuvor gefördert hatte. ${ }^{245}$ Während Thorvaldsens Unterstützung jüngerer dänischer Künstler in Form von Bilderkäufen üblicherweise als noble und selbstlose Geste des Bildhauers gelobt wurde, beklagte sich dieser hingegen bei Stampe über die fehlende Loyalität seiner jüngeren Kollegen, obwohl er „ihre schlechten Arbeiten kaufe“.246

Die zitierte Anekdote ist Teil des von unbekannter Hand vorgenommenen Transkripts von Stampes Manuskript, während sie in der publizierten Fassung der Erinnerungen der Baronin nur teilweise abgedruckt ist. ${ }^{247}$ Die Herausgeberin Rigmor Stampe begründet ihre Weglassung von Teilen der originalen und der transkribierten Version der Memoiren im Vorwort mit einem geringen Interesse für die Leserschaft. ${ }^{248}$ Ein deutlich wahrscheinlicherer Grund für die unvollständige Veröffentlichung jener Anekdote ist jedoch das darin gezeichnete Bild Thorvaldsens, das dem Topos des bescheidenen und

242 Siehe dazu Kap. II.1 und II.3.

243 Wilckens 1875, 43; Baronesse Stampes Erindringer 1912, TMA, Transkript des Manuskripts zu Stampes Memoiren, Mappe Nr. 6, 8-10; Wilckens 1973, 104. Siehe auch Kap. II.3.

244 Baronesse Stampes Erindringer 1912, TMA, Transkript des Manuskripts zu Stampes Memoiren, Mappe Nr. 6, 8 - 10. Siehe auch Berner 2005, 88. Bei Trier 1903, 207, ist die Lithografie eines anderen Thorvaldsen-Porträts von Richardt abgebildet, jedoch bleibt unklar, ob sich die oben wiedergegebene Anekdote um dieses Bild drehte.

245 Baronesse Stampes Erindringer 1912, 224. In der Sammlung von Thorvaldsens Museum in Kopenhagen befindet sich neben dem hier besprochenen ein um 1839 entstandenes Gemälde von Richardt, das eine in Porträtmalerei unterwiesene Klasse von Kunststudenten in der Kopenhagener Akademie zeigt (Inv.Nr. B284).

246 Baronesse Stampes Erindringer 1912, 224: „[...] og at jeg kiøber deres daarlige Arbeider [...].“

247 Das mit Bleistift verfasste, durch Streichungen, Überschreibungen und Einschübe teilweise kaum lesbare Originalmanuskript der Baronin sowie ein Transkript von unbekannter Hand befinden sich im Archiv in Thorvaldsens Museum. Dabei fällt auf, dass die ursprünglichen Aufzeichnungen sowohl im Transkript als auch in der veröffentlichten Fassung teilweise verändert und gekürzt wurden. Bislang wurden die drei Versionen von Stampes Memoiren noch nicht im Detail verglichen.

248 Baronesse Stampes Erindringer 1912, X. 
freundlichen Mannes widerspricht. Für den vorliegenden Kontext ist indessen gerade die Überreaktion des Künstlers auf ein entstehendes Porträt von sich aufschlussreich, da sie offensichtlich macht, dass er selbst durchaus großen Wert auf sein öffentliches Bild legte. In demselben Zusammenhang sei ferner Thorvaldsens eigene Signatur auf seinem durch Friedrich von Amerling geschaffenen Porträt von 1843 erwähnt, mit der er dieses Bild von sich gleichsam autorisierte. ${ }^{249}$

Zusammenfassend lässt sich konstatieren, dass für die Festigung von Thorvaldsens Persona und seine Sichtbarkeit auf dem anonymen Kunstmarkt einerseits Porträts von ihm und druckgrafische Vervielfältigungen seiner Werke eine tragende Rolle spielten, andererseits aber auch seine öffentlich zugänglichen Ateliers in Rom und Kopenhagen: Nicht nur entwickelten sich die Ateliers durch ihre Ausstellungsfunktion rasch zu Sehenswürdigkeiten unter den Kunstinteressierten; sie waren zugleich die zentralen physischen Orte von Thorvaldsens Selbstinszenierung sowie der Huldigung durch Zeitgenossen kurz: des Genie- und celebrity-Kults um den Bildhauer.

\section{Das Atelier als (inszenierter) Rückzugsort des Künstlergenies}

Thorvaldsens zahlreiche soziale Verpflichtungen sowie die unzähligen Besucherinnen und Besucher in seinen öffentlich zugänglichen Ateliers in Rom und Kopenhagen führten dazu, dass der Bildhauer gemäß Thiele „fast immer in einer Art Belagerungszustand“ lebte. ${ }^{250}$ In der Folge hatte er wiederholt das Bedürfnis, sich zum ungestörten Arbeiten in seine privaten vier Wände oder an abgelegene Orte zurückzuziehen. Im Folgenden werden ebendiese Rückzugsorte als Symptome des Künstler- und celebrity-Kults um Thorvaldsen näher betrachtet. Dabei stellt sich die Frage, inwiefern sich jener Rückzug mit Thorvaldsens Bemühungen um sein öffentliches Bild und seine allgemeine Sichtbarkeit verbinden lässt oder umgekehrt gar zu ihnen beitrug. Wie sich zeigen wird, war Letzteres der Fall, indem der Rückzug des Bildhauers in der Regel nur ein vordergründiger war und in Wirklichkeit Teil seiner Selbstdarstellung sowie der Stilisierung und Inszenierung des Künstlers durch die Zeitgenossen bildete.

249 Das Gemälde befindet sich im Besitz des Fürsten von Liechtenstein in Vaduz (Inv.-Nr. GE353). Siehe dazu auch Schulten 2008a, 34.

250 Thiele 1852-1856, Bd. 2, 108 und 130. Siehe auch Springer, P. 1991, 213. 


\section{Inszenierte Rückzugsorte I: Die Casa Buti in Rom}

Thorvaldsens täglichen Gang von seiner Wohnung an der Via Sistina zu seinen Ateliers an der Piazza Barberini beobachtete Bødtcher, der zwischen 1824 und 1835 im selben Quartier lebte. ${ }^{251}$ Diesen Eindruck verarbeitete er im Gedicht „Piazza Barberina“ von 1830, wo es gegen Ende übersetzt heißt: „Er kommt von seinem stillen Künstlerheim, / Wo in der Früh sein ganzer Genius gewesen ist, / Und in seiner Hand ist noch etwas vom Ton, / Den er rege drückt, während er fortschreitet." ${ }^{252}$

Aus Bødtchers Gedicht wird deutlich, dass Thorvaldsen nicht nur in seinen offiziellen Werkstätten, sondern auch in seiner Privatwohnung arbeitete. Dabei handelte es sich um die Räume, die Thorvaldsen seit Mai 1804 in der Casa Buti gemietet hatte. Diese bekannte, von der Signora Buti geführte Künstlerpension lag an der Via Felice, der heutigen Via Sistina, zwischen der Spanischen Treppe und der Piazza Barberini. ${ }^{253}$ Thorvaldsen war bereits im Frühjahr 1798 an jene Straße gezogen, nachdem er im ersten Jahr seines Romaufenthalts an der nahe gelegenen Via Babuino gewohnt und gearbeitet hatte. ${ }^{254}$ In den Jahrzehnten um 1800 sammelten sich im Quartier um diese Straßen Künstler und Romreisende aus ganz Europa, insbesondere jedoch aus dem deutschen und skandinavischen Raum. ${ }^{255}$ Ferner befanden sich in jener Gegend das oben erwähnte Caffè Greco sowie das von den Nazarenern bewohnte Kloster Sant'Isidoro. ${ }^{256}$

In der Casa Buti wohnte Thorvaldsen abwechselnd mit weiteren Künstlern unter einem Dach, darunter den Bildhauern Rauch, Freund und Wolff, dem Maler Eckersberg sowie den Brüdern Schadow. ${ }^{257}$ Infolge von Thorvaldsens Rückkehr nach Kopenhagen 1838 übernahm sein Schüler Galli sowohl sein Appartement als auch die Leitung seiner Werkstätten in Rom. ${ }^{258}$ Nachdem die Zusammenarbeit zwischen Thorvaldsen und Galli

251 Jørnæs 1991c, 88.

252 Ludvig Bødtcher, „Piazza Barberina“, 1830, zit. nach Brøndum-Nielsen 1940, 126: „Han kommer fra sit tause Kunstnerhjem, / Hvor tidligt alt hans Genius har været, / Og i hans Haand er endnu Lidt af Leret, / Som travlt han krammer, altsom han gaaer frem; [...].“ Die bei Jørnæs 1991c, 88, wiedergegebene deutsche Übersetzung aus der heutigen Zeit verwandelt Thorvaldsens „Künstlerheim“ (kunstnerhjem) in eine „Künstlerklause“ und passt damit den im dänischen Originalwortlaut wertneutrale Begriff klar dem damaligen Geniekult um den Bildhauer an.

253 Hartmann 1963, 2; Jørnæs 1989c, 29; Jørnæs 1991c, 85 und 88; Jørnæs 2011, 116-118. Das heute nicht mehr in der ursprünglichen Form existierende Haus war 1781 von Anna Maria Butis Ehemann, dem 1808 verstorbenen Architekten Camillo Buti, erworben worden; Bott, G. 1977, 51.

254 Jørnæs 1991c, 85; Jørnæs 2011, 116. Zwischen 1800 und 1804 wohnte Thorvaldsen zusammen mit dem Maler Josef Anton Koch in der ebenfalls an der Via Sistina gelegenen Pension von Orsola Polverini Narlinghi.

255 Jørnæs 1991c, 85 und 88; Jørnæs 2011, 69.

256 Bott, G. 1977, 51; Jørnæs 1989c, 29; Jørnæs 1991c, 85 und 88; spezifisch zum Caffè Greco siehe Busk-Jepsen 2014.

257 Jørnæs 1991c, 85; Jørnæs 2011, 117.

258 Jørnæs 1991c, 91-92; Tesan 1998, 68. 
im Februar 1842 im Streit beendet wurde, bezog Thorvaldsen seine ehemalige Wohnung gegen Ende seines Romaufenthalts in den Jahren 1841 und 1842 erneut, um mithilfe des Bildhauers Carl Frederik Holbech und des Malers und Kunstagenten Johan Bravo seine noch dort befindlichen Werke und persönlichen Gegenstände für den Transport nach Kopenhagen einzupacken. ${ }^{259}$

Andersen hat seine Impressionen der Casa Buti nicht nur in den erwähnten Zeichnungen hinterlassen, sondern auch in einer Erinnerung an seinen Besuch in Thorvaldsens Privaträumen. Wie bereits ausgeführt wurde, war der Dichter am 18. Oktober 1833 in Rom angekommen, am Tag von Raffaels zweiter Bestattung im Pantheon. ${ }^{260}$ Unter dem Eindruck dieses Ereignisses modellierte Thorvaldsen ein Reliefdenkmal für den bewunderten Renaissancemaler, während dessen Erschaffung Andersen den Bildhauer bei seinem Besuch in der Casa Buti vorfand (Abb. 63). ${ }^{261}$ Aus Andersens Memoiren geht hervor, dass man Thorvaldsens private Räume in der Casa Buti nicht nur besuchen, sondern dort den Bildhauer arbeiten sehen konnte. In der Tat zeichnete und modellierte Thorvaldsen erste Entwürfe zu neuen Werken weniger in einem der eigentlichen Ateliers als in seiner Wohnung. ${ }^{262}$

Folglich trügt die Vorstellung von Thorvaldsens Appartement als einem stillen Rückzugsort, denn die Privaträume des Bildhauers waren gleichfalls allen Interessierten zugänglich, sofern diese eine Visitenkarte vorzeigen konnten und nicht gerade jemand für ihn Modell saß ${ }^{263}$ Dementsprechend existieren nicht nur von Thorvaldsens offiziellen Werkstätten zahlreiche zeitgenössische Erwähnungen, sondern auch von seiner Wohnung an der Via Sistina. Eine zentrale Quelle ist dabei der Bericht der Malerin Seidler, die zwischen 1818 und 1823 in Rom lebte:

Im ersten derselben [Zimmer] war ein kleines Atelier; Staffeleien mit angefangenen Basreliefs standen darin umher, der Fußboden, die Tische und Stühle waren mit kleinen Figuren bedeckt; nur mit Mühe fand man einen Stuhl zum Sitzen, nirgend etwas, das einem Comfort ähnlich war; weder ein Bücherbrett, noch Schreibzeug, noch Schreibmaterialien. Das Schlafzimmerchen war besonders klein; trotzdem stand auch in diesem dicht vor des Künstlers Bett ein Modellirstuhl mit einem angefangenen Bildwerke darauf, an welchem er sogleich nach dem Aufstehen zu arbeiten pflegte. Hinter diesem Zimmer befand sich ein etwas größeres, die schönste Aussicht gewährendes Gemach, mit Gemälden geschmückt, durch deren Ankauf Thorwaldsen bedrängte Künstler unterstützt hatte; auf den Tischen sah man in bunter Unordnung allerlei Ausgrabungen, Vasen, Münzen, Bronzen usw. Aus diesem Raume führte eine

260 Siehe dazu Kap. II.1.

261 Andersen 1961, 152. Zum Reliefdenkmal für Raffael siehe auch Kap. II.1.

262 Wittstock 1975, 111; Helsted 1977, 10; Helsted 1982a, 49; Tesan 1991b, 232; Jørnæs 2011, 119. Siehe auch Kap. III.1.

263 Siehe bspw. Peder Brønnum Scavenius, 28 März 1819, RA, Peder Brønnum Scavenius’ privatarkiv (Digitalisat im TMA); Wittstock 1975, 111; Jørnæs 1991c, 87; Wittstock 1991, 208. 
Thür zu einer größeren, gewöhnlich unbenutzten Treppe, neben der sich eine Marmortafel befand, in welcher das Datum eines Besuches des Papstes Pius VII. bei Thorwaldsen eingegraben war. ${ }^{264}$

Nachdem Thorvaldsens Wohnung zunächst drei Zimmer gezählt hatte, kamen 1824 vier weitere hinzu. ${ }^{265}$ Die detaillierteste Beschreibung von Thorvaldsens Privaträumen stammt von Thiele, der den Bildhauer in jenem Jahr in der Casa Buti besuchte. ${ }^{266}$ Dabei kommen wie in Seidlers Erinnerung die Multifunktionalität und der öffentliche Charakter von Thorvaldsens Appartement deutlich zum Ausdruck, wenn etwa auf die verschiedenen Arbeitsmöglichkeiten, Sammlungsstücke sowie die Tafel mit den Namen der Besucherinnen und Besucher hingewiesen wird. Anders als bei Seidler - jedoch ähnlich wie in Bødtchers oben zitiertem Gedicht „Piazza Barberina“ - erhält bei Thiele auch die damalige Verehrung Thorvaldsens als Künstlergenie seinen Platz, indem eines der Zimmer als „Asyl während der stillen Besuche der Musen und Grazien“ bezeichnet wird:

Wenn man die schmale Treppe hinaufgestiegen ist und recht stark an eine mit den Namen der vielen Besuchenden beschriebene Thür gepocht hat, so darf man erwarten, dass sie von dem Künstler selbst geöffnet wird, denn in Allem, was die Aufwartung betrifft, ist er sein eigener Bedienter. [...]

Schon die Wände des ersten Zimmers, welches doch öfters nur als Atelier gebraucht wird, sind von vielen schönen Gemälden bedeckt, grösstentheils von neuern Meistern und jüngern Künstlern, die in Thorwaldsen einen eben so freudigen Gönner ihrer Kunst, als bereitwilligen Helfer gefunden haben, wo er das Talent unter dem Drucke der niedern Verhältnisse seufzen sah.

In diesem Zimmer hat der Künstler einen Schrank voll schöner griechischer Vasen und zwei Bücherschränke für seine Bibliothek. Auf diesen drei Schränken hat er später eine Sammlung ägyptischer Kunstwerke aufgestellt, die er vor einigen Jahren kaufte. Rechts steht ein Schrank mit griechischen Münzen, Pasten, geschnittenen Steinen u. dgl. und auf demselben eine Anzahl auserlesner Terracotten.

Unter dem grossen Studiofenster nach der Strasse steht ein Tisch mit Marmorfragmenten, dessen Schubladen eine Sammlung von Bronzen enthalten; in der Mitte des Zimmers ein Tisch und unter diesem seine Sammlung von Kupferstichen. [...]

Links führt eine Thür in ein kleines Zimmer, dessen Wände mit Blättern aus der Boisseree’schen Sammlung geschmückt sind, welche er abwechselnd in die Rahmen setzt. Auf einem kleinen Tische von Fichtenholz stehen mehre seiner Skizzen aufgestellt, und in einer Ecke ein alter Kasten mit hingeworfnen Papieren, unter denen er dann und wann längst bei Seite gelegte Handzeichnungen und Entwürfe zu Arbeiten hervorsucht, die gelegentlich aus dem Staube der Niedrigkeit zu unsterblicher Ehre emporsteigen. Dieses Zimmer ist sein Asyl während der stillen Besuche der Musen und Grazien; hier zaubert er in früher Morgenstunde Götter und Heroen aus einem in der andern Ecke stehenden Kübel mit nassem Thon hervor.

In einer andern kleinen Kammer, welche an diese stösst, werden Skizzen und Modelle aufbewahrt, und an den Wänden sieht man eine Anzahl Zeichnungen, die er mit grossen Kosten nach seinen eignen Ar-

264 Erinnerungen der Malerin Louise Seidler 1922, 122. Siehe auch Jørnæs 1991c, 86; Jørnæs 2011, 117 - 118. Weitere Erwähnungen von Thorvaldsens Wohnung finden sich bspw. bei Eduard Meissner, August September 1810, zit. bei Wittstock 1975, 320; M. Fayot, Aufsatz in L'Artiste, zit. bei de Loménie 1845, 17 - 18.

265 Jørnæs 1991c, 86-87.

266 Thiele $1832-1834$, Bd. 2, 74-76. 
beiten hat ausführen lassen, und von denen verschiedene in spätern Jahren in schönen Kupferstichen aus den Händen ausgezeichneter Künstler hervorgegangen sind.

Aus dem erstgenannten Zimmer tritt man in den sogenannten Saal, dessen Wände dicht mit Gemälden behängt sind. [...] An der einen Seitenwand steht der [sic] Sofa, über welchem man das Portrait S.M. König Ludwigs von Baiern, von Stieler gemalt, sieht, welches Thorwaldsen von diesem hohen Gönner zum Geschenk erhalten hat. An der entgegengesetzten Wand steht eine Schatulle, in der der Künstler ausser seinen wichtigsten Papieren die ausgesuchtesten antiken Fragmente in Bronze verwahrt. Neben den genannten Möbeln und neben dem Kamin an der mittelsten Wand sind antike Marmorbüsten griechischer Philosophen hingestellt. [...]

Links führt eine andere Thür aus dem Saal in das Schlafgemach unsers Künstlers. [...] An den Wänden befinden sich hier unter den ausgezeichnetsten seiner Cabinetstücke schöne Zeichnungen von Kock [Koch?] und von ihm selbst nach Carstens; über dem Bette hängt eine kleine Handzeichnung von Rafael. ${ }^{267}$

Bei der von Thiele genannten „Boisseree'schen Sammlung“ handelt es sich um eine von den Brüdern Sulpiz und Melchior Boisserée ab dem frühen 19. Jahrhundert zusammengetragene Sammlung von deutschen und niederländischen Gemälden des Mittelalters und der Renaissance. ${ }^{268}$ Thorvaldsen besaß eine große Anzahl von Lithografien und Kupferstichen nach diesen Werken, die in Thieles Beschreibung seiner Wohnung angedeutet sind und sich heute im Museum des Bildhauers in Kopenhagen befinden. Aus Thieles Bericht wird ferner deutlich, dass Thorvaldsen Nachzeichnungen nach seinen eigenen Werken aktiv förderte und damit bewusst zur Verbreitung seiner Schöpfungen beitrug. Schließlich nennt Thiele das um 1821/1822 von Stieler gemalte Porträt Ludwigs I. von Bayern sowie die damals Raffael zugeschriebene Zeichnung der Madonna und Kind, die beide im Kapitel II.1 erwähnt wurden.

Im Gegensatz zu den zahlreichen schriftlichen Zeugnissen von Thorvaldsens Wohnung in der Casa Buti scheint nur Ward den Bildhauer in seinem privaten Atelier dargestellt zu haben (Abb. 77). ${ }^{269}$ Die bereits im Kapitel II.3 eingeführte Karikatur existiert in drei leicht abweichenden Versionen: Die Originalfassung sowie eine etwas abgeänderte und vereinfachte Pause von 1838 werden in Thorvaldsens Museum aufbewahrt, während sich eine kolorierte Version von 1839 auf Schloss Frederiksborg in Hillerød befindet. ${ }^{270}$ In

Thiele 1832-1834, Bd. 2, 74 - 76. Siehe auch Bott, G. 1977, 53 - 55; Jørnæs 1991c, 87; Jørnæs 2011, 118.

Kopenhagen, Thorvaldsens Museum (Inv.-Nr. D1862 und D1742). Im Original sind Spuren einer früheren Skizze zu sehen, die eine menschliche Figur andeuten und beinahe wie eine mise en abyme wirken. Zur kolorierten Zeichnung: Edward Matthew Ward, Karikatur von Thorvaldsen im Atelier, 1839, Hillerød, Det Nationalhistoriske Museum på Frederiksborg Slot. Diese Zeichnung enthält vereinzelte Ergänzungen gegenüber den beiden Versionen in Thorvaldsens Museum, wie den Sockel unter der entstehenden Männerstatue oder das Modellierholz in der linken Hand des Bildhauers. Im physischen Bildarchiv von Thorvaldsens Museum befindet sich ferner die Fotografie eines ebenfalls Ward zugeschriebenen Gemäldes des Bildhauers im Atelier, jedoch ohne karikierende Züge; Informationen zu diesem Gemälde sind keine bekannt. 
allen drei Fassungen ist Thorvaldsen im Profil dargestellt und trägt einen dicken Mantel, Strumpfhosen und Hausschuhe. Die Zeichnungen karikieren seine Gesichtszüge, indem sie seine spitze Nase, sein markantes Kinn und sein berühmtes weißes, schulterlanges Haar übermäßig betonen. Außerdem trägt der Bildhauer seine Brille, die auf repräsentativen Porträts nicht zu sehen ist. Die dünnen Beine des fast Siebzigjährigen unterstreichen den karikierenden Charakter von Wards Zeichnungen zusätzlich, indem sie in einem starken Kontrast zu den muskulösen Beinen der Männerstatue auf dem Modellierbock stehen. ${ }^{271}$ Wards Zeichnungen kombinieren mit dem Profilporträt und der Karikatur zwei gerade im Kontext der damaligen celebrity-Kultur und ihres Stilisierungsbedürfnisses zentrale - Bildformen, die beide die dargestellte Person anhand weniger (in der Karikatur überspitzter) Merkmale erkennen lassen. ${ }^{272}$

Alle drei Zeichnungen sind am unteren Rand mit Wards Initialen, der Datierung und dem Motiv - „Thorwaldson in his study“ - bezeichnet. ${ }^{273}$ Die geringe Größe des dargestellten Raumes und die Bilder an dessen Wand deuten weniger auf eine der offiziellen Werkstätten als auf Thorvaldsens Atelier in der Casa Buti hin. ${ }^{274}$ Angesichts der in Wirklichkeit vielen Besucher auch in Thorvaldsens Wohnung handelt es sich möglicherweise auch bei dem intimen Charakter von Wards Zeichnung um einen karikierenden Hinweis auf die gezielte, öffentliche Inszenierung von Thorvaldsens Privaträumen als angeblichen Rückzugsorten des Künstlergenies.

Wards Karikatur sowie Seidlers und Thieles Beschreibungen von Thorvaldsens Zimmern in der Casa Buti veranschaulichen deren simultane Funktion als Wohnung, Arbeitsstätte und Kunstsammlung. Dass auch diese Räumlichkeiten als Ausstellungsort dienten, demonstrieren die museale Präsentation von Thorvaldsens Sammlungsstücken und eigenen Werken sowie die Besuchertafel. Thorvaldsens Sammeltätigkeit verdeutlicht schließlich, dass er als Bildhauer einerseits und Käufer von Kunst, Antiken und Büchern andererseits eine Doppelrolle im freien Kunstmarkt einnahm. ${ }^{275}$

\section{Thorvaldsen als Kunstsammler}

Über seine Ankäufe scheint der Bildhauer nicht Buch geführt zu haben, weshalb die Entstehungsgeschichte der bei seinem Tod deutlich über 10.000 Objekte umfassenden Kunstund Antikensammlungen im Dunkeln bleibt. ${ }^{276}$ Bekannt ist jedoch, dass Thorvaldsen je-

271 Siehe auch Berner 2005, 91-92.

272 Siehe dazu auch die Einleitung des vorliegenden Buches sowie Kap. I.2.

273 Die Inschriften weichen leicht voneinander ab: „E. M. W. May 1838 / Thorwaldson in his study from memory“ (Originalfassung), „Thorwaldson in his study at Rome. E. M. W. 1838“ (Pause) und „E. M. W. 1839 / Thorwaldson in his Study at Rome. Sketched from memory“ (kolorierte Zeichnung).

274 Siehe auch Kat. Nürnberg/Schleswig 1991, 582.

275 Siehe auch Springer, P. 1991, 218.

276 Siehe bspw. Helsted 1982b, 61; Melander 1991, 296 -297; Miss 1991, 341; Miss 2008, 29 und 33; Zahle 2010, 91. 
weils am Sonntagmorgen Kunsthändler empfing oder sich zur Piazza Montanara begab, wo Bauern und Hirten ihre Zufallsfunde anboten. Ebenfalls sonntags waren Thorvaldsens Sammlungen fest für das Publikum geöffnet. ${ }^{277}$ Dementsprechend erinnerte sich der Geistliche Zeuthen in einem Rückblick auf die Jahre 1833/1834, dass die Dänen in Rom sonntagvormittags jeweils zu Thorvaldsen gingen, um sowohl dessen in Entstehung begriffene Arbeiten als auch die Gemäldesammlung zu sehen. ${ }^{278}$ Besonders Letztere, bei der es sich um die größte Sammlung moderner Malerei in Rom gehandelt haben dürfte, galt bei den Romreisenden als Attraktion. ${ }^{279}$ Ein großer Teil dieser Sammlung umfasste italienische oder italianisierende Landschaften und Szenen aus dem dortigen Volksleben, daneben einige Historien-, religiöse und mythologische Gemälde sowie Porträts. ${ }^{280}$ Zahlreiche Gemälde stammten von jüngeren oder bedürftigen dänischen und deutschen Künstlern, wie auch aus Seidlers und Thieles oben zitierten Beschreibungen hervorgeht. Bis heute gilt Thorvaldsens Sammlung als die wohl bedeutendste während der ersten Hälfte des 19. Jahrhunderts angelegte und nach wie vor bestehende Privatsammlung von Gemälden der deutschen Romantik. ${ }^{281}$

Eine detaillierte, allerdings rein typologische Beschreibung von Thorvaldsens Bildersammlung hat der Historiker Alfred Reumont in seinen 1840 publizierten Römischen Briefen von einem Florentiner überliefert. Der Bericht ist entlang den Bildgattungen gegliedert, wobei die Stillleben sowie die Präsentationsweise der Gemälde in Thorvaldsens Räumen unerwähnt bleiben. Beginnend bei der "Geschichtsmalerei“ und der spärlich vertretenen „moderne[n] religiöse[n] teutsche[n] Schule“, führt Reumont „[n]ur im Vorbeigehen“ zu den Porträts, unter denen er Vernets Darstellung von Thorvaldsen besonders hervorhebt (Taf. IV). ${ }^{282}$ Weiter erwähnt er Werke der Genremalerei, die „hier wie in allen Sammlungen neuerer Gemälde vorherrschend“ sei, wobei er unsicher ist, „ob es so sehr die unbewußte Richtung unserer Kunst als der sogenannte Geschmack des Publicums ist, oder ob beide wirklich Hand in Hand gehen ${ }^{\text {“283 }}$ Den Abschluss von Reumonts Beschreibung bilden die Sammlungen „römischer Scenen“ und der Landschaftsmalerei. ${ }^{284}$ Für Letztere fand bereits Morse im April 1830 lobende Worte, „da ich nicht erwartet hatte, so

Von Raczynski 1836 - 1841, Bd. 3, 276; Helsted 1982b, 60; Jørnæs 2011, 209. Für weitere zeitgenössische Erwähnungen von Thorvaldsens Sammlungen siehe bspw. de Loménie 1845, 18; Johann Scholl, 4. Januar 1835, zit. bei Bott, G. 1991, 147. Zeuthen 1870, 499.

Bott, G. 1977, 52; Springer, P. 1991, 218. Thorvaldsens Gemäldesammlung umfasste bei seinem Tod 1844 rund 360 Werke. Davon stammten laut Kofoed 2015a etwas mehr als 250, laut Bott, K. 2016 gar rund 280 von zeitgenössischen, überwiegend skandinavischen und deutschen Künstlern. Siehe auch Jørnæs 2011, 208 - 209; Kofoed 2015a.

281 Thimann 2018, 71.

282 Reumont 1840, I, 172, 175 und 178.

283 Ebd., 179.

284 Ebd., 180-190 (Zitat: 180-181). 
gute Landschaftsmaler unter den Modernen in Italien zu finden - sie waren jedoch keine Italiener“ ${ }^{285}$ Mit diesem Zusatz verwies Morse auf die vielen Landschaftsbilder nordeuropäischer Künstler in Thorvaldsens Sammlung, darunter mehrere von Catel, Johan Christian Clausen Dahl, Koch, Jens Juel, Johann Christian Reinhart oder Abraham Teerlink.

Reumont bewertet die Gemälde bei Thorvaldsen als „die einzige Sammlung neuerer, welche irgendwie in Betracht kommen kann“.286 Als ein Grund für sein Urteil nennt er die taktische Sammeltätigkeit des Bildhauers, dank der man „den Fortgang dieser Kunst [der Malerei] während der letzten 40 Jahre ziemlich vollständig verfolgen“ könne. ${ }^{287}$ Dabei ist anzumerken, dass Thorvaldsen zwar zeitgenössische Gemälde in großer Zahl und aus allen Gattungen erwarb; inwiefern sein Sammeln als taktisch bezeichnet werden kann, ist hingegen fraglich, da er seine Erwerbungen nicht dokumentierte und die Qualität der Werke sehr unterschiedlich ist. Insofern scheint es sich zu einem wesentlichen Teil um wenn auch äußerst umfangreiche - Zufallskäufe gehandelt zu haben. Ferner erhielt Thorvaldsen auch immer wieder Gemälde und andere Sammlungsstücke als Pfand für von ihm vergebene Darlehen. ${ }^{288}$ Eine derart umfassende Sammlung wie jene des dänischen Bildhauers war laut Reumont nur in Rom möglich, dem „Mittelpunkt, in welchem die von allen Seiten hervorbrechenden Strahlen der modernen Kunst sich wenigstens zeitlich concentriren“289 Schließlich waren es nicht zuletzt „Thorwaldsen's hohe Stellung als Künstler" sowie sein rund vier Jahrzehnte dauernder Romaufenthalt, die es ihm ermöglichten, Gemälde „von Meistern zu erhalten, die man sonst nicht leicht in den Salons von Privatleuten antrifft“. ${ }^{290}$ Thorvaldsen verfügte also über eine Kunstsammlung, die zur Attraktivität eines Besuchs seiner Privaträume in der Casa Buti beitrug und damit wiederum seine eigene Sichtbarkeit und Bekanntheit steigerte.

\section{Inszenierte Rückzugsorte II: Montenero}

Im Hinblick auf seinen Erfolg als Künstler war Thorvaldsen auf eine allgemeine Sichtbarkeit auf dem Kunstmarkt angewiesen - und genoss die ihm zuteil gewordene Aufmerksamkeit zweifellos, worauf seine gezielte Selbstdarstellung und die Öffnung sowohl seiner offiziellen Ateliers als auch seiner Privaträume hindeuten. Zugleich beklagte er sich bei seinen Freunden darüber, dass er wegen der vielen Besuche und sozialen Verpflichtungen kaum zum Arbeiten komme. Es scheint bei Künstlern in Rom nicht unüblich gewesen zu

Samuel F. B. Morse, 19. April 1830, zit. nach Prime 1875, 204: „He was at home, and showed me his private collection of pictures, some ancient, but mostly modern, and very fine, in landscape particularly, for I was unprepared to find so good landscape-painters among the moderns in Italy - they were not Italians, however.“

287 Ebd.

288 Thimann 2018, 73. Zu Thorvaldsens Darlehensvergabe siehe auch Kap. II.2.

289 Reumont 1840, I, 171.

290 Ebd. Die Qualität von Thorvaldsens Gemäldesammlung hebt auch von Kölle 1834, 144, hervor. 
sein, Stadtführer dafür zu bezahlen, dass diese sie besonders empfahlen und Touristen in ihre Werkstätten brachten. Im Gegensatz dazu habe Thorvaldsen diese Stadtführer eher bezahlen wollen, „um fort zu bleiben“, wie die Baronin Stampe die Situation überspitzt beschrieben hat. ${ }^{291}$

Thorvaldsens Wunsch nach mehr Ruhe - und auch die Überzeugung in seinem Freundeskreis, dass er wegen seiner angeschlagenen Gesundheit der schlechten Luft in der Großstadt und seinem Liebesverhältnis mit Anna Maria Magnani für eine Weile entweichen sollte - veranlassten den Baron Schubart bereits 1804 dazu, dem bewunderten Bildhauer ein Arbeitszimmer in einem zu seiner Sommerresidenz im toskanischen Montenero bei Livorno gehörenden Gebäude einzurichten. ${ }^{292}$ Nach Thiele hatte sich Schubart „mit dem Gedanken geschmeichelt, daß der ,dänische Praxiteles' hier sogleich unsterbliche Meisterwerke ausführen sollte“. ${ }^{293}$ Am 12. April 1804 schrieb Schubart an seine Schwester Sybille Reventlow, dass er und seine Ehefrau Jacqueline Schubart „das Glück [haben], unseren berühmten Bildhauer Thorvaldsen hier zu besitzen“.294 Dieses Schreiben ist vermutlich Teil einer Sammlung von fingierten Briefen, die das Korpus für Schubarts geplante, jedoch nie vollendete Memoiren bilden sollten. ${ }^{295}$ Denn Thorvaldsen besuchte Montenero nicht im April, sondern erstmals im Juli 1804, als er die Porträtbüsten von Jacqueline und Herman Schubart modellierte. ${ }^{296}$ In dem zitierten Brief berichtete Schubart außerdem vom Relief Der Tanz der Musen auf dem Helikon, das sich bei Thorvaldsen als Geburtstagsgeschenk für Jacqueline Schubart in Arbeit befinde und ein „chef d'oeuvre“ zu werden scheine. ${ }^{297}$ Weiter schwärmte er wie andere Zeitgenossen von Thorvaldsens Leichtigkeit und Geschwindigkeit im Modellieren von Ton, wobei es sich um einen althergebrachten Künstlertopos handelt. ${ }^{298}$ Diese Fertigkeiten hob Schubart durch die Betonung der knappen Zeitspanne bis zum Geburtstag seiner Gattin Jacqueline Elisabeth (Elise) zusätzlich hervor:

\section{2.}

9. und vor dem 16. Juli 1804 (Entwurf in Monetenero verfasst), TMA, Ref. m28, nr. 112. Siehe auch Hartmann 1958, 277 - 278; von Einem 1974, 38.

297 Herman Schubart an Sybille Reventlow, 12. April 1804, zit. bei Hartmann 1958, 274.

298 Ebd. Zum Lob von Thorvaldsens Geschwindigkeit im Modellieren siehe auch Bruun, R. E. 1817, 539. 
Sein reizendes Basrelief, von dem Europa eines Tages sprechen wird, muss in Gips vollendet sein, um es meiner Elise am 10. September zu überreichen. Dieses Datum ist nicht sehr weit entfernt, und es braucht die Fülle seines [Thorvaldsens] Genies, um dieses Werk fertigzustellen. ${ }^{299}$

Knapp zwei Wochen nach dem Geburtstag der Baronin war das Relief vollendet. ${ }^{300}$ Nachdem Thorvaldsen in den Jahren 1804 und 1805 jeweils eine Sommerreise nach Montenero unternommen hatte, lud ihn der Baron am 14. Februar 1806 erneut zu sich ein. Auch aus diesem Brief kommt Schubarts starke Verehrung des Bildhauers zum Ausdruck:

Kommen Sie bald ins reizende Montenero. Ein helles und einladendes Zimmer erwartet Sie. Dort können Sie arbeiten und - ähnlich einem wahren Prometheus - menschliche Gestalten aus Ton formen. ${ }^{301}$

Trotz Schubarts Bemühungen ließ Thorvaldsens nächster - und zugleich letzter - Aufenthalt in Montenero bis 1810 auf sich warten. ${ }^{302}$ Hingegen hatte er 1806 mit einer am Ende jedoch unvollendet gebliebenen Marmorfassung des Tanzes der Musen auf dem Helikon begonnen und sollte dieses Relief zehn Jahre später nochmals in Gips überarbeiten ${ }^{303}$ In einem vom 10. Mai 1806 datierenden Brief an seine Schwester schwärmte Schubart erneut von jenem Werk, für dessen Betrachtung zahlreiche Menschen auf schnellstmöglichem Weg nach Florenz gereist seien, wo sich Thorvaldsen in jenen Jahren mehrfach aufhielt. Außerdem seien Gedichte geschrieben worden, „die die Berühmtheit von Thorvaldsen und seinem Basrelief " gesteigert hätten. ${ }^{304}$

Obwohl der Bildhauer nur dreimal zu Schubarts Sommerresidenz reiste, bestand eine enge zwischenmenschliche Beziehung zwischen ihm und dem Baronenpaar. Dies kommt nebst ihrem Briefverkehr besonders in den eigenhändigen Zeichnungen des Bildhauers zum Ausdruck, mit denen er die Schubarts an ihren Geburtstagen beschenkte und die der Baron 1815 zur Ausstellung im Salon der Kopenhagener Kunstakademie beisteuerte. ${ }^{305}$

299 Herman Schubart an Sybille Reventlow, 12. April 1804, zit. bei Hartmann 1958, 274: „Son charmant bas relief dont l'Europe parlera un jour, doit être achevé en plâtre pour le présenter à mon Elise le 10 Septembre. Cette date n'est pas fort éloignée, et il faut l'abondance de son génie pour terminer cet ouvrage." Auch in einem weiteren Brief schwärmte Schubart vom Tanz der Musen auf dem Helikon; Herman Schubart an Sybille Reventlow, 12. September 1804, zit. bei Hartmann 1958, 274.

300 Herman Schubart an Carl Frederik Ferdinand Stanley, 24. September 1804, TMA, Ref. m30 II, nr. 4.

301 Herman Schubart an Bertel Thorvaldsen, 14. Februar 1806, zit. nach Hartmann 1958, 277: „Venite presto al delizioso Montenero. Una camera chiara ed accogliente Vi attende. Lì potete lavorare e - simile ad un vero Prometeo - formare di creta esseri umani. “

302 Bencard 2010.

303 Kopenhagen, Thorvaldsens Museum (Inv.-Nr. A705 und A341). Nach letzterem Modell führte Georg Christian Freund unter Bissens Aufsicht nach 1844 eine Marmorfassung aus (Inv.-Nr. A340).

304 Herman Schubart an Sybille Reventlow, 10. Mai 1806, zit. nach Hartmann 1958, 275: „[...] des poêsies charmantes qui ajoutèrent à la célébrité de Thorvaldsen et de son bas-relief.“

305 Siehe bspw. Hartmann 1958, 277 - 278. Zum erwähnten Salon siehe Kap. I.2. 
Wie bereits mit Blick auf Thorvaldsens Jason-Statue angesprochen wurde, wird in Quellen und Sekundärliteratur zudem die Rolle der Baronin Schubart für seine Auseinandersetzung mit dem christlichen Glauben hervorgehoben, gelegentlich ist gar von Bekehrung die Rede. ${ }^{306} \mathrm{Da}$ sich der Bildhauer jedoch auch anschließend bedeckt hielt, was seine religiösen Überzeugungen betraf, sowie in seiner Kunst weiterhin hauptsächlich antike Motive verarbeitete, bleibt die Bedeutung jenes Kontakts mit dem Christentum für Thorvaldsens Selbstverständnis und Künstlerbiografie fraglich. Insgesamt lässt sich festhalten, dass das Atelier in Montenero durchaus als Rückzugsort für Thorvaldsen diente. Vor allem jedoch huldigte Schubart damit dem Kult um den jungen Bildhauer, bemühte sich um eine Steigerung von dessen Berühmtheit und konnte sich durch Thorvaldsens Präsenz selbst nobilitieren.

\section{Inszenierte Rückzugsorte III: Nysø}

Mit Blick auf Wards Karikatur von Thorvaldsen bei der Arbeit in seinen Privaträumen in Rom wurde die gleichsam öffentliche Inszenierung jenes Rückzugsortes des Bildhauers angesprochen. In ähnlicher Weise kann dessen Werkstatt in Montenero betrachtet werden, mit der sich Schubart zweifellos selbst schmücken wollte. Am meisten gilt dies jedoch für Thorvaldsens Atelier auf Stampes Landgut Nysø beim dänischen Præstø, das im Folgenden genauer betrachtet werden soll.

Mit Thorvaldsens wachsendem Ruhm stieg auch das öffentliche Interesse am Leben und Schaffen des Bildhauers. Besonders nach der Rückkehr in seine Heimatstadt Kopenhagen 1838 nahmen die Besuche in seinem Atelier auf Charlottenborg und seine gesellschaftlichen Verpflichtungen ein solches Ausmaß an, dass er sich mit den Worten beklagt haben soll: „Ich werde hier wohl auf den Grund treiben. “307 Neben Kunstkennern und -liebhabern wurde er auch immer wieder von Menschen aus niedrigeren Gesellschaftsschichten aufgesucht oder angeschrieben, die aufgrund eigener isländischer Wurzeln oder eines ähnlichen Namens von einer Blutsverwandtschaft mit dem international gefeierten, weitgereisten Zeitgenossen überzeugt waren. ${ }^{308}$ Auch darin zeigt sich Thorvaldsens längst gefestigter celebrity-Status.

Als Reaktion auf seine Unzufriedenheit bot die Baronin Stampe dem Bildhauer im Frühjahr 1839 an, sie gelegentlich auf ihrem Landsitz Nysø zu besuchen. ${ }^{309}$ Tatsächlich war sie bereits vor Thorvaldsens Heimkehr nach Dänemark vom damaligen Kronprinzen

307 Zit. nach Thiele 1852-1856, Bd. 3, 44. Siehe auch Thiele 1831-1850, Bd. 4, 70-73; Thiele 1852-1856, Bd. 3, 41 - 44 und 50 - 51; Baronesse Stampes Erindringer 1912, 94; Henschen 1982, 55; Helsted 2001b, 9; Berner 2005, 78.

309 Henschen 1982, 55. Der Landsitz Nysø war zwischen 1671 und 1673 für den Kaufmann Jens Lauridsen, den Sohn des ehemaligen Bürgermeisters von Præstø, Laurids Nielsen, gebaut worden und befand sich seit 1800 im Besitz der Familie Stampe; Bech 2009a. 
Christian Frederik gebeten worden, sich des berühmten Bildhauers anzunehmen. Der Grund für Christian Frederiks Wahl von Stampe dürfte deren schon früh einsetzendes, reges Engagement für die Errichtung eines Museums für Thorvaldsen in Kopenhagen gewesen sein, worauf der nächste Teil dieser Arbeit eingehen wird. ${ }^{310}$

Über eine bereits vor Thorvaldsens Rückkehr nach Dänemark existierende Bekanntschaft zwischen ihm und der Baronin ist nichts eindeutig belegt. Man geht davon aus, dass der persönliche Kontakt hauptsächlich über Stampes Schwager, den Botaniker Joachim Frederik Schouw, zustande kam, der den Bildhauer schon länger gekannt hatte und in Kopenhagen ebenfalls auf Schloss Charlottenborg wohnte. ${ }^{311}$ Überliefert ist hingegen, dass die Baronin während einer früheren Italienreise Thorvaldsens studio grande besucht hatte, jedoch möglicherweise in Abwesenheit des Bildhauers. ${ }^{312}$ Zwei Briefe aus Stampes Umfeld belegen ferner, dass Thorvaldsen im Sommer 1830 eine nicht erhaltene Porträtskulptur des in diesem Jahr im Kleinkindalter verstorbenen Sohnes der Baronin, Jean August Carl Louis Fritz, zu modellieren begann. ${ }^{313}$ Das weitere Schicksal dieses Werks ist unbekannt.

Im Frühsommer des Jahres 1839 folgte schließlich Thorvaldsens erster Besuch auf Nysø: Am Abend des 4. Juni wurde er dort mit bekränzten Booten, „Lang lebe Thorvaldsen!“-Rufen und Kanonenschüssen empfangen. ${ }^{314}$ Seither verbrachte Thorvaldsen einen großen Teil seiner Zeit auf Stampes Landgut. Während er in seinem Kopenhagener Atelier auf Schloss Charlottenborg unzählige Besucherinnen und Besucher empfing, sollte er hier zu Ruhe und Konzentration finden. Durch Thorvaldsens oben zitierte Dramatisierung seiner Situation in der Hauptstadt zeigt jedoch sein dezidierter Rückzug Ansätze einer Selbstinszenierung. ${ }^{315}$ Umgekehrt entpuppt sich die auf den ersten Blick als selbstlos erscheinende Geste seitens der Baronin rasch als deren Bemühung, Einfluss auf die künstlerische Arbeit und das soziale Leben des Bildhauers auszuüben. Wie im Kapitel I.3 angesprochen wurde, führte die Baronin praktische Vorarbeiten im Bildhauerprozess aus

310 Entgegen der hier vertretenen Ansicht soll Christian Frederiks Bitte gemäß Sekundärliteratur auf dem Wissen gegründet haben, dass die Baronin italienische Gerichte kochen konnte, was Thorvaldsen beim Einleben helfen sollte; siehe dazu Henschen 1982, 55; Gelius/Henschen/Miss 2001, 7 - 8; Helsted 2001a, 7 - 8; Helsted 2001b, 8.

311 Baronesse Stampes Erindringer 1912, 3; Schultz 1938, 77; Gelius/Henschen/Miss 2001, 8; Helsted 2001a, 7-8; Helsted 2001b, 8-9.

312 Baronesse Stampes Erindringer 1912, 3 und 6; Schultz 1938, 76-77; Gelius/Henschen/Miss 2001, 7; Helsted 2001a, 7; Helsted 2001b, 8; Henderson 2005, 56. Gemäß Thiele kannte Thorvaldsen die Familie Stampe hingegen schon von Italien her, was sich jedoch nicht belegen lässt; Thiele 1831-1850, Bd. 4, 70 - 71; Thiele $1852-1856$, Bd. 3, 49.

313 Joachim Frederik Schouw an Bertel Thorvaldsen, 15. Juni 1830, TMA, Ref. m15 1830, nr. 87; Jean Antoine Dalgas an Bertel Thorvaldsen, 31. Januar 1831, TMA, Ref. m16 1831, nr. 11.

314 Baronesse Stampes Erindringer 1912, 7 - 8 und 12 - 13; auch Thiele 1852 - 1856, Bd. 3, 49; Repholtz 1911, 23; Repholtz 1921, 92; Schultz 1938, 75; Henschen 1982, 56; Helsted 2001a, 8; Helsted 2001b, 9; Berner 2005, 78 - 79; Bech 2009a.

315 Mit Blick auf das 20. und 21. Jahrhundert siehe diesbezüglich auch Tippner/Laferl 2014, 30. 
und unterstützte Thorvaldsen damit aktiv in seinem Schaffen. Außerdem saß sie ihm für Arme und Köpfe von Frauenfiguren Modell, während der Baron Stampe als Vorbild für Männerfiguren diente. ${ }^{316}$

Über diese kunstbezogene Ebene hinaus organisierte Stampe für Thorvaldsen Reisen im In- und Ausland sowie regelmäßige Abendgesellschaften mit den gefeiertsten dänischen Künstlern der Zeit. ${ }^{317}$ Unter den Reisen ist besonders jene nach Italien bemerkenswert: Thorvaldsen und die Familie Stampe brachen am 25. Mai 1841 in Dänemark auf und reisten auf dem Landweg durch Europa, um am 12. September in Rom anzukommen. ${ }^{318}$ Bei fast jedem Halt wurde der Bildhauer mit opulenten Festlichkeiten empfangen. Thiele hat jene Reise entsprechend als „Thorvaldsens Triumphzug durch Deutschland“ bezeichnet, da der Bildhauer gerade in den deutschen Städten, die mit den Monumenten für Eugène de Beauharnais (1827 - 1829, München; Abb. 83), Maximilian I. (1830-1839, München), Johannes Gutenberg (1833-1837, Mainz) und Friedrich Schiller (1835-1839, Stuttgart) von ihm gefertigte Denkmäler besaßen, enthusiastisch gefeiert wurde. ${ }^{319}$ Außerdem soll der Bildhauer allein während der Reise von Kopenhagen nach Rom ganze $17 \mathrm{Mal}$ für Porträts gesessen haben. ${ }^{320}$ Eine Zeichnung, die Thorvaldsens Status als Mittelpunkt spezifisch der Dänen in der Ewigen Stadt treffend zum Ausdruck bringt, schuf Constantin Hansen an Stampes Weihnachtsfest während jenes Romaufenthalts 1841 (Abb. 87). Das Blatt zeigt in einer ovalen Komposition die Büstenporträts von Stampes Gästen, die um das in ihrem Zentrum stehende Porträt des Bildhauers angeordnet sind. ${ }^{321}$ Die Rückreise von Rom traten Thorvaldsen und die Baronenfamilie getrennt an: Während Letztere be-

Baronesse Stampes Erindringer 1912, 74 und 109. Zu Stampes aktiver Rolle während Thorvaldsens Schaffen siehe auch Heinrich Steffens an Christine Stampe, 6. April 1844, KB, Ref. NKS 1732, $2^{\circ}$ (Transkript im TMA).

317 Thiele 1831-1850, Bd. 4, 71-72; Thiele 1852-1856, Bd. 3, 49-51; auch Baronesse Stampes Erindringer 1912, $288-289$.

318 Die Reise von Thorvaldsen und der Familie Stampe führte über Rostock, Berlin, Dresden, Leipzig, Frankfurt a. M., Mainz, Mannheim, Karlsruhe, Stuttgart, Augsburg, München, Hohenschwangau, Lindau, Schaffhausen, Zürich, Luzern, das Berner Oberland, den St. Gotthard, Mailand, Genua, Livorno, Florenz und Perugia nach La Storta und schließlich Rom. Für eine genaue Beschreibung dieser Reise siehe Thiele 1831-1850, Bd. 4, 143-154; Thiele 1852 - 1856, Bd. 3, 117 - 125 (nach Thiele begann die Reise jedoch bereits am 21. Mai 1841); Repholtz 1911, 75 -83; Baronesse Stampes Erindringer 1912, 113 -143; auch Bätschmann 1997, 91; Jørnæs 2011, 233 - 234.

319 Thiele 1852-1856, Bd. 3, 119. Spezifisch zu den Einladungen und Festlichkeiten zu Thorvaldsens Ehren in und um Dresden und Leipzig siehe Schulz/Weigel 1916, bes. 4-14; Stephan 1994, bes. 25 - 32; Priever 1997, bes. $169-170$.

320 Baronesse Stampes Erindringer 1912, 129; Jørnæs 2011, 233.

321 Die Zeichnung zeigt im Uhrzeigersinn von oben den Autor Hans Peter Holst (mit Brille), den Maler Albert Küchler, den Theologen Hendrik Wilhelm Breinholm, die Bildhauer Jens Adolf Jerichau und Carl Frederik Holbech, den Medailleur Peter Petersen, die Maler Adam Müller, Constantin Hansen und Peter Raadsig, den Juristen P. C. Jespersen, den späteren Konsul Johan Bravo sowie den Maler Friedrich Thøming. Siehe dazu Gelius/Henschen/Miss 2001, 49; auch Repholtz 1911, 88 - 91; Bach 2001, 43. 


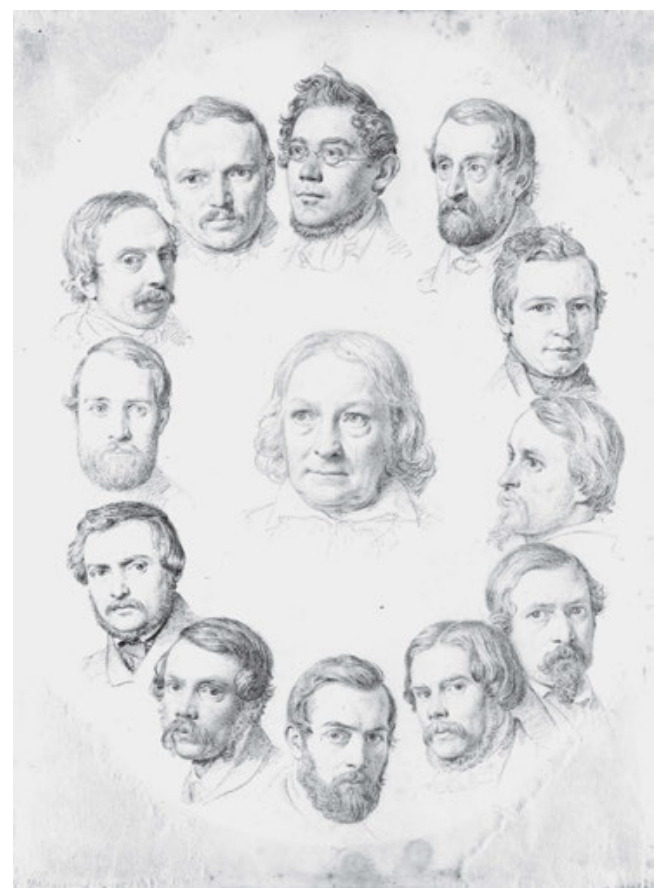

87_Constantin Hansen, Thorvaldsen mit seinen Landsleuten an Stampes Weihnachtsabend 1841 in Rom, 1841, Bleistift auf Papier, $280 \times 220 \mathrm{~mm}$, Nysø, Thorvaldsen-Samlingen (Inv.-Nr. NysøP)

reits Anfang 1842 in Richtung Dänemark abreiste, brach Thorvaldsen erst am 3. Oktober desselben Jahres zu seiner Heimkehr auf. ${ }^{322}$ Die nur drei Wochen dauernde Fahrt gestaltete sich weit weniger festlich als die Hinreise, gemäß Thiele weil Thorvaldsen sich nicht „wie ein Wunderthier“ vorführen lassen wollte. ${ }^{323}$

$\mathrm{Zu}$ den oft gesehenen Gästen auf Nysø zählten neben Oehlenschläger und Andersen auch die Dichter, Gelehrten und Wissenschaftler Grundtvig, Ingemann, Hjort, Holst, Høyen, Ørsted, Schouw, Henrik Nicolai Clausen, Carsten Hauch und Caspar PaludanMüller sowie die Künstler und Handwerker Jensen, Marstrand, Constantin Hansen, Gottlieb Nicolai Sibbern und Peter Christian Skovgaard. ${ }^{324}$ Magnet und unbestrittenes Zentrum dieses Kreises war Thorvaldsen. Die illustre Gesellschaft, die sich auf Nysø zusammenfand, hielt beispielsweise Marstrand zwischen 1842 und 1845 in einer Karikatur-

322 Die Rückreise führte Thorvaldsen über Livorno, Marseille, Straßburg, Mannheim, Mainz, Frankfurt a. M., Kassel, Göttingen, Hannover, Altona und Kiel nach Kopenhagen. Siehe dazu Thiele 1831-1850, Bd. 4, 170 -182; Thiele 1852-1856, Bd. 3, 138-147.

323 Thiele 1852 -1856, Bd. 3, 138. Auch gemäß Oehlenschläger wurde Thorvaldsen bei Abendgesellschaften vorgezeigt, „als ob er eine Schildkröte wäre“; zit. nach Helsted 2001b, 9; Berner 2005, 78. Eine ähnliche Anekdote ist für Lord Byron überliefert; siehe dazu Lilti 2014, 303.

324 Schultz 1938, 79-80; Henschen 1989, 100; Helsted 2001b, 10; Bech 2009a. 


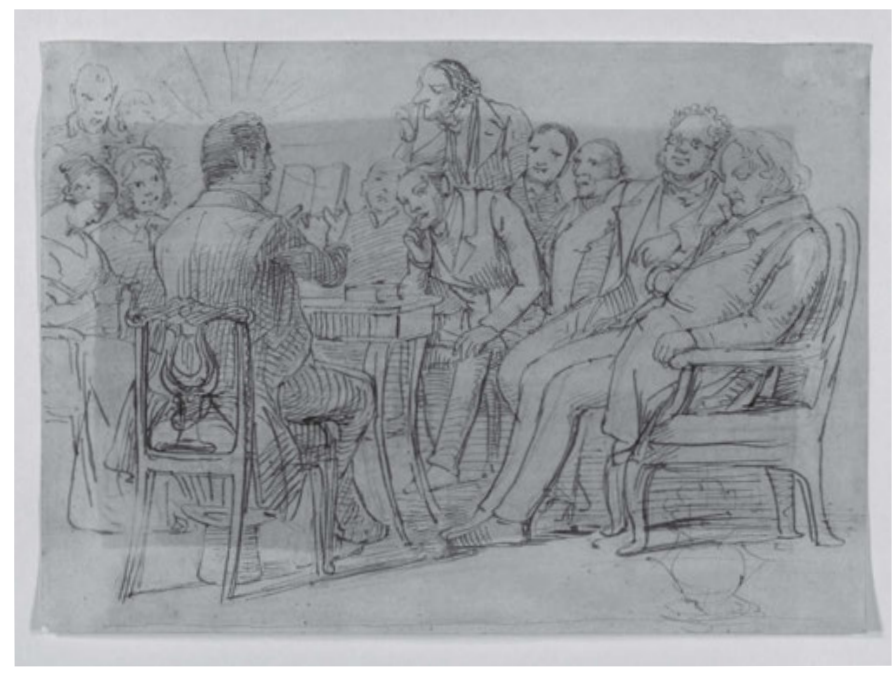

88__Wilhelm Marstrand, Adam Oehlenschläger liest in Stampes Kreis laut vor, zwischen 1842 und 1845, Feder und braune Tinte auf Papier, $160 \times 230 \mathrm{~mm}$, Kopenhagen, Thorvaldsens Museum (Inv.-Nr. D1857)

zeichnung fest (Abb. 88). Dargestellt ist eine Lesung von Oehlenschläger, um dessen Kopf ein nimbusartiger Strahlenkranz leuchtet, während zuvorderst im Publikum der eingenickte Thorvaldsen sitzt. Die Identifizierung der Anwesenden gestaltet sich schwierig, doch geht man davon aus, dass der Mann mit Brille neben Thorvaldsen Holst oder Hjort und derjenige daneben Schouw oder Høyen ist. Grundtvig sitzt vornübergebeugt vor Paludan-Müller und dem stehenden, Tabak schnupfenden Andersen. Links im Bild sieht man die Gastgeber, das Baronenpaar Stampe. Trotz ihres karikierenden Charakters verdeutlicht Marstrands Zeichnung, dass es sich beim Landsitz Nysø keineswegs um einen stillen Rückzugsort abseits des städtischen Rummels handelte, sondern durchaus um einen Ort, an dem der Geniekult um zeitgenössische Künstler zelebriert und inszeniert wurde.

\section{Thor in Vølunds Werkstatt}

Nachdem die Baronin für Thorvaldsen zunächst ein Zimmer auf der Beletage ihres Herrenhauses als Werkstatt eingerichtet hatte, ließ sie im Juli 1839 ein separates Atelier nach ihrem eigenen Entwurf im Garten des Anwesens erbauen. ${ }^{325}$ Einen getreuen Eindruck des 


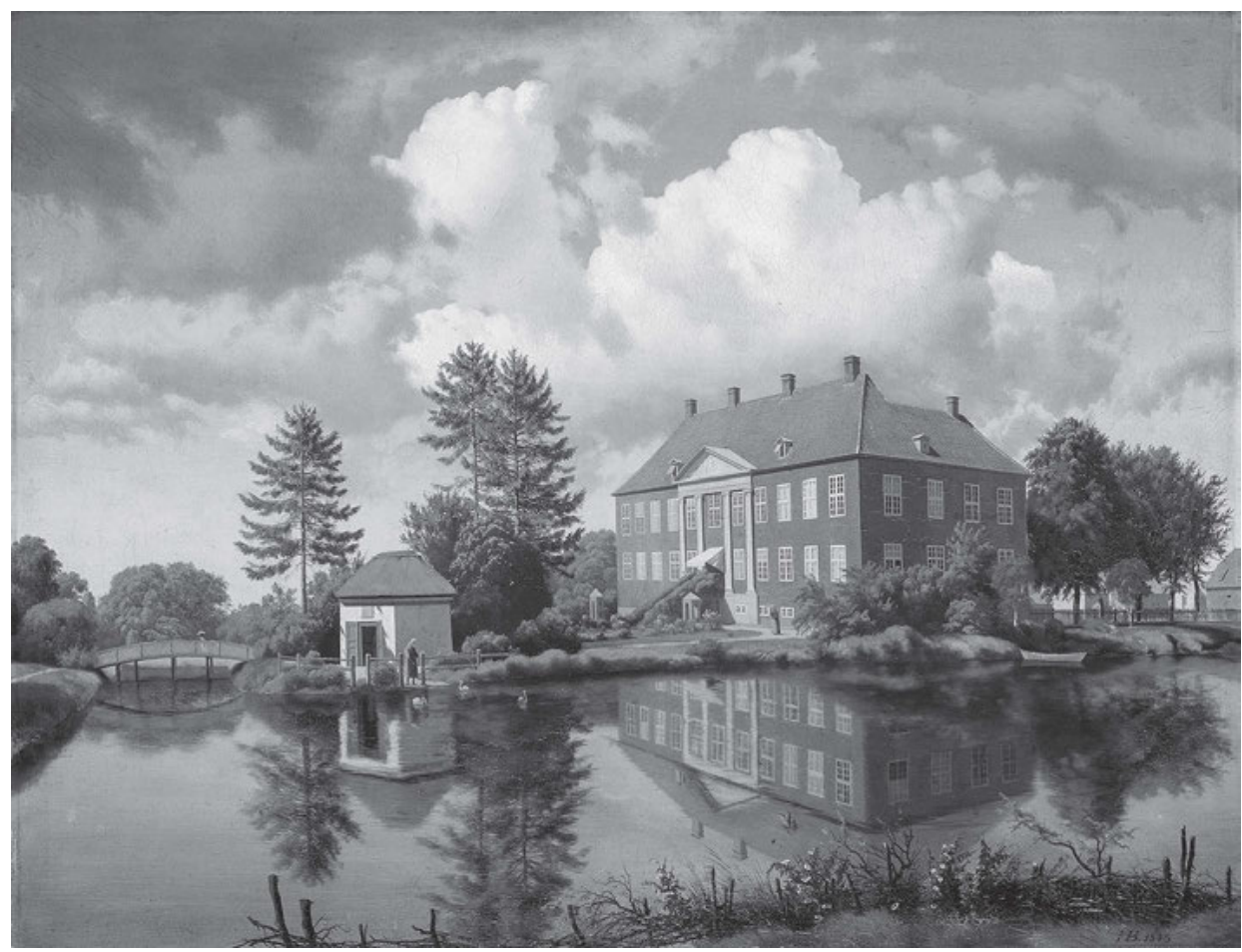

89_Heinrich Buntzen, Das Landgut Nysø mit Bertel Thorvaldsen vor seinem Atelier, 1843, Öl auf Leinwand, 55,5 × 71,2 cm, Kopenhagen, Thorvaldsens Museum (Inv.-Nr. B203)

Landguts Nysø vermittelt ein 1843 entstandenes Gemälde von Heinrich Buntzen (Abb. 89). Es zeigt das in einem weitläufigen Park gelegene Herrenhaus aus rotem Backstein und am Ufer des Sees das Atelier von Thorvaldsen. Davor steht der Bildhauer in einen Morgenrock gekleidet und füttert die Schwäne. Dieses Gemälde war 1843 Christine Stampes Weihnachtsgeschenk an den Bildhauer. ${ }^{326}$ Es basiert auf einer ungefähr gleichzeitig entstandenen, fast identischen Bleistiftzeichnung, worauf einzig Thorvaldsen und die Schwäne fehlen. ${ }^{327}$

Wie Buntzens Gemälde zeigt, handelt sich bei dem nach wie vor existierenden Atelier um ein kleines, aus einem einzigen Raum bestehendes Hexagon mit Oberlicht. Die Außenwände wurden über mehrere Jahre mit verschiedenen Reliefs von Thorvaldsens Hand geschmückt: Um das Gebäude läuft ein Fries mit sich abwechselnden Putti und Rosetten,

327 Nysø, Thorvaldsen-Samlingen (Inv.-Nr. NysøS). Siehe auch Repholtz 1911, 13. 
während über den beiden Eingängen die 1840 entstandenen Reliefs Diana und Jupiter und Hygieia und Amor prangen. ${ }^{328}$ Die übrigen vier Wände sind bezeichnenderweise mit den Relieftondi der Genien der Bildhauerei (1843 und 1844), der Malerei (1843) und der Dichtung (1844) geschmückt. ${ }^{329}$

Das Atelier auf Nysø war nach einer Bauzeit von nur zwei Wochen am Abend des 24. Juli 1839 feierlich eingeweiht worden. Im Zentrum des hell beleuchteten Hexagons wurde ein eigens angefertigter Modellierstuhl aufgestellt und mit einem Tuch bedeckt. Darauf platzierte man Bissens Büste seines Lehrers Thorvaldsen und bekrönte sie mit einem Lorbeerkranz. ${ }^{330}$ Die Festlichkeiten umfassten ferner ein Klavierspiel des Barons Stampe, eine Märchenlesung von Andersen sowie Thorvaldsens geliebtes Lottospiel. ${ }^{331}$ Außerdem hatte Grundtvig zur Einweihung des Ateliers ein Gedicht verfasst, das die Anwesenden einstudiert hatten und zu einer von Christoph Ernst Friedrich Weyse komponierten Melodie sangen. ${ }^{332}$ In diesem Lied wurde Thorvaldsen auf verschiedenen Ebenen mit dem altnordischen Meisterschmied Vølund verglichen und gar als „Vølund-Thorvaldsen“ bezeichnet. ${ }^{333}$ Dadurch sollte der längst international berühmte Bildhauer der lokalen, skandinavischen Geschichte einverleibt werden.

Eine gekürzte Version des erwähnten Gedichtes publizierte Grundtvig zusammen mit einer erklärenden Einleitung im November 1839 in der Zeitschrift Brage og Idun. ${ }^{34}$ Diese Einleitung war zugleich eine Einführung in die nordische Mythologie, die „in den Ohren der meisten noch wie chinesisch" klinge. ${ }^{335}$ Damit verwies Grundtvig auf die im Gegensatz zur antiken Mythologie nach wie vor geringe Popularität der erst kürzlich wiederentdeckten nordischen Sagenwelt. ${ }^{336}$ Infolge der langjährigen Mythisierung von Thorvaldsens nordischer Herkunft diente die Einschreibung des Bildhauers in die nordische Sagenwelt gleichsam als Motto des neu errichteten Ateliers auf Nysø: Es war auch Grundtvig, der das

Siehe auch Repholtz 1911, 42; Baronesse Stampes Erindringer 1912, 34; Berner 2005, 79. Die originalgroßen Gipsmodelle der beiden genannten Reliefs befinden sich in Thorvaldsens Museum in Kopenhagen (Inv.-Nr. A345 und A373).

329 Die originalgroßen Gipsmodelle befinden sich in Thorvaldsens Museum in Kopenhagen (Inv.-Nr. A522, A523, A520 und A527).

330 Repholtz 1911, 25 (schreibt jedoch Juni statt Juli 1839); Baronesse Stampes Erindringer 1912, 34; auch Repholtz 1921, 92; Henschen 1982, 56; Bach 2001, 36; Berner 2005, 78; Kofoed 2014a.

331 Repholtz 1911, 28-29.

332 Nikolai Frederik Severin Grundtvig an Bertel Thorvaldsen, 24. Juli 1839, TMA, Ref. m33, nr. 19; Grundtvig 1839, 173 - 174; Baronesse Stampes Erindringer 1912, 34; Kofoed 2014a.

333 Grundtvig 1839, $173-174$.

334 Ebd., $168-174$.

335 Ebd., 171: „[...] Nordens Myther, der endnu i de Flestes Øren klinger som Chinesisk [...].“ (Hervorhebungen im Original.) Nach Grundtvig 1839, 170, handelte es sich dabei um eine gewünschte Rede, nach Baronesse Stampes Erindringer 1912, 34, hingegen um eine Überraschung.

336 Grundtvig 1839, 171. 
kleine Gebäude in einer Inschrift über der Eingangstüre als Vølunds Vorksted (Vølunds Werkstatt) benannte. ${ }^{337}$

Abgeleitet von den altnordischen Begriffen vél und lund bedeutet der Name jenes mythologischen Schmiedes so viel wie ,auf kunstvolle Weise. ${ }^{338}$ Interessant ist im vorliegenden Zusammenhang ferner, dass das altnordische Wort smiðr sowohl allgemein einen Handwerker als auch spezifisch einen Schmied bezeichnete. Dementsprechend gilt Vølund in der nordischen Sagenwelt als Personifikation der Kunstfertigkeit und entspricht damit Hephaistos in der griechischen und Vulkan in der römischen Mythologie. ${ }^{339} \mathrm{Im}$ Unterschied zu diesen ist er jedoch keine göttliche, sondern eine Heldenfigur. Ferner ist er Dädalus verwandt, dessen Name sich in vergleichbarer Weise vom griechischen Verb $\delta a i \delta a \lambda \lambda \varepsilon ı v$ für ,kunstvoll arbeiten' ableitet. Doch nicht nur in etymologischer Hinsicht besteht eine Parallele zwischen Vølund und Dädalus, vielmehr konnten auch beide mit selbst hergestellten Flügeln fliegen. ${ }^{340}$ Gerade aufgrund dieser Fähigkeit betrachtete Grundtvig Vølund in seinem Zeitschriftenartikel nicht als eigentliches Äquivalent zu Hephaistos beziehungsweise Vulkan, sondern als diesem überlegen. ${ }^{341}$ Ferner sah er in jener Fähigkeit zum Fliegen die Verbindung zu dem angeblich wie Vølund aus Island stammenden Thorvaldsen, dem seine Kunst ebenfalls - zumindest im übertragenen Sinn - selbst geschaffene Flügel verlieh. ${ }^{342}$

Mit dem Ausdruck Vølunds Vorksted referierte Grundtvig in der Zeitschrift Brage og Idun auf eine kurz zuvor entdeckte Briefsammlung aus England. Die Altertumswissenschaftler seien sich jedoch uneinig, ob die in der Briefsammlung vorkommende Bezeichnung Vølunds Voerksted ein ehemaliges Haus jenes „Dädalus des Nordens“ (gemeint ist Vølund) benenne oder aber einen Berg, wo nach einem Aberglauben „jene mythische Person, wie andere kunstfertige Zwerge, seine Schmiede hatte“. ${ }^{343}$ Diese Zwerge, vor allem jedoch Vølund selbst, waren nach Grundtvig die Vorbilder von Thorvaldsen, den er als

337 Hammerich 1876, 118; Repholtz 1911, 25; Baronesse Stampes Erindringer 1912, 34; Repholtz 1921, 92; Schultz 1938, 88; Bjarne Jørnæs, in: Helsted 1973, 53; Henschen 1982, 56; Bach 2001, 36; Bech 2009a; Kofoed 2014a; auch Henschen 1989, 100 -101; Jørnæs 2011, 221. Zur Mythisierung und Stilisierung von Thorvaldsens nordischer Herkunft siehe die Kap. I.3 und II.2.

338 Siehe bspw. Arthur 2002. Für eine knappe Zusammenfassung des Vølundliedes (Volundarkviða) siehe Nedoma 2007a, 92.

339 Siehe bspw. Henderson 2005, 38; Jørnæs 2011, 222.

340 Grundtvig 1839, 171; Hammerich 1876, 118.

341 Grundtvig 1839, 170: „[...] Vølund eller Vaulunder, som overflyver Grækernes Hefaestos, thi Smede og Krøblinger Begge, gjorde Hefoestos sig kun Fødder, mens Vølund gjorde sig Vinger.“ (Hervorhebungen im Original.)

342 Ebd., 171.

343 Ebd., 168: „For endeel Aar siden fandt Man denne Benævnelse i et gammelt Engelsk Brevskab, og Antikvarerne trættes endnu om, enten derved menes et Huus, der fordum beboedes af denne Nordens Dædalos, eller et Bjerg, hvor overtroiske Folk meende, denne mythiske Person, ligesom andre konstige Dværge, havde sin Smedde; [...].“ (Hervorhebung im Original.) 
den „ersten historischen Heros“ der nordischen Kunst bezeichnete. ${ }^{344}$ Grundtvigs Verweis auf die selbst geschmiedeten Flügel und die Zwerge verrät ferner, dass er seine Ausführungen über Vølund auf die Thidrekssaga aus dem 13. Jahrhundert stützte. ${ }^{345}$

Eine zweite, heute nicht mehr vorhandene Inschrift an Thorvaldsens Atelier auf Nysø lautete übersetzt: „Am kleinsten ist der in Dovre lebende Zwerg, Thor in dieser Hütte ist doppelt so groß. ${ }^{\text {“346 }}$ Dieser ebenfalls von Grundtvig stammende Vers enthielt ein Wortspiel mit dem Namen Thor, der sowohl auf den Donnergott als auch auf den Kosenamen des Bildhauers verwies und Letzteren durch diese Anspielung zugleich vergöttlichte. Die Gegenüberstellung des norwegischen Zwerges und Thor war eine Gegenüberstellung von kleinsten und größten Wesen und assoziierte Thorvaldsen dadurch abermals mit dem mächtigen Donnergott. Überdies dürfte die Erwähnung des Zwerges erneut auf die Legende von Vølund hingedeutet haben, dessen Schmiedekunst zumindest nach der Thidrekssaga mithilfe der magischen Kräfte von Zwergen entstand.

Wie bereits im Kapitel I.3 erwähnt wurde, war das Atelier auf Nysø eigens für Thorvaldsens Arbeit am Selbstbildnis mit der Statue der Hoffnung errichtet worden (Abb. 32). ${ }^{347}$ Man geht gar davon aus, dass diese Selbstporträtstatue das einzige Werk ist, das in jenem kleinen, sechseckigen Gebäude entstand. ${ }^{348}$ Dies verleiht der hier vertretenen Annahme einer bewussten Auseinandersetzung des Bildhauers mit der nordischen Mythologie zusätzlich Gewicht: Nicht nur erinnert sein Selbstbildnis an die Thor-Ikonografie; vielmehr ist sie auch eine spiegelverkehrte Version seiner Statue des Vulkan, der als mythologische Figur seine Entsprechung im altnordischen Vølund findet (Abb. 41). Möglicherweise in diesem Zusammenhang bemerkte Oehlenschläger über Thorvaldsens Selbstporträtstatue: „Wie ein echter Vaulundur [= Vølund] steht er mit Hammer und Meißel da. ${ }^{\text {“349 }}$ Oehlenschläger hatte eine zentrale Rolle bei der Bekanntmachung der wiederentdeckten nordischen Mythologie gespielt und bereits lange vor der Publikation seiner Gedichtsammlung Nordens Guder (dt. Titel: Die Götter Nordens) von 1819 mit seinem erstmals 1805 erschienenen Waulundur eine adaptierte, romantisierte Märchenversion des Vølundliedes veröffentlicht. ${ }^{350}$

344 Grundtvig 1839, 170: „[...] den Nordiske Konst, som i Thorvaldsen fik sin første historiske Heros, har aabenbar sit mythiske Forbillede i de konstige Dværge og ret øiensynlig i Vølund eller Vaulunder [...].“ (Hervorhebungen im Original.)

345 Siehe bspw. Nedoma 2007a, 92; Krause 2010, 174-175. Im Gegensatz dazu kann der Schmied in der ungefähr zeitgleich verschriftlichten Lieder-Edda in Vogelgestalt fliegen und wird nicht mit Zwergen, sondern mit Elfen in Verbindung gebracht.

346 Baronesse Stampes Erindringer 1912, 34: „Mindst er Dværgen, som i Dovre boer, Thor i Hytten findes dobbelt stor." Siehe auch Repholtz 1911, 25; Schultz 1938, 88; Helsted 1973, 52 - 53; Henschen 1982, 56; Bech 2009a.

347 Bjarne Jørnæs, in: Helsted 1973, 53; Jørnæs 2011, 222.

348 In der Regel arbeitete Thorvaldsen im Wohnhaus der Familie Stampe; Gelius/Henschen/Miss 2001, 22.

349 Oehlenschläger 1850, Bd. 4, 147.

350 Nedoma 2007b, bes. $83-87$. 


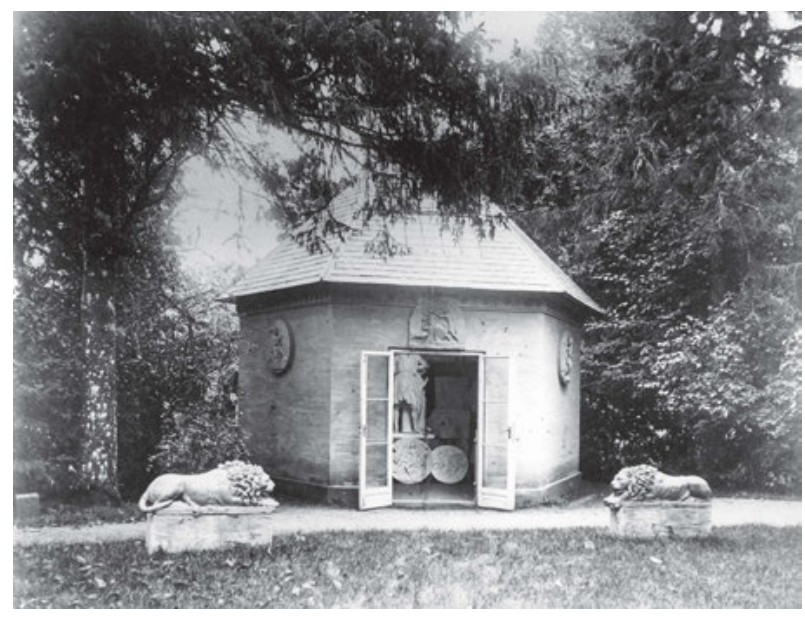

90__Johan Frederik Busch, Bertel Thorvaldsens Werkstatt auf Nysø (,Vølunds Veerksted“), 1860er oder 1870er Jahre, Fotografie, aus: Historisk Samfund, Præstø Amt, 1961

Die Benennung des Ateliers auf Nysø als Vølunds Vorksted und des darin schaffenden Bildhauers als Thor trug zur Stilisierung und Inszenierung der nordischen Herkunft des international gefeierten Künstlers bei. Zugleich brachte sie zwei verschiedene, in der nordischen Mythologie unabhängig voneinander bestehende Legenden zusammen. Diese künstliche Verbindung zwischen Thor und Vølund wird beispielhaft, doch zweifellos unabsichtlich in Johan Frederik Buschs Fotografie aus den 1860er oder 1870er Jahren veranschaulicht: Die offene Ateliertüre, über der die genannte Inschrift prangt, gibt den Blick auf Thorvaldsens Selbstbildnis mit der Statue der Hoffnung frei (Abb. 90). Es ist Thor in Vølunds Werkstatt.

Geht man den Vergleichen des dänischen Bildhauers mit Gestalten aus der nordischen Mythologie nach, zeigt sich rasch deren Oberflächlichkeit, indem es sich nicht um ernsthafte Beschäftigungen der Zeitgenossen mit dem kulturellen Erbe Skandinaviens handelte. Insofern ist dieses Phänomen vergleichbar mit den zeitgenössischen Bezeichnungen von Thorvaldsen als neuem Prometheus, Praxiteles oder Phidias, auf die in den Kapiteln I.1 und I.2 eingegangen wurde. Folglich sind die Assoziationen des Bildhauers mit gefeierten antiken Künstlern oder mächtigen mythologischen Figuren weniger als spezifische Analogien denn als Topoi und Ausdruck des zeitgenössischen Künstlerkults zu begreifen. Zugleich können sie als ein Aspekt des Stilisierungsbedürfnisses der celebrity-Kultur im frühen 19. Jahrhundert verstanden werden.

Durch die Bezeichnung des Ateliers auf Nysø als Vølunds Vorksted und die genannten Reliefs mit Motiven aus der antiken Mythologie an dessen Außenwänden wird Thorvaldsen als nordischer Bildhauer stilisiert und inszeniert, dessen Kunst jedoch weitestgehend klassizistischen Idealen folgte. Damit kann das Atelier gleichsam als eine Verdoppelung seines Selbstbildnisses mit der Statue der Hoffnung betrachtet werden, das durch eine Rezeption sowohl der antiken Kunst und Mythologie als auch der altnordischen Sagenwelt 
charakterisiert ist. ${ }^{351}$ Insofern lässt sich jenes kleine Atelier selbst als Porträt des Künstlers und zweifellos als Visualisierung des Kults um ihn verstehen. Gerade letzterer Aspekt kommt auch in den Quellen zum Ausdruck, wenn beispielsweise Steffens das Atelier auf Nysø als „Thorvaldsens Tempel“ bezeichnet, wohin die „besten Künstler Pilgerfahrten unternehmen“" würden. ${ }^{352}$

In Vølunds Vorksted waren bis ins 20. Jahrhundert hinein die Gipsmodelle und vereinzelte Bozzetti der meisten auf Nysø ausgeführten Werke sowie einige Gipsabgüsse von in Kopenhagen vollendeten Arbeiten aufgestellt. ${ }^{353}$ Dies veranschaulicht auch Buschs Fotografie: Die geöffneten Türflügel gewähren einen Blick in den kleinen Innenraum, wo man unter anderem die beiden Relieftondi Perseus und Andromeda (1839) und Der Genius der Skulptur (1843) sowie Thorvaldsens Selbstbildnis mit der Statue der Hoffnung erkennt. ${ }^{354} 1926$ wurde die Thorvaldsen-Sammlung auf Nysø als eigenständiges Museum im östlichen Flügel des zum Landsitz gehörenden Gehöfts eingerichtet. ${ }^{355}$ Hier befinden sich heute Bozzetti und Tonfragmente, Originalgipse und Abgüsse, Marmorwerke, zahlreiche eigenhändige Zeichnungen, Werkzeuge, Abgüsse von Thorvaldsens Händen sowie Haare und persönliche Gegenstände des Bildhauers, so genannte Thorvaldseniana. Außerdem enthält die Sammlung Werke von weiteren dänischen Künstlern, die Nysø um die Mitte des 19. Jahrhunderts besuchten, darunter ein 1842 von Constantin Hansen gezeichnetes Porträt von Thieles kleinem Sohn Nicolai Thorvald, der nach dem bewunderten Bildhauer benannt worden war. ${ }^{356} \mathrm{Im}$ Gegensatz zur Thorvaldsen-Sammlung ist Vølunds Verksted dem breiteren Publikum nicht mehr zugänglich, doch wurde die ursprüngliche Aufstellung von Thorvaldsens Werken in Form von Gipsabgüssen weitgehend beibehalten.

351 Siehe dazu Kap. I.3.

352 Heinrich Steffens an Christine Stampe, 6. April 1844, KB, Ref. NKS 1732, $2^{\circ}$ (Transkript im TMA): „Nysøe er Thorwaldsens Tempel. De beste Kunstnere ville anstille Pilgrimsreiser didhen.“

353 Repholtz 1911, 143.

354 Kopenhagen, Thorvaldsens Museum (Inv.-Nr. A486 und A522); Nysø, Thorvaldsen-Samlingen (Inv.Nr. Nysø1).

355 Bech 2009a.

356 Thiele 1917, 75. 
